UNIVERSIDADE DE SÃO PAULO

FACULDADE DE SAÚDE PÚBLICA

\title{
ÍNDICE GLICÊMICO DA DIETA HABITUAL E ALTERAÇÃO DA HOMEOSTASE GLICÊMICA EM NIPO-BRASILEIROS DE BAURU
}

\section{Daniela Saes Sartorelli}

Tese apresentada ao Departamento de Nutrição da Faculdade de Saúde Pública da Universidade de São Paulo, para obtenção do Título de Doutor em Saúde Pública.

ÁREA DE CONCENTRAÇÃO: Nutrição

ORIENTADORA: Profa. Dra. Marly Augusto Cardoso

São Paulo 
FICHA CATALOGRÁFICA

Sartorelli, Daniela Saes
Índice glicêmico da dieta habitual e alteração da homeostase
glicêmica entre Nipo-Brasileiros de Bauru. São Paulo, SP, 2005.
125 p.
Tese de Doutorado, apresentada à Faculdade de Saúde
Pública/USP - Área de concentração: Nutrição.
Orientadora: Cardoso, Marly Augusto.
1 Dieta habitual. 2 Homeostase glicêmica. 3 Diabetes tipo 2. 4
Epidemiologia nutricional. 5 Imigrantes japoneses.




\section{Ao meu mentor}

"Quem tem Deus como Império No mundo não está sozinho"

(Marisa Monte) 


\section{Recebam minhas flores de gratidão,}

\section{Por seu apoio profissional:}

Fundação de Amparo a Pesquisa do Estado de São Paulo (FAPESP) pelo auxílio financeiro concedido ao projeto de pesquisa e bolsa de doutorado.

Minha orientadora, Marly Augusto Cardoso, Departamento de Nutrição da Faculdade de Saúde Pública da USP. Estrela de luz que me introduziu ao caminho profissional escolhido. Agradeço o incentivo, tolerância, amizade e dedicação.

Grupo de Estudos de Diabetes na Comunidade Nipo-Brasileira de Bauru coordenado pelo Departamento de Medicina Preventiva da UNIFESP pelo intenso trabalho de coleta dos dados. Agradeço a receptividade e companheirismo.

Renata Damião Freire, doutoranda do Departamento de Medicina Preventiva da UNIFESP, pelo auxílio na organização do banco de dados, além de seu carisma e amizade.

Aos professores da banca pelas sugestões oportunas que contribuíram na melhoria do conteúdo da tese: Dr. Bruce Duncan (UFRS), Dr. Carlos Augusto Monteiro (USP), Dr. Laércio Joel Franco (USP), Dr. Paulo Lotufo (USP).

Docentes e funcionários do Departamento de Nutrição da Faculdade de Saúde Pública da USP pelo apoio e companheirismo. Em especial, Regina Rodrigues, pelo belo trabalho de editoração da tese.

Ao Grupo de Epidemiologia Nutricional do Laboratório de Nutrição Humana da Faculdade de Saúde Pública, coordenado por Marly Augusto Cardoso. Impossível descrever a gratidão que sinto pelo carinho, companheirismo e incentivo. Em especial, Teresa Gontijo de Castro pelas lições de estatística, humildade e responsabilidade social. 


\section{Por seu apoio do emocional:}

Meus amados pais, Leonildo Sebastião Sartorelli (in memorian) e Izaura Saes Sartorelli. Minha amada "mama", que dedicou a vida às suas filhas. Como por encanto, compartilhamos hoje de um mesmo sonho de criança: ser professora.

Minhas irmãs Adriana Saes Sartorelli e Carolina Saes Sartorelli pelo incentivo e amor.

Querida família e amigos paulistanos: Flávia Saes Cominale, Vanesca Sartorelli Medeiros, Verusca Sartorelli Medeiros, Giana Longo, William Nakamura, Júlio Carlos Luz da Conceição e, em especial, minha companheira de todos os momentos: Patrícia Ramos de Oliveira. Vocês foram o alicerce que me sustentou nos momentos mais difíceis e o doce perfume que encantou meus dias mais sublimes. Obrigada por existirem em minha vida.

Eternos amigos Gustavo Vettorazo Jorge, Deise de Oliveira Buzo e Carlos Eduardo Guimarães, meus irmãos.

Aos amigos dos grupos de Psicodrama e Centro Espírita Discípulos de Jesus por fortalecerem minha alegria de viver.

Por último, agradeço minha coragem de atravessar turbulências quase insuportáveis e a perseverança no deserto das dificuldades em busca da realização de um grande sonho: lecionar e pesquisar. 


\section{ÍNDICE}

RESUMO

SUMMARY

1. INTRODUÇÃO

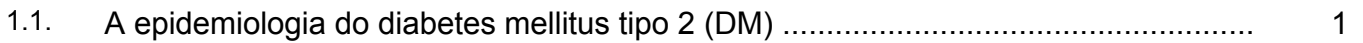

1.1.1. Magnitude e distribuição ................................................................. 1

1.1.2. Fatores de risco para o diabetes .......................................................

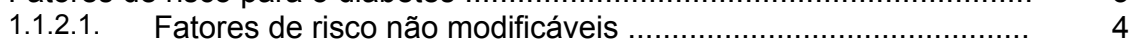

1.1.2.2. Fatores de risco modificáveis ................................................ 5

1.1.2.2.1. Variação de peso corpóreo, obesidade abdominal e excesso de peso .......................................... 5

1.1.2.2.2. Sedentarismo …......................................... 7

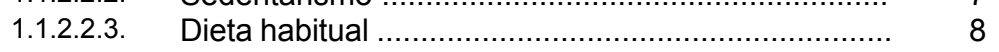

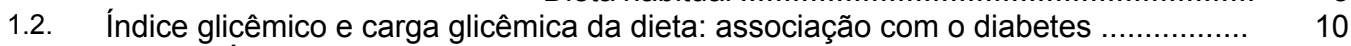

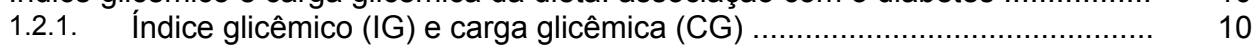

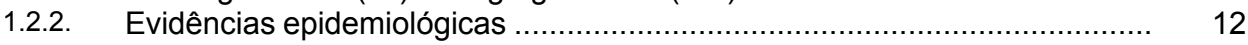

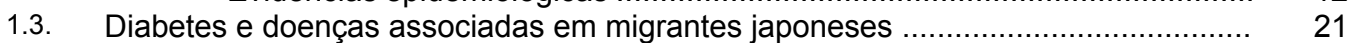

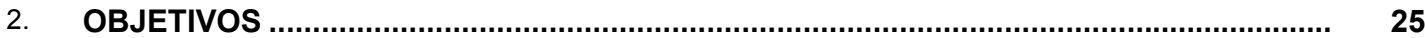

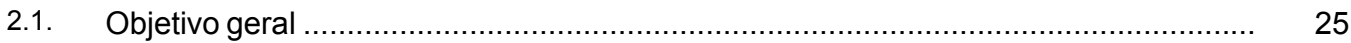

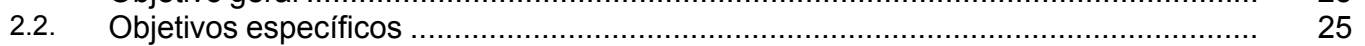

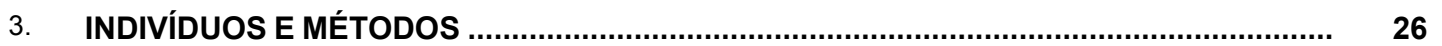

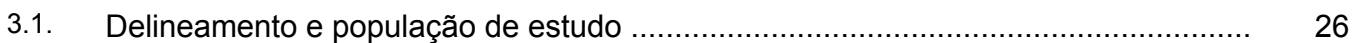

3.2. Variáveis sócio-demográficas e de estilo de vida .............................................. 28

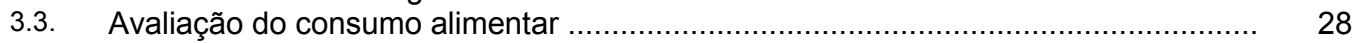

3.4. Avaliação clínica e antropométrica ............................................................. 30

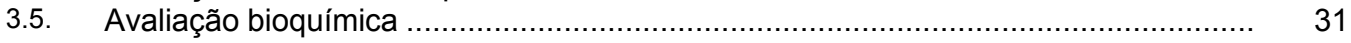

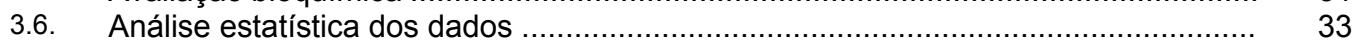

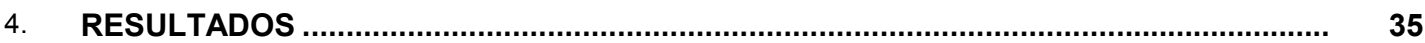

4.1. Características gerais da população de estudo .................................................. 35

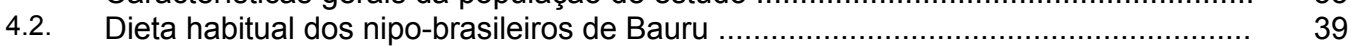

4.3. Associação entre IG, CG, dieta habitual e glicemia de jejum, insulinemia de jejum e HOMAR

4.4. Associação entre IG, CG, dieta habitual e homeostase glicêmica ............................. 50

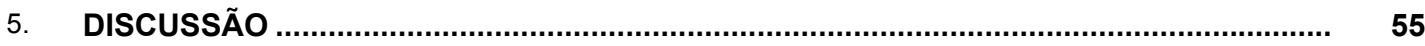

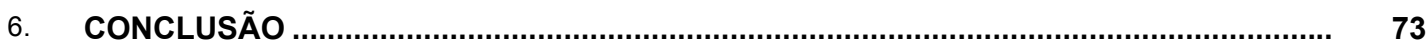

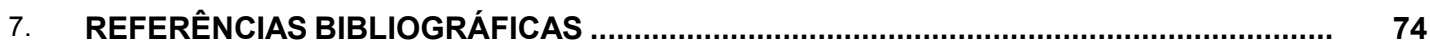

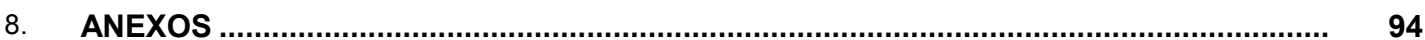

Anexo 1 - Aprovação do Comitê de Ética em Pesquisa da Escola Paulista de Medicina da Universidade Federal de São Paulo (UNIFESP) + Carta de Informação + Termo de Consentimento

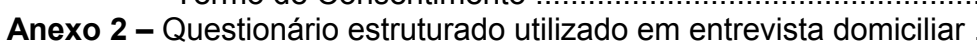

Anexo 3 - Questionário Quantitativo de Freqüência Alimentar (QQFA) desenvolvido e validado para a população Nipo-Brasileira

Anexo 4 - Valores de Carboidratos $(\mathrm{CH})$, índice glicêmico (IG) e carga glicêmica $(\mathrm{CG})$ atribuídos aos alimentos do Questionário Quantitativo de Freqüência Alimentar (QQFA) 


\section{LISTA DE TABELAS}

Tabela 1 - Características gerais da comunidade nipo-brasileira segundo categorias de homeostase glicêmica. Bauru, 2000

Tabela 2 - Freqüências de excesso de peso, obesidade abdominal, hipertensão arterial sistêmica e dislipidemia na comunidade nipo-brasileira segundo categorias de homeostase glicêmica. Bauru, 2000

Tabela 3 - Média e desvio-padrão (DP) de variáveis antropométricas e mediana de níveis pressóricos (PA) e variáveis bioquímicas segundo categorias de homeostase glicêmica. População adulta de nipo-brasileiros. Bauru, 2000 $(n=1.054)$

Tabela 4 - Média e desvio-padrão (DP) de idade, variáveis antropométricas e mediana de níveis pressóricos (PA) e variáveis bioquímicas segundo categorias de homeostase glicêmica. População adulta feminina de nipo-brasileiros. Bauru, $2000(n=579)$

Tabela 5 - Média e desvio-padrão (DP) de idade, variáveis antropométricas e mediana de níveis pressóricos (PA) e variáveis bioquímicas segundo categorias de homeostase glicêmica. População adulta masculina de nipo-brasileiros. Bauru, $2000(n=475)$

Tabela 6 - Mediana do consumo diário e intervalo interquartil (P25, P75) de calorias totais (VCT) e frações, índice glicêmico, carga glicêmica, fibras e nutrientes da dieta habitual segundo classificação da homeostase glicêmica. População adulta de nipo-brasileiros. Bauru, 2000 ( $n=1.054)$

Tabela 7 - Mediana do consumo diário e intervalo interquartil (P25, P75) de calorias totais (VCT) e frações, índice glicêmico, carga glicêmica, fibras e nutrientes da dieta habitual segundo classificação da homeostase glicêmica. População adulta feminina de nipo-brasileiros. Bauru, $2000(n=579)$

Tabela 8 - Mediana do consumo diário e intervalo interquartil (P25, P75) de calorias totais (VCT) e frações, índice glicêmico, carga glicêmica, fibras e nutrientes da dieta habitual segundo classificação da homeostase glicêmica. População adulta masculina de nipo-brasileiros. Bauru, $2000(n=475)$...........

Tabela 9 - Mediana e intervalo interquartil (P25, P75) de consumo diário de grupos de alimentos (g) da dieta habitual segundo classificação da homeostase glicêmica. População adulta de nipo-brasileiros. Bauru, $2000(n=1.054)$

Tabela 10 - Mediana e intervalo interquartil (P25, P75) de consumo diário de grupos de alimentos (g) da dieta habitual segundo classificação da homeostase glicêmica. População adulta feminina de nipo-brasileiros. Bauru, 2000 $(n=579)$

Tabela 11 - Mediana e intervalo interquartil (P25, P75) de consumo diário de grupos de alimentos (g) da dieta habitual segundo classificação da homeostase glicêmica. População adulta masculina de nipo-brasileiros. Bauru, 2000 $(n=475)$

Tabela 12 - Coeficientes de correlação de Pearson $(r)$ entre o consumo de calorias totais, índice glicêmico, carga glicêmica, demais variáveis dietéticas e glicemia e insulinemia de jejum e HOMA R. População adulta de nipobrasileiros. Bauru, $2000(n=1.054)$

Tabela 13 - Coeficientes de correlação de Pearson $(r)$ entre o consumo diário de grupos de alimentos (g) e glicemia e insulinemia de jejum e HOMA R. População adulta de nipo-brasileiros. Bauru, $2000(n=1.054)$ 
Tabela 14 - Coeficientes de regressão ß1 (IC 95\%) entre o índice glicêmico, carga glicêmica e nutrientes selecionados em modelos de regressão linear múltiplos e valores de glicemia e insulinemia de jejum e HOMA R. População adulta de nipo-brasileiros. Bauru, 2000 ( $n=1054)$

Tabela 15 - Coeficientes de regressão ß1 (IC 95\%) entre o índice glicêmico, carga glicêmica e nutrientes selecionados em modelos de regressão linear múltiplos e valores de glicemia e insulinemia de jejum e HOMA R. População adulta feminina de nipo-brasileiros. Bauru, $2000(n=579)$

Tabela 16 - Coeficientes de regressão ß1 (IC 95\%) entre o índice glicêmico, carga glicêmica e nutrientes selecionados em modelos de regressão linear múltiplos e valores de glicemia e insulinemia de jejum e HOMA R. População adulta masculina de nipo-brasileiros. Bauru, $2000(n=475)$

Tabela 17 - Coeficientes de regressão ß1 (IC 95\%) entre o consumo diário de grupos de alimentos em modelos de regressão linear múltiplos e valores de glicemia e insulinemia de jejum e HOMA R. População adulta de nipobrasileiros. Bauru, $2000(n=1.054)$

Tabela 18 - Coeficientes de regressão ß1 (IC 95\%) entre o consumo diário de grupos de alimentos em modelos de regressão linear múltiplos e valores de glicemia e insulinemia de jejum e HOMA R. População adulta feminina de nipo-brasileiros. Bauru, $2000(n=579)$

Tabela 19 - Coeficientes de regressão ß1 (IC 95\%) entre o consumo diário de grupos de alimentos em modelos de regressão linear múltiplos e valores de glicemia e insulinemia de jejum e HOMA R. População adulta masculina de nipo-brasileiros. Bauru, $2000(n=475)$

Tabela 20 - Razão de chances bruta (IC 95\%) para co-variáveis segundo categorias de alteração de homeostase glicêmica em nipo-brasileiros (AHG). Bauru, 2000.

Tabela 21 - Razão de chances (IC 95\%) para alteração de homeostase glicêmica (AHG) entre tercis de índice glicêmico, carga glicêmica e nutientes da dieta habitual em nipo-brasileiros. Bauru, 2000

Tabela 22 - Razão de chances (IC 95\%) para alteração de homeostase glicêmica $(\mathrm{AHG})$ entre tercis de consumo habitual de grupos de alimentos em nipobrasileiros. Bauru, 2000 


\section{LISTA DE FIGURAS}

Figura 1 - Prevalência do diabetes mellitus tipo 2 (DM) e tolerância à glicose diminuída (TGD) observada em algumas comunidades no mundo (Comunicação pessoal, Gimeno SGA, 2004). Fontes: King et al, 1998; Gimeno et al, $2003^{8}$

Figura 2 - Seleção da população amostral do estudo

Figura 3 - Mediana de consumo de alimentos segundo tercil de índice glicêmico da dieta em nipo-brasileiros. Bauru, 2000

Figura 4 - Mediana de consumo de alimentos segundo tercil de carga glicêmica da dieta em nipo-brasileiros. Bauru 2000

Figura 5 - Mediana de consumo de alimentos segundo tercil de fibra total da dieta, segundo classificação de homeostase glicêmica. Bauru, 2000 


\section{LISTA DE ABREVIAÇÕES ADOTADAS NA TESE}

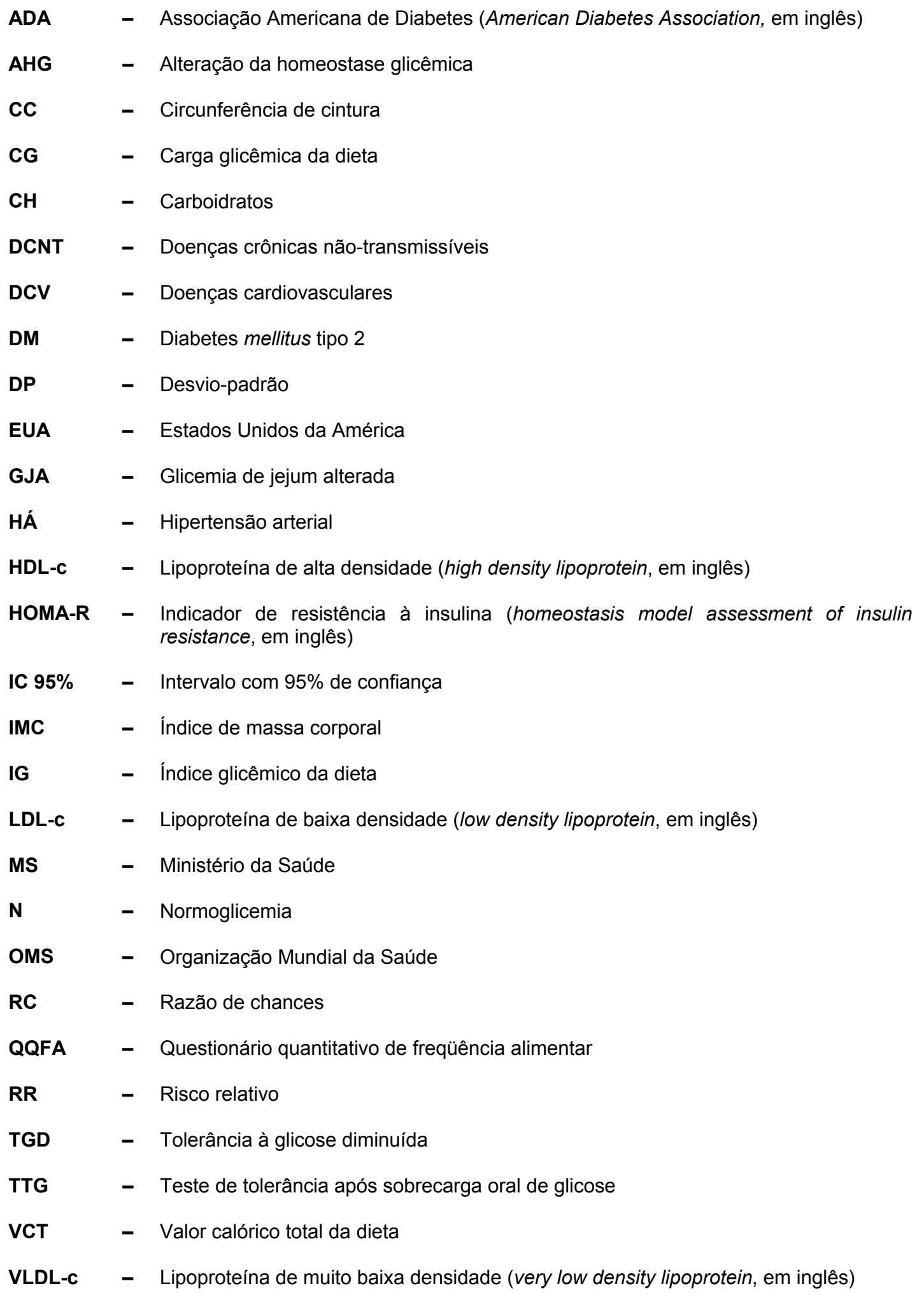




\section{RESUMO}

Sartorelli DS. Índice glicêmico da dieta habitual e alteração da homeostase glicêmica em Nipo-Brasileiros de Bauru. São Paulo, 2005 [Tese de Doutorado - Faculdade de Saúde Pública da Universidade de São Paulo].

Objetivos. Investigar a associação entre consumo alimentar, índice glicêmico (IG) da dieta habitual com glicemia e insulinemia de jejum, resistência à insulina (HOMA R) e alteração da homeostase glicêmica (AHG: glicemia de jejum alterada - GJA, tolerância à glicose diminuída - TGD e diabetes mellitus tipo 2). Indivíduos e métodos. 1.054 nipo-brasileiros residentes em Bauru, ambos os sexos, 30 a 90 anos, primeira e segunda gerações, que participaram de inquérito transversal conduzido em 2000, sem diagnóstico prévio de AHG e/ou uso de hipoglicemiantes orais/insulina. Para avaliação da dieta habitual, utilizou-se questionário quantitativo de freqüência alimentar, previamente validado, com o auxílio do programa Dietsys versão 4.0. Os fatores dietéticos foram ajustados pelas calorias totais pelo método residual, após transformação logarítmica. As variáveis independentes foram inicialmente selecionadas segundo correlação de Pearson com glicemia e insulinemia de jejum ou HOMA R (variáveis dependentes contínuas) com valor de $p<0,20$. A associação entre nutrientes/ alimentos com as variáveis dependentes contínuas foi avaliada em modelos de regressão linear múltiplos. Modelos de regressão logística múltiplos foram utilizados para investigar a relação entre fatores dietéticos (tercis) com AHG, ajustados por fatores de confusão. Resultados. Após ajuste múltiplo, houve associações inversas entre o consumo dos grupos de laticínios integrais (g/dia), doces (g/dia), IG da dieta e glicemia de jejum (mg/dl). Relação inversa entre o consumo de IG da dieta e HOMA R também foi observada. Verificou-se razão de chances - RC (IC 95\%) - para GJA de 1,70 (1,06 $2,74)$ no último tercil de consumo de fibras totais em que as principais fontes alimentares foram o arroz polido, pão branco e frutas/sucos de frutas. Efeito protetor entre o tercil intermediário do consumo de vegetais $[0,61(0,38-$ $0,98)$ ] foi observado para TGD. Conclusão. Em nossa população de estudo, a fibra dietética proveniente do consumo excessivo de arroz polido, pão branco, frutas e sucos representou risco para AHG. Por outro lado, observou-se efeito protetor do maior consumo de vegetais para TGD.

Descritores. Dieta habitual. Homeostase glicêmica, Índice glicêmico da dieta. Diabetes tipo 2. Epidemiologia nutricional. Imigrantes japoneses. 


\section{SUMMARY}

Sartorelli DS. Dietary glycemic index in relation to impaired glucose homeostasis disturbances in Japanese-Brazilians living in Bauru. São Paulo, 2005. [Doctor's degree thesis - Faculdade de Saúde Pública da Universidade de São Paulo].

Objective. To investigate the effects of food intake and dietary glycemic index $(\mathrm{Gl})$ on fasting plasma levels of glucose and insulin, homeostasis model assessment of insulin resistance (HOMA R) and impaired glucose disturbance - IGD (impaired fasting glucose - IFG, impaired glucose tolerance - IGT and diabetes mellitus type 2). Subjects and methods. 1,054 Japanese-Brazilians living in Bauru, of both genders, 30 to 90 years-old, firstand second-generation, who completed all the information for the crosssectional survey in 2000, without previous diagnosis of IGD and/or use of oral hipoglycemic medication/insulin. Food consumption was assessed using a validated food frequency questionnaire, with the aid of the software Dietsys 4.0. All dietary factors were log-transformed and adjusted for total energy intake by residual method. The dependent variables were first selected using Pearson correlation with fasting plasma levels of glucose and insulin or HOMA R (continuous independent variables), with $p<0.20$. The associations between selected nutrients/foods and the continuous independent variables were assessed using multiple linear regression models. Logistic regression models were used to investigate the relationship between dietary factors (tercile) and IGD, while adjusting for confounding factors. Results. After multiple adjustments, intakes of whole dairy products and sweets (g/day) and dietary GI were inversely correlated with fasting glucose levels (mg/dl). Dietary GI was also inversely correlated with HOMA R. The odds ratio (95\% confidence interval) for IFG was $1.70(1.06-2.74)$ in the highest tercile of total dietary fiber (main food sources: white rice and bread, fruits/fruit juices). The second tercile of vegetable intake was associated with a risk reduction of IGT [0.61 (0.38 - 0.98)]. Conclusion. In our study population, the intake of total dietary fiber, largely attributable to high intakes of white rice, white bread, fruits/fruit juices, was positively associated with risk of IGD. On the other hand, a protective effect was observed for higher intake levels of vegetables.

Descriptors. Habitual diet. Impaired glucose disturbance. Dietary glycemic index. Diabetes type 2. Nutritional epidemiology. Japanese migrants. 


\section{INTRODUÇÃO}

\subsection{A epidemiologia do diabetes mellitus tipo 2 (DM)}

\subsubsection{Magnitude e distribuição}

Em muitos países do mundo a prevalência do diabetes tem se elevado vertiginosamente e espera-se um incremento ainda maior. Nos países em desenvolvimento há uma tendência futura de aumento na freqüência em todas as faixas etárias, especialmente nas mais jovens, cujo impacto negativo sobre a qualidade de vida dos indivíduos e a carga da doença aos sistemas de saúde é imensurável. ${ }^{1}$

Nos próximos 20 anos, estima-se um incremento de $42 \%$ do número de indivíduos acometidos pelo diabetes nos países desenvolvidos, especialmente nas faixas etárias mais avançadas, decorrente do aumento da esperança de vida e do crescimento populacional. Nos países em desenvolvimento, espera-se um aumento de $170 \%$ do número de indivíduos portadores da doença em todas as faixas etárias, principalmente no grupo de 45 - 64 anos, cuja prevalência deverá triplicar, duplicando nas faixas etárias de 20 - 44 e 65 e mais anos. A estimativa da prevalência do diabetes entre indivíduos com idade superior a 20 anos em 1995 era de 4\% da população mundial. Em 2025, estima-se uma prevalência de 5,4\% nesta faixa etária. No Japão, onde $6,5 \%$ dos indivíduos adultos ( $\geq 20$ anos) eram acometidos pela doença em 1995, estima-se uma prevalência de 8,7\% em 2025. No Brasil, a prevalência de diabetes era de 5,2\% em 1995 e estima-se que $7,2 \%$ dos adultos brasileiros ( $\geq 20$ anos) sejam portadores de diabetes no ano de $2025 .^{1}$

Os dados oficiais do Brasil são provenientes de um estudo multicêntrico de base populacional, conduzido em 1988 em nove capitais de estados brasileiros. Este estudo demonstrou que as prevalências do 
diabetes e da tolerância à glicose diminuída (TGD) em população urbana, entre 30 e 69 anos de idade, eram de 7,6 e $7,8 \%$, respectivamente. Os principais fatores de risco identificados foram idade, história familiar de diabetes e obesidade. Além disso, observou-se que $46 \%$ dos indivíduos portadores da doença desconheciam o diagnóstico, que provavelmente seria feito por ocasião de manifestação de alguma complicação crônica do diabetes. $^{2} \mathrm{O}$ diabetes representa uma importante causa de morte em adultos e idosos brasileiros, refletindo a magnitude deste problema de saúde pública no país. ${ }^{3,4,5}$

Apesar das maiores taxas de prevalência de alteração de homeostase glicêmica (AHG) observadas entre os índios Pima, estima-se que nos próximos 20 anos a maior número de casos novos sejam registrados na China e Índia. ${ }^{1}$ Prevalências alarmantes de distúrbios do metabolismo da glicose vêm sendo detectadas em populações migrantes de origem asiática, como os nipo-americanos e nipo-brasileiros, sugerindo que a exposição à alteração de estilo de vida repercuta em um impacto deletério no metabolismo de indivíduos geneticamente susceptíveis, favorecendo a ocorrência do diabetes. Entre os asiáticos, além da hipótese do impacto negativo da adaptação cultural ao novo estilo de vida, uma maior susceptibilidade à resistência à insulina em relação a outras etnias vem sendo sugerida, independente do peso corporal. ${ }^{6}$ Estudos epidemiológicos conduzidos na Universidade de Washington, Estados Unidos (EUA), demonstraram que a prevalência do diabetes entre os nipo-americanos residentes em Seattle, com idade entre 45 e 74 anos, era cerca de 5 vezes superior à observada entre japoneses residentes em Tóquio com faixa etária superior a 40 anos. $^{7}$ No Brasil, em 1993, entre migrantes japoneses de primeira e segunda gerações, confirmou-se a hipótese do impacto negativo do processo migratório na prevalência do diabetes, com freqüências semelhantes às diagnosticadas em nipo-americanos. Após 7 anos, um incremento exorbitante de distúrbios do metabolismo da glicose foi identificado, sendo os nipo-brasileiros considerados a comunidade portadora 
da maior prevalência de AHG relatada no mundo. ${ }^{8}$ Conforme demonstrado na Figura 1, muitas comunidades vêm sendo afetadas pelas elevadas prevalências de diabetes e TGD em alguma magnitude.

Figura 1 - Prevalência do diabetes mellitus tipo 2 (DM) e tolerância à glicose diminuída (TGD) observada em algumas comunidades no mundo (Comunicação pessoal, Gimeno SGA, 2004). Fontes: King et al, 1998; Gimeno et al, 2003. ${ }^{8}$

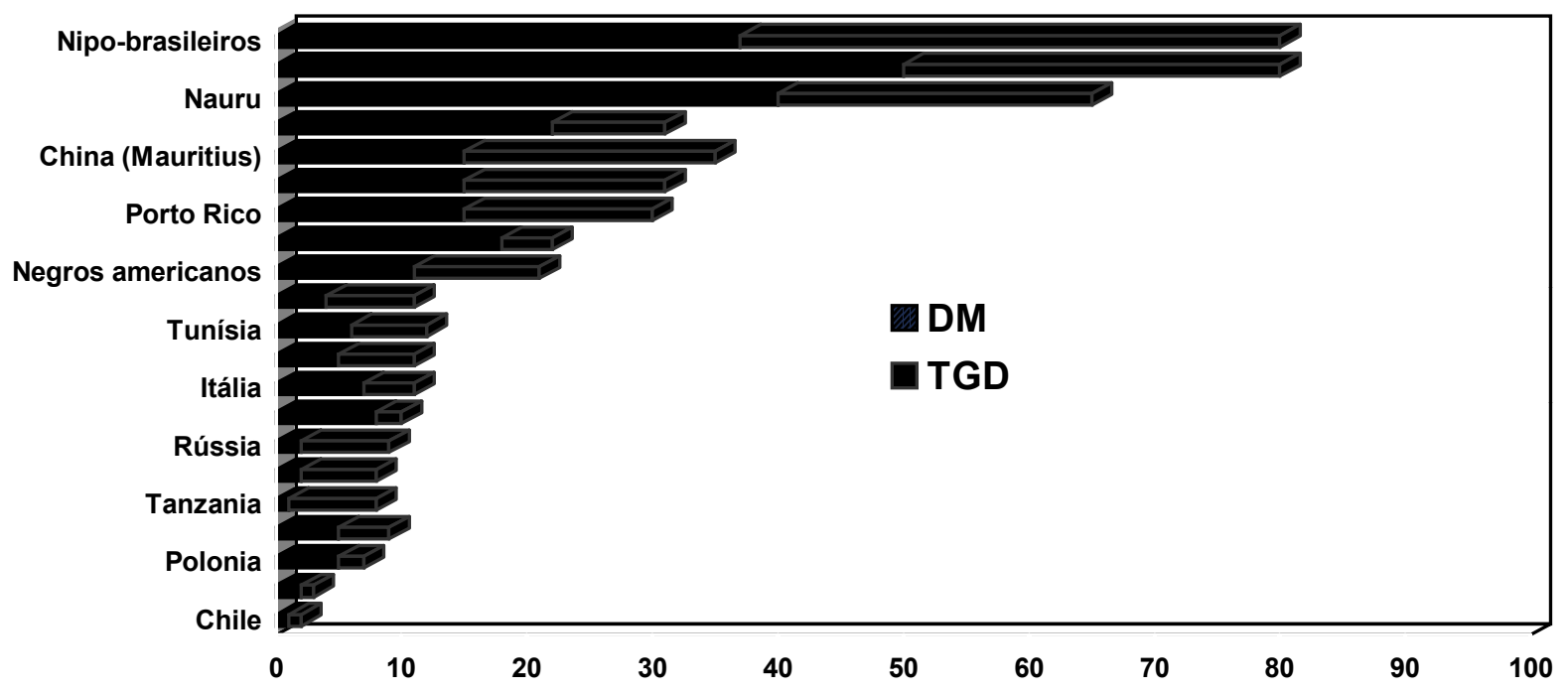

\subsubsection{Fatores de risco para o diabetes}

As fases de evolução para a hiperglicemia crônica e progressão do diabetes iniciam-se pela resistência tecidual periférica à ação da insulina e disfunção conseqüente ou concomitante das células $ß$ do pâncreas, progredindo aos estágios intermediários de alteração da homeostase glicêmica (AHG): glicemia de jejum alterada (GJA) e TGD. ${ }^{9}$

Os estágios intermediários de AHG pré-clínicos ou clínicos podem evoluir em ambas as direções, tanto para o desenvolvimento do diabetes como para a normalização da glicemia. Evidências demonstram que a alteração do metabolismo de carboidratos representa um importante fator de risco para doenças macrovasculares. ${ }^{10,11} \mathrm{~A}$ hiperglicemia e hiperinsulinemia 
contribuem para a evolução de doenças cardiovasculares (DCV) tanto quanto a duração clínica do diabetes. ${ }^{12}$

Apesar dos estágios intermediários de alteração do metabolismo dos carboidratos serem considerados fatores de risco em potencial tanto para o desenvolvimento de doenças macrovasculares como do diabetes propriamente dito, estudos sobre seus fatores determinantes, especialmente relacionados ao consumo alimentar habitual, são ainda escassos e os resultados são inconclusivos. ${ }^{13}$

\subsubsection{Fatores de risco não modificáveis}

Evidências sugerem uma forte influência da carga genética e agregação familiar na determinação do diabetes, embora a natureza da contribuição genética ainda não seja totalmente esclarecida. Estima-se que o risco de desenvolver a doença entre familiares de primeiro grau de portadores de diabetes seja $35 \%$ superior ao observado na população em geral. Além disso, uma maior concordância para ocorrência do diabetes entre gêmeos homozigóticos (50-90\%) foi observada em relação aos heterozigóticos. Entretanto, a maior susceptibilidade verificada entre indivíduos com histórico familiar de diabetes pode ser considerado um fator relacionado tanto a influência genética como ao semelhante estilo de vida compartilhado na agregação familiar. ${ }^{13}$

A variação das taxas de prevalência do diabetes entre populações de diferentes origens étnicas que compartilham o mesmo ambiente sugere a influência da raça na susceptibilidade de desenvolver a doença, o que pode ser fundamentado pela verificação de taxas 50 a 100\% maiores entre afroamericanos e hispânicos que residem nos EUA em relação ao observado entre os caucasianos. ${ }^{14}$ Embora alguns estudos conduzidos em nipoamericanos apontem maior propensão ao acúmulo de gordura na região abdominal como um dos fatores envolvidos na alta prevalência de síndrome 
metabólica, ${ }^{15,16}$ uma maior predisposição para a resistência à insulina foi verificada entre asiáticos independente do peso, circunferência de cintura, dieta habitual ou idade. ${ }^{6}$

Estudos prévios sugerem que a diferença observada na prevalência e incidência do diabetes segundo sexo seja influenciada por fatores relacionados à composição corporal e prática de atividades físicas inerentes a cada gênero. Por outro lado, o incremento do risco segundo idade é registrado em diversas populações, embora haja divergências da faixa etária inicial de aumento da ocorrência da doença segundo susceptibilidade genética e influência ambiental. ${ }^{1}$

\subsubsection{Fatores de risco modificáveis}

\subsection{Variação de peso corpóreo, obesidade abdominal e excesso de peso}

De acordo com relatório recente da Organização Mundial da Saúde (OMS) sobre dieta, nutrição e prevenção de doenças crônicas, ${ }^{17}$ a associação entre $\mathrm{o}$ ganho de peso, obesidade abdominal e o desenvolvimento de diabetes é convincente. O número de estudos epidemiológicos, incluindo-se estudos prospectivos e ensaios clínicos aleatorizados, pode ser considerado suficiente na demonstração da força causal destes fatores de risco em relação ao diabetes.

O ganho de peso na vida adulta é apontado como um importante fator de risco para o desenvolvimento de diversas doenças crônicas. ${ }^{18} \mathrm{Um}$ incremento de peso de $5 \%$ em relação ao peso referido aos 20 anos de idade está relacionado à ocorrência de hipertensão arterial (HA), dislipidemia e, principalmente, hiperinsulinemia. ${ }^{19} \mathrm{Em}$ uma amostra de 530 nipobrasileiros de 40 a 79 anos de idade, cada quilograma de peso adquirido na idade adulta representou um aumento de $2 \%$ no risco de AHG isolada e de 
$15 \%$ na chance de AHG associada a HA e dislipidemia, independente da idade ou sexo. ${ }^{20}$

Estudos com populações migrantes de origem asiática residentes nos EUA e Brasil sugerem que a propensão ao acúmulo de gordura na região abdominal, característico desta população, é um dos fatores relacionados à alta prevalência de síndrome metabólica e doenças associadas. ${ }^{15,16,21} \mathrm{Em}$ 2000, a prevalência de obesidade abdominal entre os nipo-brasileiros de primeira e segunda geração foi de 26 e 37\% para as mulheres e de 26 e $45 \%$ para os homens, respectivamente. No Japão, em 1998, a prevalência de sobrepeso entre homens e mulheres correspondia a 18 e 13\%, respectivamente. ${ }^{7}$ Em uma amostra de 290 nipo-americanos de segunda geração, a obesidade abdominal representou um incremento de $60 \%$ no risco de incidência de diabetes após 6 anos de seguimento. ${ }^{22}$ Sugere-se que a obesidade abdominal seja um dos principais fatores envolvidos na crescente incidência mundial de diabetes observada nos últimos anos. ${ }^{23}$ Uma das hipóteses seria sua relação direta com a resistência à insulina, ${ }^{24,25}$ além de sua composição de fácil mobilização, aumentando assim o risco para doenças crônicas não-transmissíveis (DCNT). ${ }^{26}$

Na América Latina, estima-se que entre 80 e 90\% dos indivíduos acometidos pelo diabetes sejam portadores de obesidade e o risco está diretamente associado ao aumento de índice de massa corporal (IMC). ${ }^{27}$ No Brasil, observa-se um aumento na prevalência da obesidade em homens e mulheres. ${ }^{28} \mathrm{~A}$ crescente freqüência do excesso de peso entre mulheres de classes sociais menos favorecidas tem apontado a obesidade como uma relevante alavanca da desigualdade em saúde no país, ${ }^{29}$ expondo a população a um maior risco para doenças crônicas relacionadas com o excesso de peso corporal.

Apesar da carência de estudos epidemiológicos sobre o impacto do excesso de peso na gênese de doenças crônicas em brasileiros, os dados 
disponíveis concordam com as evidências científicas do maior risco de hipertensão, alteração do metabolismo da glicose e dislipidemia em adultos $^{30}$ e idosos ${ }^{31}$ portadores de sobrepeso ou obesidade. Alguns estudos também sugerem que a prevalência de fatores de risco para doenças cardiovasculares, como o excesso de peso, sedentarismo, tabagismo, dislipidemia, hipertensão e diabetes em adultos brasileiros são bastante elevadas, $^{32,33,34}$ enfatizando a necessidade de implementação de medidas preventivas para o controle de doenças crônicas em nossa população.

\subsubsection{Sedentarismo}

O sedentarismo favorecido pela vida moderna é um fator de risco tão importante quanto a dieta inadequada na etiologia da obesidade ${ }^{35}$ e possui uma relação positiva com a incidência do diabetes em adultos, independentemente do $\mathrm{IMC}^{36,37}$ ou história familiar de diabetes. ${ }^{38}$

Há evidências fundamentadas por vários estudos que o controle de peso e aumento da atividade física diminuem a resistência à insulina reduzindo a probabilidade de se desenvolver o diabetes. ${ }^{39,40}$ Estudos prospectivos recentes sugerem que a prática moderada ou intensa de atividades físicas de lazer pode reduzir significativamente o risco de diabetes, ${ }^{41}$ sendo esta evidência confirmada mesmo entre indivíduos geneticamente susceptíveis, como os índios $\mathrm{Pima}^{42}$ e asiáticos, independente de outros fatores de risco. ${ }^{43}$

De acordo com a OMS, ${ }^{17}$ o número de estudos longitudinais fornecem evidências suficientes sobre a força causal do sedentarismo em relação ao diabetes, assim como o papel protetor da prática de atividades físicas regulares independente do grau de adiposidade. A prática mínima de atividades físicas efetiva na prevenção do diabetes não é bem estabelecida. Entretanto, sabe-se que exercícios físicos regulares com intensidade de 80$90 \%$ do batimento cardíaco máximo durante 20 minutos numa freqüência de 5 vezes por semana aumenta a sensibilidade à insulina. 
A prática de atividades físicas regulares promove um aumento da utilização da insulina por maior captação hepática e melhor sensibilidade dos receptores periféricos. ${ }^{44}$ Além disso, sua prática habitual associada à dieta melhora o perfil lipídico de indivíduos em risco de desenvolvimento de DCV. ${ }^{45}$

A importância da prática habitual de atividades físicas de lazer na promoção da saúde e prevenção de doenças crônicas, como as DCV, vem sendo sugerida por estudos epidemiológicos. ${ }^{46,47} \mathrm{O}$ estímulo à prática de atividades físicas de recreação, tais como pedalar ou caminhar, tem sido recomendado para prevenção e controle metabólico do diabetes. ${ }^{48}$

No Brasil, um estudo transversal de base populacional conduzido nos estados do Nordeste e Sudeste em 1997 estimou uma prevalência de cerca de $87 \%$ de adultos sedentários, ou seja, que referiram prática de atividades físicas de lazer inferior a 30 minutos por semana. ${ }^{49} \mathrm{~A}$ redução do nível de atividade física tem sido atribuída à modernização dos processos produtivos, inclusive na agricultura, observado nas últimas décadas. ${ }^{50}$ Entretanto, estudos conduzidos no Rio de Janeiro demonstraram que, inclusive entre adolescentes, um maior tempo gasto com atividades sedentárias, tais como assistir TV ou jogar "vídeo-game", é freqüente e está positivamente associado ao IMC. ${ }^{51}$ Entre mulheres adultas, o sedentarismo foi inversamente relacionado com a escolaridade, ${ }^{52}$ sugerindo a influência de fatores culturais e sócio-econômicos no estilo de vida adotado pelos brasileiros.

\subsubsection{Dieta habitual}

Conforme a OMS, ${ }^{17}$ o consumo alimentar habitual constitui um dos principais fatores determinantes passíveis de modificação para DCNT. Estudos epidemiológicos apontam uma provável evidência de risco do consumo excessivo de gorduras saturadas ( $\geq 10 \%$ das calorias totais) e do baixo consumo habitual de fibras da dieta (menor que $20 \mathrm{~g}$ ao dia) para 
diabetes. Além disso, são considerados fatores de risco possíveis para o diabetes o consumo habitual de dietas com composição química: hiperlipídicas ( $\geq 37 \%$ das calorias totais); ricas em ácidos graxos trans; elevados teores de índice glicêmico (IG), assim como as de baixos teores de ácidos graxos ๗-3. Um relação protetora do consumo de vitamina $\mathrm{E}$, cromo, magnésio e consumo moderado de álcool em relação ao diabetes foi sugerida por alguns estudos, mas estes resultados são controversos. ${ }^{17}$

O Nurses' Health Study, estudo prospectivo conduzido nos EUA que acompanhou 84.941 mulheres durante 16 anos, demonstrou papel protetor do estilo de vida saudável (ausência de tabagismo, prática de 30 minutos de atividades físicas diária, manutenção de peso corporal e padrão alimentar habitual rico em fibras e ácidos graxos polinsaturados, pobre em gorduras saturadas e ácidos graxos trans com baixo IG) na incidência do diabetes, conferindo uma redução de $91 \%$ no risco de desenvolver a doença. ${ }^{53}$

Inúmeros estudos sugerem uma relação importante da qualidade dos lipídios da dieta no risco de desenvolvimento do diabetes. Dados prospectivos sugerem correlação positiva entre consumo de gorduras saturadas e os níveis de glicemia de jejum e pós-prandial, ${ }^{54,55,56}$ insulina $^{57,58}$ e maior risco de progressão de TGD para o diabetes. ${ }^{59}$ Outro estudo prospectivo demonstrou que um consumo generoso de peixes, ricos em ácidos graxos $\omega-3$, reduziu o risco de TGD em $50 \%$ em relação aos indivíduos que não consumiam fontes de $\omega-3$ com freqüência. ${ }^{60}$

Estudos prospectivos indicam que uma alimentação rica em gorduras de origem vegetal, magnésio, potássio, ${ }^{60}$ cereais integrais, ${ }^{61}$ peixes, verduras e legumes ${ }^{56}$ está inversamente associada ao risco de se desenvolver o diabetes, independentemente do IMC. 
Um padrão alimentar rico em frutas, verduras, legumes e peixes, associado ao consumo infreqüente de frituras, vem sendo apontado como um fator protetor para o desenvolvimento da TGD. ${ }^{62}$

\section{2. Índice glicêmico e carga glicêmica da dieta: associação com o diabetes}

\subsection{1. Índice glicêmico (IG) e carga glicêmica (CG)}

O conceito do IG foi proposto desde 1981 por Jenkins e colaboradores com o intuito de caracterizar o perfil de absorção dos carboidratos e resposta metabólica após as refeições. ${ }^{63}$ Consiste em uma escala de resposta glicêmica a uma quantidade fixa de carboidrato $(50 \mathrm{~g})$ quando comparado à resposta glicêmica de um alimento padrão, geralmente glicose ou pães. O conceito do IG pode ser considerado uma extensão da hipótese da fibra dietética, sugerindo que a absorção lenta dos nutrientes de alguns alimentos seria benéfica à saúde. O IG da dieta habitual é um indicador da qualidade do carboidrato da dieta consumida. ${ }^{64} \mathrm{~A}$ carga glicêmica (CG) do alimento é o produto do IG pela quantidade de carboidratos. A CG da dieta seria o resultado do efeito glicêmico da dieta como um todo, sendo uma medida de avaliação da quantidade e qualidade de carboidratos, considerando o efeito na glicemia do consumo de uma porção usual de um alimento. ${ }^{65}$

A velocidade de absorção dos carboidratos é diretamente influenciada por outros componentes da dieta como o teor de lipídios, proteínas e fibras. O teor de lipídios dos alimentos retarda o esvaziamento gástrico e a velocidade de liberação dos nutrientes para a corrente sangüínea, reduzindo o pico hiperglicêmico pós-prandial imediato. ${ }^{66}$ Por outro lado, uma dieta rica em proteínas possui ação direta na hipersecreção de insulina amenizando a elevação da glicemia após as refeições. Entretanto, sugere-se que este efeito seja dependente da fonte protéica consumida. Em animais, uma maior secreção de insulina foi observada após consumo de proteínas provenientes 
de laticínios como os queijos magros que são rapidamente digeridos. Por outro lado, este resultado não foi observado quando a fonte protéica avaliada foi albumina de ovos crus, que possui digestibilidade mais lenta. ${ }^{67}$ O efeito das fibras solúveis na redução da velocidade de absorção da glicose vem sendo atribuído tanto ao retardo do esvaziamento gástrico como em decorrência da adsorção e interação com os nutrientes, conferindo uma menor superfície de contato direto com a parede do intestino delgado. A maior resistência à difusão através da mucosa ocorre em virtude da viscosidade conferida ao bolo alimentar de uma dieta rica em fibras. ${ }^{68}$

Em relação às fibras insolúveis, a suposta ação protetora ainda não é bem elucidada. Estudos epidemiológicos prospectivos sugerem um efeito protetor no consumo de uma dieta com baixo IG e altos teores de fibras de cereais integrais para o risco de desenvolver o diabetes. ${ }^{69} \mathrm{Em}$ análise transversal com dados provenientes do estudo de Framingham, observou-se uma relação inversa entre o consumo de cereais integrais e insulina de jejum, razão cintura-quadril e LDL-colesterol (LDL-c). ${ }^{70}$ Entretanto, especulase se o efeito protetor da fibra proveniente de cereais integrais não seria atribuído ao alto teor de magnésio contido nestes alimentos. ${ }^{71} \mathrm{Em}$ alguns estudos epidemiológicos que encontraram associação protetora do consumo de cereais integrais em relação ao diabetes, esta relação não se manteve significante após o ajuste pelo magnésio da dieta. ${ }^{70,72,73}$

Além da composição química, o tamanho das partículas e o processamento dos alimentos poderão influenciar a velocidade de digestão e absorção dos carboidratos. O menor tamanho das partículas determinado tanto pelo processamento/preparo do alimento como pelo maior tempo de mastigação facilita a digestão e absorção dos carboidratos, interferindo na exposição das moléculas à ação da amilase salivar responsável pela quebra parcial da parede celular. Além disso, a forma de cocção também poderá interferir na disposição das moléculas e velocidade de absorção. O amido em presença de água, mediante aquecimento, sofre o processo de 
gelatinização facilitando a ação da amilase. Por outro lado, durante o resfriamento do alimento ocorre a retrogradação, que consiste na recristaliazação das moléculas impedindo a ação da amilase. ${ }^{71} \mathrm{Um}$ estudo experimental conduzido no Brasil demonstrou que a integridade da parede celular dos feijões interfere no aproveitamento do amido, podendo atuar como uma barreira física que dificulta a gelatinização dos grânulos e a ação das enzimas hidrolíticas. Assim, um maior tempo de coç̧ão das leguminosas poderá facilitar a hidrólise e velocidade de absorção dos carboidratos, aumentando seu $1 \mathrm{G} .{ }^{74}$ Além do feijão, o rompimento da estrutura da casca de outros alimentos, como a pipoca e aveia, vem sendo apontado como um fator modificador de seu IG, sugerindo a necessidade de se considerar a integridade dos grãos habitualmente consumidos nos estudos epidemiológicos. ${ }^{71}$

\subsubsection{Evidências epidemiológicas}

A associação entre a qualidade dos carboidratos e o excesso de peso e resistência à insulina em pesquisa experimental há muito vem sendo sugerida. $^{75}$ Estudos epidemiológicos recentes sugerem que tanto a quantidade como a qualidade dos carboidratos constituiriam importantes fatores preditores de dislipidemia, DCV e diabetes, principalmente entre indivíduos susceptíveis à resistência à insulina, com elevado IMC. .9,76 $^{\text {(n) }}$

Sugere-se que uma dieta com baixo IG promove uma maior sensação de saciedade, prolongando o período de reincidência da fome e reduzindo o consumo calórico nas refeições subseqüentes. Este efeito estaria relacionado à hiperinsulinemia e hipoglicemia reacional decorrente da hiperglicemia pós-prandial imediata após o consumo de uma refeição rica em carboidratos de rápida absorção. A hiperinsulinemia promove maior captação tecidual de nutrientes e acúmulo no tecido adiposo em detrimento de sua oxidação, impulsionando ganho de peso corporal. ${ }^{77}$ Além disso, prorrogando-se o tempo de absorção dos nutrientes pode-se produzir 
estímulo contínuo aos receptores do trato gastrointestinal mediados pela ação de hormônios como a colecistoquinina e peptídeo 1 semelhante ao glucagon (glucagon-like peptide 1, em inglês) a atuarem nos centros hipotalâmicos de controle da saciedade decorrente da dieta com baixo IG. Por outro lado, a hipoglicemia reacional observada após uma refeição com elevado IG parece exacerbar a sensação de fome em período reduzido de tempo. ${ }^{78}$ Desta forma, uma dieta com elevado IG vem sendo apontada como um possível fator desencadeante da obesidade, considerada fator de risco convincente no desenvolvimento de diversas doenças crônicas. ${ }^{17}$

Em relação ao risco para $\mathrm{DCV}$, estudos sugerem uma possível associação positiva com uma dieta habitual de elevado IG e CG. ${ }^{79} \mathrm{~A}$ correlação entre a qualidade dos carboidratos da dieta e importantes fatores de risco de DCV, como dislipidemia, ${ }^{80}$ insulina imunoreativa, ${ }^{81}$ proteína Creativa, ${ }^{82}$ síndrome metabólica ${ }^{83}$ e obesidade ${ }^{77}$ vem sendo assinalada por estudos epidemiológicos recentes.

Sugere-se que uma dieta habitual hiperglicídica seja um possível fator de risco para a dislipidemia, assim como ocorre em dietas hiperlipídicas. Os mecanismos fisiopatológicos ainda não estão bem esclarecidos, mas se especula que este efeito seria atribuído ao maior estímulo à lipogênese hepática, especialmente na síntese de triglicérides, assim como um menor cleareance do VLDL-colesterol (VLDL-c) através de uma maior oferta de glicose plasmática. Mulheres em período pós-menopausa, indivíduos com obesidade abdominal, HA, hiperinsulinemia e hiperglicemia parecem ser mais susceptíveis à indução de síntese de triglicérides mediado por dieta hiperglicídica. ${ }^{84}$ Por outro lado, a hipótese de explicação da relação do IG da dieta e a proteína C-reativa estaria relacionada ao desencadeamento do processo inflamatório. ${ }^{82}$ Uma outra explicação seria a excreção urinária excessiva de cromo, mineral envolvido no metabolismo de carboidratos e lipídios, promovida pela hiperglicemia pós-prandial. ${ }^{79}$ 
Um estudo prospectivo conduzido nos Estados Unidos avaliou o efeito da quantidade e qualidade dos carboidratos da dieta habitual na ocorrência de DCV entre 75.000 mulheres de 38-63 anos durante 10 anos de seguimento. $O$ consumo mediano de $C G$ ajustado pelas calorias totais foi de 161 unidades diárias. Após ajuste por tabagismo, idade, consumo calórico total da dieta (VCT) e outros fatores de risco, o risco relativo (RR) e intervalo com $95 \%$ de confiança (IC 95\%) para DCV no quintil superior de CG foi de $1,98(1,41 ; 2,77)$. Em análises estratificadas por IMC, observou-se que o RR (IC95\%) foi maior entre mulheres com IMC $>29 \mathrm{~kg} / \mathrm{m}^{2}$ [1,74 (1,42; 1,97)] quando comparadas às mulheres com IMC entre 23 e $29 \mathrm{~kg} / \mathrm{m}^{2}$ [1,2 (1,05; $2,03)]$ e com IMC $<23 \mathrm{~kg} / \mathrm{m}^{2}$ [(0,94 (1,00; 1,11)], sugerindo que o papel da qualidade dos carboidratos no risco de DCV seja influenciado pelo peso corpóreo, por sua vez diretamente relacionado a maior resistência à ação periférica da insulina. ${ }^{76}$

Em relação ao diabetes, uma das principais medidas de prevenção e controle metabólico consiste no controle glicêmico. A glicemia é modulada principalmente pela velocidade de liberação de carboidratos para a corrente sangüínea após as refeições, pelo tempo de depuração através da síntese de insulina e pela sensibilidade tecidual periférica à sua ação. Desta forma, a quantidade e qualidade dos carboidratos há muito vem sendo considerada um importante fator dietético envolvido na homeostase glicêmica. Em recente meta-análise de ensaios clínicos aleatorizados sobre o efeito do IG no controle metabólico de portadores de diabetes, Brand-Miller e colaboradores $^{85}$ concluíram que a adoção de uma dieta com baixo IG (média de 65 unidades/dia) a médio prazo proporcionaria um melhor controle glicêmico dos indivíduos portadores de diabetes, com redução de hemoglobina glicada $7,5 \%$ superior quando comparado aos efeitos observados em indivíduos consumindo dietas convencionais ou de elevado IG (83 unidades/dia). 
Embora o papel de uma dieta com baixo IG no controle metabólico de indivíduos portadores de diabetes esteja bem estabelecido, os estudos sobre a associação entre a quantidade e qualidade dos carboidratos da dieta habitual e prevenção primária do diabetes são controversos. ${ }^{86}$

Estudos epidemiológicos que avaliem a associação entre o consumo alimentar e risco de GJA ou TGD são escassos na literatura até o presente momento. Não identificamos estudos prospectivos sobre o consumo da qualidade e quantidade de carboidratos da dieta e incidência de distúrbios intermediários de metabolismo da glicose, como a GJA e TGD. Um ensaio clínico aleatorizado cruzado conduzido com 34 indivíduos portadores de TGD com idade entre 30 e 65 anos avaliou o impacto de quatro dietas diferentes durante 4 meses na glicemia e insulinemia de jejum: 1. dieta hiperglicídica (acima de $55 \%$ das calorias provenientes de carboidratos e $30 \%$ de lipídios) com elevado IG; 2 . dieta hiperglicídica com baixo IG; 3. dieta hipoglicídica (consumo de carboidratos inferior a $45 \%$ do VCT); 4 . dieta rica em ácidos graxos monoinsaturados ( $45 \%$ das calorias de carboidratos, $40 \%$ de lipídios sendo $20 \%$ de monoinsaturados através do consumo de azeite de oliva e margarina preparada utilizando óleo de canola não hidrogenado). Os indivíduos que receberam dietas com elevado ou reduzido IG foram orientados a consumirem pelo menos uma porção de alimento com elevado (pão branco, biscoitos, arroz polido ou batata) ou baixo IG (cereais integrais, massas, arroz parboilizado, leguminosas ou sopas instantâneas) em cada refeição, respectivamente. Entre os indivíduos portadores de TGD, a redução de glicemia 2 horas pós carga (G2hs) na dieta hipoglicídica foi semelhante à observada na dieta com baixo IG, demonstrando que a quantidade de carboidratos foi mais importante que a qualidade no controle glicêmico desta população. A concentração plasmática de insulina foi $20 \%$ superior no grupo com a dieta de baixo IG em relação a observada no grupo com consumo de dieta com elevado IG. ${ }^{87}$ 
Alguns autores sugerem que o efeito benéfico do consumo de uma dieta com baixo IG consistiria na redução do pico pós-prandial de insulina e glicose ${ }^{64}$ promovendo menor sobrecarga pancreática a longo prazo, cuja falência poderia ser originada por um efeito tóxico direto causado pela hiperglicemia. ${ }^{69}$ Além disso, sugere-se que os efeitos adversos de uma dieta com elevado IG estariam relacionados ao incremento na concentração pósprandial tardia de ácidos graxos livres acarretando maior resistência à insulina. Este mecanismo seria desencadeado pela hipersecreção de hormônios contraregulatórios, como o cortisol, glucagon e hormônio do crescimento, em decorrência da hipoglicemia reacional promovida por uma dieta de elevado IG. ${ }^{88}$ Neste processo, tanto a quantidade como a qualidade dos carboidratos contidos nos alimentos influenciaria a resposta metabólica após o consumo habitual deste alimento. ${ }^{64}$

Entretanto, conforme a Associação Americana de Diabetes (ADA) em recente documento sobre a quantidade e qualidade de carboidratos em relação à prevenção e controle de diabetes ${ }^{86}$ e em documento da OMS sobre dieta, nutrição e prevenção de doenças crônicas, ${ }^{17}$ as evidências de uma relação causal do IG e CG da dieta em relação ao diabetes são inconsistentes, sendo necessário maior número de investigações científicas, em especial ensaios clínicos aleatorizados. Embora as dietas com baixo IG sejam predominantemente ricas em fibras, essas consideradas um provável fator protetor para o diabetes, o elevado consumo de fibras totais não assegura por si só uma alimentação saudável, sendo adequado considerar a composição da alimentação como um todo. Por exemplo, o aporte de gorduras da dieta está inversamente relacionado ao seu IG devido ao efeito dos lipídios no retardo do esvaziamento gástrico promovendo uma menor velocidade de absorção dos carboidratos. Entretanto, o consumo excessivo de lipídios não pode ser considerado um hábito saudável. ${ }^{17}$

No estudo epidemiológico prospectivo Nurses' Health Study, conduzido em 65.173 mulheres americanas com idade entre 40 e 65 anos, 
demonstrou-se uma associação positiva entre o consumo de uma dieta habitual com elevado IG e a incidência de diabetes após 6 anos de seguimento. A mediana de consumo de IG e CG foi de 75 e 166 unidades/dia. O RR (IC 95\%) do quintil superior de IG da dieta foi de 1,37 $(1,09 ; 1,71)$ quando comparado ao quintil inferior de consumo ajustado por possíveis fatores de confusão. Em relação à CG, o RR (IC 95\%) do quintil superior foi de $1,47(1,16 ; 1,86)$ após a inclusão de fibra de cereais no modelo múltiplo. Por outro lado, o RR (IC 95\%) do quintil superior de consumo de fibras de cereais foi de $0,72(0,58 ; 0,90)$ quando comparado ao quintil inferior. Observou-se que o consumo habitual do tercil superior de CG (mediana superior a 165 unidades/dia) associada ao consumo do tercil inferior de fibras de cereais (mediana inferior a 2,5g/dia) estava relacionado ao risco de $2,5(1,14 ; 5,51)$ para diabetes entre as mulheres estudadas. ${ }^{72}$

Entre as 91.249 mulheres jovens (20-44 anos) acompanhadas pelo Nurses' Health Study II, elevados valores de IG foram associados ao risco para diabetes após 8 anos de seguimento [RR 1,59 (1,21-2,10)]. Em relação ao consumo de fibra de cereais, o RR (IC 95\%) foi de 0,64 $(0,48-0,86)$ no quintil superior quando comparado ao menor consumo deste nutriente. Nenhuma associação foi observada entre a CG da dieta e risco de diabetes nesta população. ${ }^{89}$ Neste recente estudo epidemiológico, controverso em relação a estudos prévios, o risco de diabetes relacionado ao maior consumo de IG, assim como o efeito protetor do maior consumo de fibras de cereais, foram independentes do consumo de magnésio. Nos modelos múltiplos de regressão, além do ajuste por idade, IMC, história familiar de diabetes, atividade física, tabagismo, história de HA, dislipidemia, reposição hormonal, consumo habitual de álcool e calorias totais, também foram consideradas variáveis como o consumo de magnésio, cafeína, fibra de cereais, gorduras totais e frações.

No estudo americano prospectivo Health Professionals Follow-Up Study, conduzido em 42.759 homens entre 40 e 75 anos de idade, observou- 
se uma associação positiva entre elevado IG da dieta e incidência do diabetes após 6 anos de seguimento. Os valores medianos de consumo de IG e CG da dieta habitual foram de 73 e 160 unidades/dia. O RR (IC 95\%) do quintil superior de consumo de IG foi de $1,37(1,02 ; 1,83)$ quando comparado ao menor consumo. Em relação ao consumo de fibras de cereais, o RR do quintil superior de consumo foi de $0,7(0,51 ; 0,96)$ quando comparado ao menor consumo, mantendo-se significante mesmo após ajuste por magnésio da dieta. Uma dieta habitual com elevado IG (mediana de 188 unidades/dia no tercil superior de consumo) e reduzidos teores de fibras provenientes de cereais (mediana de $3,2 \mathrm{~g} / \mathrm{dia}$ no tercil inferior) resultou em RR de $2,17(1,04 ; 4,54)$ de desenvolver diabetes. Neste estudo, não foi observada nenhuma relação entre o consumo de carboidratos totais e CG da dieta e risco de diabetes. ${ }^{90}$ Importante ressaltar que a relação entre IG e incidência de diabetes apenas se tornou estatisticamente significante após a inclusão de fibras provenientes de cereais nos modelos múltiplos.

Os dados do Health Professionals Follow-Up Study foram explorados em relação ao consumo de cereais integrais e refinados e o risco para diabetes após 12 anos de seguimento. O consumo mediano de cereais integrais foi de 1,1 porções/dia e cereais refinados de 1,7 porções diárias. Em modelos de regressão logística ajustados por idade, prática de atividades físicas, tabagismo, história familiar de diabetes, consumo de álcool, valor calórico total e consumo de frutas e vegetais da dieta habitual, observou-se um RR (IC 95\%) de 0,58 (0,47-0,70) para o quintil superior do consumo de cereais integrais quando comparado ao quintil inferior de consumo. Nenhuma relação estatisticamente significante foi observada para o consumo de cereais refinados em relação ao risco para diabetes. ${ }^{73}$ Nestas análises, após o ajuste para o consumo de magnésio, fibra de cereais e CG da dieta, o efeito protetor do consumo de cereais integrais em relação ao diabetes não se manteve significante, sugerindo que a associação observada pode ser atribuída ao consumo destes últimos componentes 
dietéticos. Além disso, o consumo de cereais integrais e refinados não foi ajustado pelas calorias totais.

Um outro estudo prospectivo americano, lowa Women's Health Study, avaliou a relação entre o consumo de carboidratos, fibra total, magnésio, alimentos fonte de carboidratos, IG e incidência de diabetes em 35.988 mulheres após 6 anos de seguimento. Os valores medianos de consumo de IG e CG da dieta habitual foram de 69 e 120 unidades/dia, respectivamente. Neste estudo, não houve associação entre o consumo de carboidratos totais, grãos refinados, frutas, vegetais, fibra solúvel e IG e incidência de diabetes. O RR (IC 95\%) do quintil superior de consumo de cereais integrais foi de $0,79(0,65 ; 0,96)$ e de fibra total de $0,78(0,64 ; 0,96)$ quando comparado ao quintil inferior de consumo. Em relação ao magnésio, o RR (IC 95\%) de incidência de diabetes no quintil superior de consumo foi de $0,67(0,55 ; 0,82)$ quando comparado ao menor consumo após o ajuste por possíveis fatores de confusão não dietéticos. ${ }^{91}$

A associação entre o consumo de fibra dietética, IG da dieta habitual e incidência do diabetes também foi investigada em 12.251 adultos afroamericanos e adultos caucasianos. O Atherosclerosis Risk in Communities (ARIC) Study, ${ }^{92}$ estudo prospectivo com 9 anos de seguimento, não encontrou associação entre o consumo de fibra total, fibra de frutas, fibra de leguminosas, IG ou CG e incidência de diabetes, após ajuste por idade, IMC, sexo, centro de tratamento do estudo, escolaridade, tabagismo, atividade física e consumo de fibra de cereais. A razão de Hazard do quintil superior de consumo de fibra de cereais foi de 0,75 $(0,60-0,92)$ em caucasianos, mas não significante em afro-americanos $[0,86(0,65-1,15)]$ quando comparado ao quintil inferior de consumo.

O efeito do consumo habitual de cereais integrais e fibras dietéticas sobre a incidência de diabetes também foi avaliado em estudo prospectivo conduzido em 2.286 homens e 2.030 mulheres de 40-69 anos na Finlândia. 
Após 10 anos de seguimento, observou-se um RR (IC 95\%) do consumo de fibra de cereais de $0,39(0,20-0,77)$ em relação ao quintil inferior de consumo. Entretanto não houve associação entre consumo do grupo de cereais integrais com diabetes [RR 0,65 $(0,36-1,18)]$, após ajuste por fatores de confusão não dietéticos, calorias totais, consumo de vegetais, frutas em geral e frutas vermelhas da dieta habitual. ${ }^{93}$ Entretanto, os modelos não incluíram o magnésio da dieta.

Estudos transversais investigaram a associação entre o consumo da quantidade e qualidade de carboidratos da dieta e sua associação com a resistência à insulina. Em análise transversal do estudo de Framingham sobre a relação entre o consumo de fibras, cereais e IG e prevalência de síndrome metabólica demonstrou-se uma relação protetora do quintil superior de consumo de cereais integrais [RR 0,67 (0,48-0,91)], fibra de cereais [RR 0,62 $(0,45-0,86)]$ e risco do quintil superior de consumo de IG da dieta [RR 1,41 (1,04-1,91)] para HOMA R quando comparado ao quintil inferior de consumo, após ajuste por potenciais fatores de confusão não dietéticos, calorias totais, porcentagem de gordura saturada e polinsaturada. Não houve associação entre o consumo de carboidratos e fibras totais, fibras provenientes de frutas, vegetais ou leguminosas, CG ou cereais refinados e prevalência de síndrome metabólica. ${ }^{70}$ Entretanto, o consumo do grupo de cereais integrais e refinados não foi ajustado pelas calorias totais. Além disto, após inclusão do consumo de magnésio e fibra total da dieta nos modelos de regressão logística múltiplos, a relação entre cereais integrais e indicador de resistência à insulina (HOMA R) não se manteve significante, sugerindo que o efeito observado pode ser atribuído aos altos teores de fibras e magnésio encontrados na casca dos grãos não refinados.

A relação entre o consumo de cereais integrais e sensibilidade à insulina entre indivíduos normoglicêmicos $(N)$ ou portadores de TGD também foi investigada em modelos de regressão linear em estudo transversal prévio, demonstrando uma possível relação inversa entre o 
consumo deste grupo de alimentos e a insulina após ajuste para fatores de confusão não dietéticos e calorias totais. ${ }^{94}$

\subsection{Diabetes e doenças associadas em migrantes japoneses}

Estudos epidemiológicos com populações migrantes têm sido desenvolvidos com o intuito de avaliar o papel de fatores ambientais na ocorrência de doenças crônicas. Diversas evidências científicas foram embasadas em pesquisas que compararam populações que se deslocaram para regiões com estilos de vida e freqüência de morbidades diferentes do local de origem. ${ }^{7,95,96}$ As marcantes mudanças do comportamento do estilo de vida em imigrantes, especialmente relacionados ao padrão de consumo alimentar, despertam grande interesse científico na investigação de doenças cuja etiologia é reconhecidamente relacionada a fatores genéticos e ambientais. $^{7}$

O impacto deletério dos fatores ambientais na gênese das doenças crônicas entre estes indivíduos geneticamente susceptíveis foi apontado por estudos epidemiológicos prévios. Em 1974, Kagan e colaboradores ${ }^{95}$ demonstraram que os japoneses residentes no Havaí e Califórnia apresentavam maiores médias de colesterol total e ácido úrico em relação aos japoneses residentes no Japão. Apesar do VCT semelhante da dieta, os migrantes residentes nos Estados Unidos relataram um maior aporte de gordura total e gorduras saturadas da dieta, maior consumo de carboidratos simples e menor consumo de arroz do que o observado entre os residentes no Japão. Um outro estudo conduzido com nipo-americanos, residentes em Seattle, observou uma prevalência de diabetes 4 vezes superior à observada em japoneses residentes em Tóquio, demonstrando o efeito negativo da migração e a adoção do estilo de vida americano no desenvolvimento de doenças crônicas. ${ }^{97}$ 
No Brasil, que conta com a maior população de origem japonesa residente fora do Japão concentrados essencialmente no Estado de São Paulo $^{98}$, vários estudos observaram também que os nipo-brasileiros possuem maior risco de mortalidade por diabetes e DCV quando comparados ao japoneses residentes no Japão, sugerindo que a adoção do estilo de vida brasileiro exerceria um impacto desfavorável sobre a prevalência destas doenças. ${ }^{99,100,101}$

Na década de 1980, pesquisadores do Grupo de Estudos de Diabetes em Nipo-Brasileiros do Departamento de Medicina Preventiva da Universidade Federal de São Paulo (UNIFESP) e de outras instituições iniciaram a trajetória dos estudos em nipo-brasileiros com o objetivo de avaliar a prevalência do diabetes e fatores associados nesta população. ${ }^{7}$ No ano de 1987, o Centro de Estudos de Nipo-Brasileiros planejava o desenvolvimento de um censo para estimar a dimensão da população de origem japonesa no país, quando um inquérito sobre diabetes auto-referido foi realizado observando-se prevalências ajustadas por idade de 5,3 e 5,8\% em indivíduos de primeira e segunda gerações, respectivamente, sendo semelhante ao verificado em nipo-americanos. ${ }^{102} \mathrm{Em}$ 1992, o censo populacional foi concluído disponibilizando dados sobre as estimativas da população total, distribuição entre gerações e faixa etária dos nipobrasileiros. No ano de 1993, o primeiro estudo transversal: "Diabetes mellitus e doenças associadas na comunidade Nipo-Brasileira de Bauru" foi desenvolvido no município de Bauru, SP. ${ }^{7,103}$ Nesta etapa, que contou com a participação de 647 indivíduos com idade entre 40 e 79 anos, uma elevada prevalência de diabetes $(22,6 \%)$ foi verificada. ${ }^{7}$

No ano de 2000, um segundo inquérito transversal foi concluído na população nipo-brasileira de Bauru. Nesta segunda etapa, todos os indivíduos acima de 30 anos, primeira e segunda gerações não miscigenados, identificados no censo realizado em $1997(n=1.751)$ foram convidados a participar do estudo e 1.283 indivíduos completaram todas as 
informações do inquérito nutricional e exame clínico/antropométrico. Observou-se que a prevalência do diabetes, TGD e GJA aumentou vertiginosamente nos últimos anos, sugerindo o impacto de condições ambientais e provável susceptibilidade genética sobre os riscos de desenvolver alterações no metabolismo da glicose. ${ }^{8}$

Dados obtidos no estudo transversal de 2000 apontam um maior impacto do diabetes entre indivíduos acima de 60 anos. Entretanto, mais de $50 \%$ dos indivíduos com idade inferior a 40 anos apresentaram AHG. A prevalência dessas alterações (GJA: 19,3\%, TGD: 23,4\% e diabetes: 36,2\%) nesta comunidade é de cerca de $78 \%$, sendo considerada uma das maiores do mundo. ${ }^{8}$

No Japão, os hábitos alimentares no início do século passado consistiam de uma dieta rica em arroz, em algumas regiões misturado com cevada e centeio, acompanhados por verduras cozidas, conserva de nabo e vegetais folhosos e sopa de missô. Em algumas regiões, o arroz era substituído por tubérculos servidos com soja e seus derivados. Consumo de pescados e frutos do mar era habitual nas regiões litorâneas. Após intervenções governamentais para melhoria da qualidade da dieta e no período pós-guerra, os hábitos alimentares japoneses vêm se alterando substancialmente com incremento importante na participação dos lipídios como fonte energética total. Entretanto, embora a alteração dos hábitos alimentares seja um fator comum entre os japoneses residentes no Japão, nas populações migrantes este processo é mais acelerado e de forma mais intensa. ${ }^{7}$

A análise do consumo alimentar da comunidade Nipo-Brasileira sugere um consumo alimentar habitual de maior densidade energética, caracterizada por um alto teor de gordura, quando comparado com o consumo habitual de japoneses residentes no Japão. Mudanças nos hábitos alimentares tradicionais japoneses associadas à adoção de estilo de vida 
sedentário têm sido sugeridas como responsáveis principais pela alta prevalência de sobrepeso, obesidade central e alterações metabólicas observadas nesta comunidade. ${ }^{104}$ Após sete anos de seguimento, observouse uma redução do consumo de carnes vermelhas e aves e um aumento do consumo de laticínios, frutas e sucos de frutas. Nestes indivíduos, observouse que a mudança no consumo de fibra total da dieta estava inversamente relacionada à alteração de colesterol total durante o período investigado, reforçando a hipótese de um elevado consumo de fibras na prevenção de dislipidemia entre nipo-brasileiros. ${ }^{7,105}$

Estudos que investigaram a associação entre o consumo alimentar e a prevalência de AHG entre os nipo-brasileiros que participaram do inquérito de 2000 são inexistentes. O propósito do presente estudo foi avaliar a associação entre fatores dietéticos, com especial enfoque para a qualidade dos carboidratos da dieta habitual, e a AHG. 


\section{OBJETIVOS}

\subsection{Objetivo geral}

- Avaliar a associação entre fatores dietéticos e homeostase glicêmica em Nipo-Brasileiros de Bauru.

\subsection{Objetivos específicos}

- Estimar o índice glicêmico e carga glicêmica da dieta habitual.

- Investigar a associação entre o consumo de nutrientes, fibras, índice glicêmico, carga glicêmica e grupos de alimentos da dieta habitual e glicemia de jejum, insulinemia de jejum e indicador de resistência à insulina (HOMA R).

- Investigar a associação entre o consumo de nutrientes, fibras, índice glicêmico, carga glicêmica e grupos de alimentos da dieta habitual e alterações na homeostase glicêmica (glicemia de jejum alterada, tolerância à glicose diminuída e diabetes). 


\section{3. ÍNDIVIDOS E MÉTODOS}

\subsection{Delineamento e população de estudo}

O estudo de Diabetes na comunidade Nipo-Brasileira de Bauru é um estudo de base populacional conduzido desde a década de 1980 para estimar a prevalência do diabetes e doenças associadas.

No censo populacional realizado no ano de 1992, 1.518 nipobrasileiros foram identificados em Bauru, sendo que 1.060 indivíduos não miscigenados (293 isseis e 764 niseis) estavam na faixa etária entre 40 e 79 anos de idade. No primeiro inquérito de saúde conduzido em 1993 pelo Grupo de Estudos de Diabetes em Nipo-Brasileiros foram convidados a participar do estudo 706 nipo-brasileiros com idade superior a 40 anos, dos quais 293 eram isseis (todos os indivíduos de primeira geração) e 308 eram niseis (amostra aleatória de 1/3 dos indivíduos de segunda geração com acréscimo de $20 \%$ para possíveis perdas). No total, 647 indivíduos participaram do inquérito transversal realizado em 1993.

Em 1997 um novo censo populacional foi realizado entre migrantes japoneses residentes em Bauru, identificando-se 1.751 nipo-brasileiros não miscigenados de primeira e segunda gerações com idade superior a 30 anos. Todos esses nipo-brasileiros foram convidados a participar do segundo inquérito transversal concluído no ano de 2000. Nesta fase, 936 novos indivíduos e 394 previamente avaliados em 1993 concordaram em participar, totalizando 1.330 participantes de ambos os sexos. Destes, 276 $(20,7 \%)$ foram excluídos, dos quais $47(3,5 \%)$ não completaram todas as informações da avaliação nutricional, $148(11,1 \%)$ relataram diagnóstico prévio de DM, $72(5,4 \%)$ apresentaram AHG no inquérito de 1993 e 9 indivíduos $(0,7 \%)$ não completaram o exame de glicemia após sobrecarga de glicose (TTG). No total, 1.054 participantes $(60,2 \%$ do censo de 1997$)$ foram analisados no presente estudo, conforme demonstrado na Figura 2. 
Figura 2 - Seleção da população amostral do estudo.

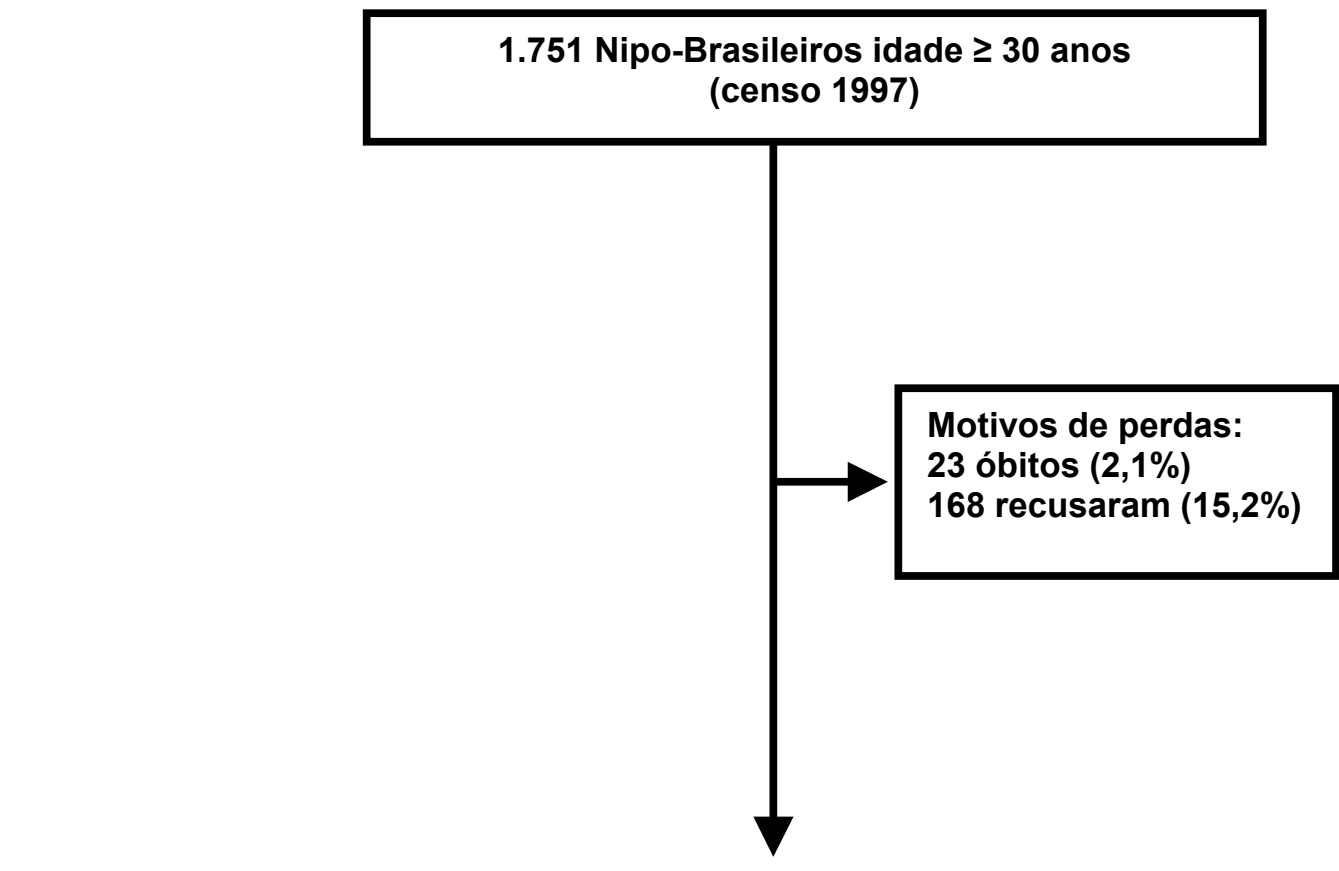

1.330 participantes em 2000

(75,9\% do censo 1997$)$

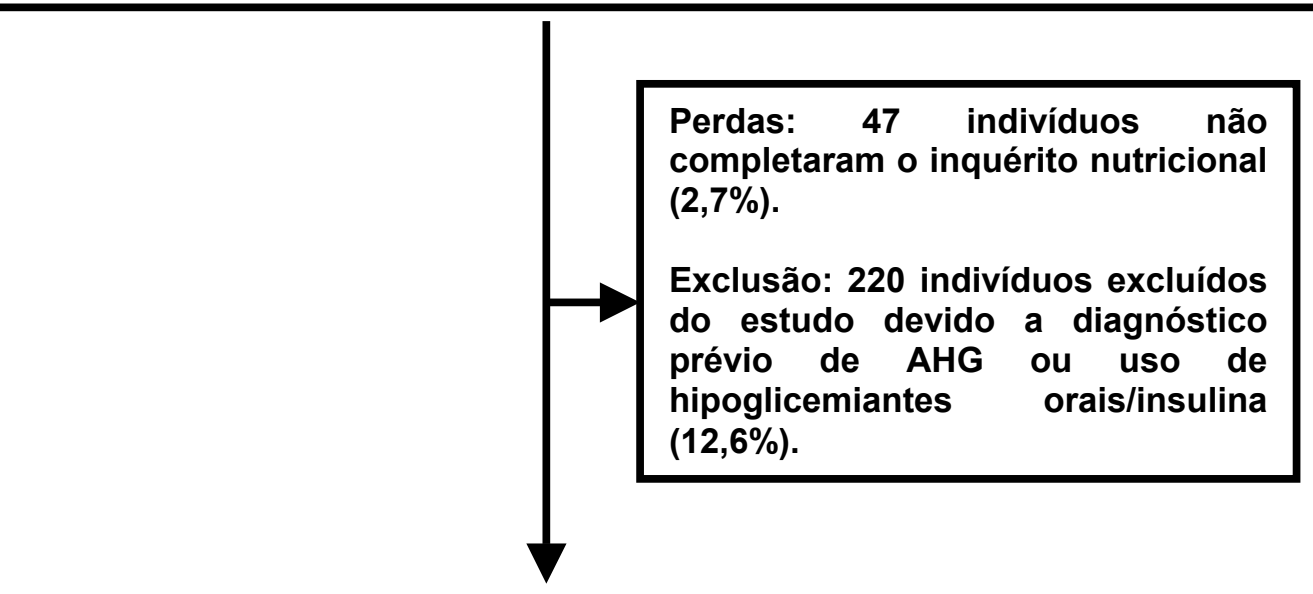

1.054 participantes considerados na análise

$(60,2 \%$ do censo 1997$)$

O projeto de pesquisa foi analisado e aprovado pelo Comitê de Ética em Pesquisa da Escola Paulista de Medicina da Universidade Federal de São Paulo (UNIFESP). Todos os participantes foram esclarecidos sobre os objetivos da pesquisa e assinaram o termo de consentimento (Anexo 1). 


\subsection{Variáveis sócio-demográficas e de estilo de vida}

Dados pessoais (idade, sexo, profissão, escolaridade, prática habitual de atividades físicas de lazer (sim ou não), tabagismo (atual, nunca fumou ou ex-fumantes), uso de medicamentos e consumo de bebidas alcoólicas) foram obtidos através de um questionário estruturado (Anexo 2) em entrevista domiciliar. Os medicamentos considerados no presente estudo foram os hipoglicemiantes, antihipertensivos e antilipidêmicos.

\subsection{Avaliação do consumo alimentar}

A avaliação da dieta habitual individual empregou um questionário quantitativo de freqüência alimentar (QQFA) desenvolvido e validado para a população Nipo-Brasileira ${ }^{106,107}$ (Anexo 3).

O QQFA contém 122 itens alimentares e questões sobre práticas e preferências alimentares usuais, ingestão habitual de gordura visível de carnes, tipo e quantidade usual de adoçante em bebidas, tempero de saladas, outros alimentos não listados de consumo habitual e uso de suplementos dietéticos. Para cada item alimentar do QQFA, os participantes informaram a freqüência média de consumo habitual relativo ao último ano, a respectiva unidade de tempo (se diariamente, semanalmente, mensalmente ou anualmente) e qual o tamanho de sua porção individual usual (se pequena, média, grande ou extra grande em relação à porção média de referência).

A análise nutricional das dietas foi realizada através do programa de computador Dietsys 4.0 com dupla digitação e análise de consistência dos dados de consumo alimentar. A análise da composição química dos alimentos foi realizada com base nas tabelas oficiais do Brasil, Japão e EUA, conforme descrito em trabalho prévio. ${ }^{106}$ Foram calculadas tanto a 
quantidade média diária de consumo de alimentos, como também a média de consumo de nutrientes da dieta habitual.

O IG dos alimentos do QQFA foi calculado com base na tabela internacional de IG. ${ }^{65}$ Para alguns alimentos/preparação nacionais sem alimento equivalente na tabela foi utilizado o valor do IG de outro alimento com composição química semelhante, segundo valor calórico total (VCT), teor de carboidratos, fibras e lipídeos. O cálculo da CG foi realizado através da multiplicação da quantidade de carboidratos contida em cada porção de alimento pelo seu IG, multiplicando-se a freqüência de consumo. Os valores de carboidratos, IG e CG atribuídos aos alimentos do QQFA encontram-se no Anexo 4.

Os teores de ácidos graxos trans dos alimentos do QQFA foram obtidos em tabelas nacionais para batata frita, biscoito e sorvete ${ }^{108}$ ou em tabela internacional. ${ }^{109}$ Para alguns alimentos e preparações nacionais não identificados alimentos equivalentes nas tabelas publicadas utilizou-se o teor de ácidos graxos trans de alimento de composição química e processamento semelhantes.

Para a presente análise, os alimentos consumidos foram agrupados segundo sua composição química e plausibilidade biológica de associação com os desfechos de interesse em:

- Cereais/pães/massas: arroz polido, japonês ou integral, milho, trigo, farelo, aveia, granola, pães em geral, massas em geral, sanduíches, biscoitos e pipoca.

- Carnes vermelhas/aves/embutidos: carne bovina, suína, embutidos, miúdos e aves. 
- Pescados/frutos do mar: peixes em geral, sashimi (peixe cru), chikuwa (embutido à base de peixe), camarão.

- Leguminosas: feijão carioca, branco e preto, ervilha, lentilha e soja.

- Frutas: todas as frutas (incluindo-se as cítricas) e sucos de frutas naturais.

- Frutas cítricas: somente laranja, tangerina e ponkan.

- Vegetais: todas as verduras e legumes, exceto batata, mandioca e inhame.

- Laticínios integrais: leite integral, queijos amarelos, iogurte integral, manteiga e queijos cremosos.

- Laticínios pobres em gordura: leite desnatado, queijo fresco e ricota.

- Miso-shiru: sopa à base de missô (pasta de soja fermentada).

- Óleos e frituras: batata frita, óleo para tempero de salada ou preparo dos alimentos.

- Doces: açúcar, sorvetes, bolos, tortas doces, doces de fruta, refrigerantes, balas, chocolates, geléia, mel e preparações com adição de açúcar.

\subsection{Avaliação clínica e antropométrica}

A pressão arterial (PA) foi aferida através de esfigmomanômetro automático (Omron, modelo HEM-712C, Omron Health Care, Inc, USA), considerando-se o valor médio de três medidas seguidas pela manhã, com o 
participante sentado após 5 minutos de descanso, com intervalo mínimo de 15 minutos entre as aferições. A HA foi definida quando o indivíduo apresentava PA sistólica ou diastólica $\geq 140 / 90 \mathrm{mmHg}$, conforme critérios da $\mathrm{OMS}^{110}$ ou pelo uso de medicamentos antihipertensivos.

Medidas de peso (em $\mathrm{kg}$ ) e altura (em $\mathrm{m}$ ) foram obtidas com os indivíduos sem sapatos e vestindo roupas leves em balança digital (capacidade $150 \mathrm{Kg}$, precisão $100 \mathrm{~g}$ ) e em estadiômetro portátil, respectivamente. O IMC foi obtido dividindo-se o peso pela estatura ao quadrado. O excesso de peso foi definido através dos pontos de corte sugeridos pela $\mathrm{OMS}^{111}$ para a população asiática, em ambos os sexos, IMC $\geq 23,0 \mathrm{~kg} / \mathrm{m}^{2}$.

A circunferência de cintura foi obtida com uso de fita métrica inextensível, utilizando-se como ponto de referência o plano horizontal na altura da cicatriz umbilical, com o paciente em pé, abdome relaxado, os braços ao longo do corpo e pés unidos, sem comprimir a pele. A classificação da obesidade abdominal utilizou ponto de corte de circunferência de cintura sugerida pela OMS para a população asiática: circunferência de cintura $\geq 80 \mathrm{~cm}$ para mulheres e $\geq 90 \mathrm{~cm}$ para homens. ${ }^{111}$

\subsection{Avaliação bioquímica}

Amostras sangüíneas em jejum entre 8 e 12 horas foram obtidas em ambiente climatizado $\left(22-24^{\circ} \mathrm{C}\right)$ para dosagem de glicose, insulina, triglicérides, colesterol total e frações. Os participantes foram submetidos ao teste padronizado de tolerância à glicose (TTG) após a administração de fórmula industrializada de $75 \mathrm{~g}$ de glicose anidra (GLUTOL ${ }^{\circledR}$ ) e uma nova coleta de sangue após 2 horas foi realizada para dosagem de glicose e insulina. O material foi centrifugado e a determinação da glicose plasmática, através do método da glicose-oxidase, ${ }^{112}$ foi realizada em intervalo de tempo inferior a 2 horas após sua coleta. Para cada série de dosagem de glicose 
foram obtidas 3 amostras controles, cuja variação dos valores foi inferior a $5 \%$. Embora recomendações recentes da ADA sugiram a redução do ponte de corte de glicemia de jejum $\geq 100 \mathrm{mg} / \mathrm{dl}$ para diagnóstico de GJA, ${ }^{113}$ na presente análise adotamos a classificação da homeostase glicêmica reconhecidos pela OMS ${ }^{114}$ : N (glicemia de jejum $<110 \mathrm{mg} / \mathrm{dl}$ e glicemia póscarga de glicose < $140 \mathrm{mg} / \mathrm{dl}$; GJA (glicemia de jejum entre $110 \mathrm{mg} / \mathrm{dl}$ e 126 $\mathrm{mg} / \mathrm{dl}$ com glicemia pós-carga de glicose $<140 \mathrm{mg} / \mathrm{dl}$ ), TGD (glicemia de jejum $<126 \mathrm{mg} / \mathrm{dl}$ e após sobrecarga entre $140 \mathrm{mg} / \mathrm{dl}$ e $200 \mathrm{mg} / \mathrm{dl}$ ) e DM (glicemia de jejum $\geq 126 \mathrm{mg} / \mathrm{dl}$ e/ou pós-carga com glicose $\geq 200 \mathrm{mg} / \mathrm{dl}$ ).

Após a centrifugação do sangue, as amostras de soro destinadas à determinação dos lipídios séricos (triglicérides, colesterol total e frações) foram congeladas e estocadas a $-20^{\circ} \mathrm{C}$ até sua dosagem, realizada por procedimentos enzimáticos em analisador automático (Cobas-Mira plus ${ }^{\circledR}$, Roche), no Laboratório de Endocrinologia da UNIFESP. Para o controle de qualidade das determinações dos lipídios séricos, cerca de $30 \%$ das amostras foram analisadas em laboratório de referência em São Paulo (Fleury), cuja variação média do colesterol total e HDL-c foi inferior a $5 \%$ e do triglicérides entre 5 e $8 \%$. A análise de insulina foi realizada pelo método imunofluorimétrico baseado em anticorpo monoclonal (Auto Delfia, Perkin Elmer Life Science Inc, Norton, USA). ${ }^{115}$

A classificação da dislipidemia foi definida quando o indivíduo apresentava colesterol total $\geq 200 \mathrm{mg} / \mathrm{dl}$, LDL-c $\geq 130 \mathrm{mg} / \mathrm{dl}$, triglicérides $\geq$ $150 \mathrm{mg} / \mathrm{dl}$ ou HDL-colesterol (HDL-c) $\leq 40 \mathrm{mg} / \mathrm{dl}$, conforme os critérios do National Cholesterol Eduacation Program ${ }^{116}$ ou em uso de medicamentos antilipêmicos.

A estimativa do HOMA R foi calculada através da fórmula proposta por Matthews e colaboradores: ${ }^{117}$

HOMA R = glicemia de jejum (mmol/L) $x$ insulina de jejum $(\mathrm{mU} / \mathrm{L}) / 22,5$ 
INDIVÍDUOS E MÉTODOS

Esses modelo assume que indivíduos normais apresentem resistência à insulina igual a 1.

\subsection{Análise estatística dos dados}

Distribuições de freqüências relativas e absolutas, mediana, média e desvio-padrão (DP) das variáveis estudadas foram calculadas. Para a comparação de variáveis de interesse segundo categorias de homeostase glicêmica, empregou-se o teste de $X^{2}$, ANOVA ou Kruskal-Wallis.

As variáveis bioquímicas e de consumo alimentar que não apresentaram distribuição normal (avaliada através da simetria e curtose da distribuição dos dados) sofreram transformação logarítmica antes das análises estatísticas. $O$ ajuste de consumo alimentar pelas calorias totais foi realizado pelo método residual, considerando-se as calorias da dieta como variável independente e os nutrientes ou alimentos como variáveis dependentes em modelos de regressão linear simples. Os valores dos resíduos não padronizados gerados pelos modelos de regressão foram somados ao consumo esperado do nutriente ou alimento para a média da ingestão calórica da população estudada, obtendo-se os valores de nutrientes ou grupos de alimentos ajustados pelas calorias totais. ${ }^{118}$

Coeficientes de correlação de Pearson foram calculados entre variáveis dietéticas (nutrientes e consumo de alimentos) e os desfechos de interesse (glicemia e insulina de jejum e HOMA R) para os dados brutos e ajustados pelas calorias totais. Para seleção inicial das variáveis dietéticas a serem consideradas nos modelos de regressão linear considerou-se um valor de $p<0,2$, sendo também investigados outros fatores dietéticos de interesse. A associação entre IG, CG da dieta, nutrientes e grupos de alimentos (como variáveis independentes) e glicemia e insulina de jejum e HOMA R (variáveis dependentes) foi avaliada em modelos de regressão linear múltiplos, após ajuste pelos seguintes fatores de confusão ou 
modificadores de efeito: sexo (feminino/masculino), idade (anos), geração ( $1^{\mathrm{a}} / 2^{\mathrm{a}}$ geração), presença de dislipidemia e/ou HA ou uso de medicamentos antilipêmicos ou antihipertensivos (sim/não), prática habitual de atividades físicas de lazer (sim/não), escolaridade (não freqüentou a escola, até $1^{\circ}$ grau, $\geq 2^{\circ} \mathrm{grau}$ ), tabagismo (sim/não), consumo habitual de álcool ( $\operatorname{sim} /$ não), circunferência de cintura (cm), consumo de fibras (g/dia) e VCT (kcal/dia). Os modelos de investigação de fatores associados à glicemia de jejum ou insulinemia de jejum e HOMA $R$ incluíram também como variáveis de controle o colesterol (mg/dia) e gordura total da dieta (g/dia), respectivamente.

A associação entre IG, CG, nutrientes e grupos de alimentos selecionados ajustados pelas calorias totais (em tercis de consumo) e AHG (GJA, TGD, DM) foi avaliada através de modelos de regressão logística nãocondicional, após ajuste de potenciais fatores de confusão ou modificadores de efeito. As covariáveis incluídas foram: sexo (feminino/masculino), idade (em anos), geração ( $1^{a}$ ou $2^{a}$ geração), presença de dislipidemia e/ou HA ou uso de medicamentos antilipêmicos ou antihipertensivos (sim/não), prática de atividades físicas de lazer (sim/não), escolaridade (não freqüentou a escola, até $1^{\circ} \mathrm{grau}, \geq 2^{\circ} \mathrm{grau}$ ), tabagismo ( $\operatorname{sim} /$ não), obesidade abdominal ( $\operatorname{sim} /$ não), consumo de fibras totais (g/dia - tercis de consumo), colesterol dietético (mg/dia - tercis de consumo) e consumo calórico total (kcal/dia em tercis de consumo). A adequação do ajuste dos modelos foi avaliada pelo teste de Hosmer-Lemeshow.

Todas as análises estatísticas foram conduzidas no programa de computador SPSS versão 10. Adotou-se como significante o valor de $p<0,05$. 


\section{RESULTADOS}

\subsection{Características gerais da população de estudo}

$\mathrm{Na}$ presente análise, os 1.054 nipo-brasileiros $(54,9 \%$ do sexo feminino), com média (DP) de idade 56 (12) anos eram predominantemente de segunda geração $(82,7 \%)$.

A Tabela 1 descreve as características gerais dos participantes do estudo segundo categorias de homeostase glicêmica. Houve diferenças estatisticamente significantes entre os grupos de AHG para proporção de indivíduos de primeira e segunda gerações, escolaridade, relato de trabalho remunerado e prática de tabagismo e nas médias de idade, com uma tendência de indivíduos normoglicêmicos serem mais jovens.

Tabela 1 - Características gerais da comunidade nipo-brasileira segundo categorias de homeostase glicêmica. Bauru, 2000.

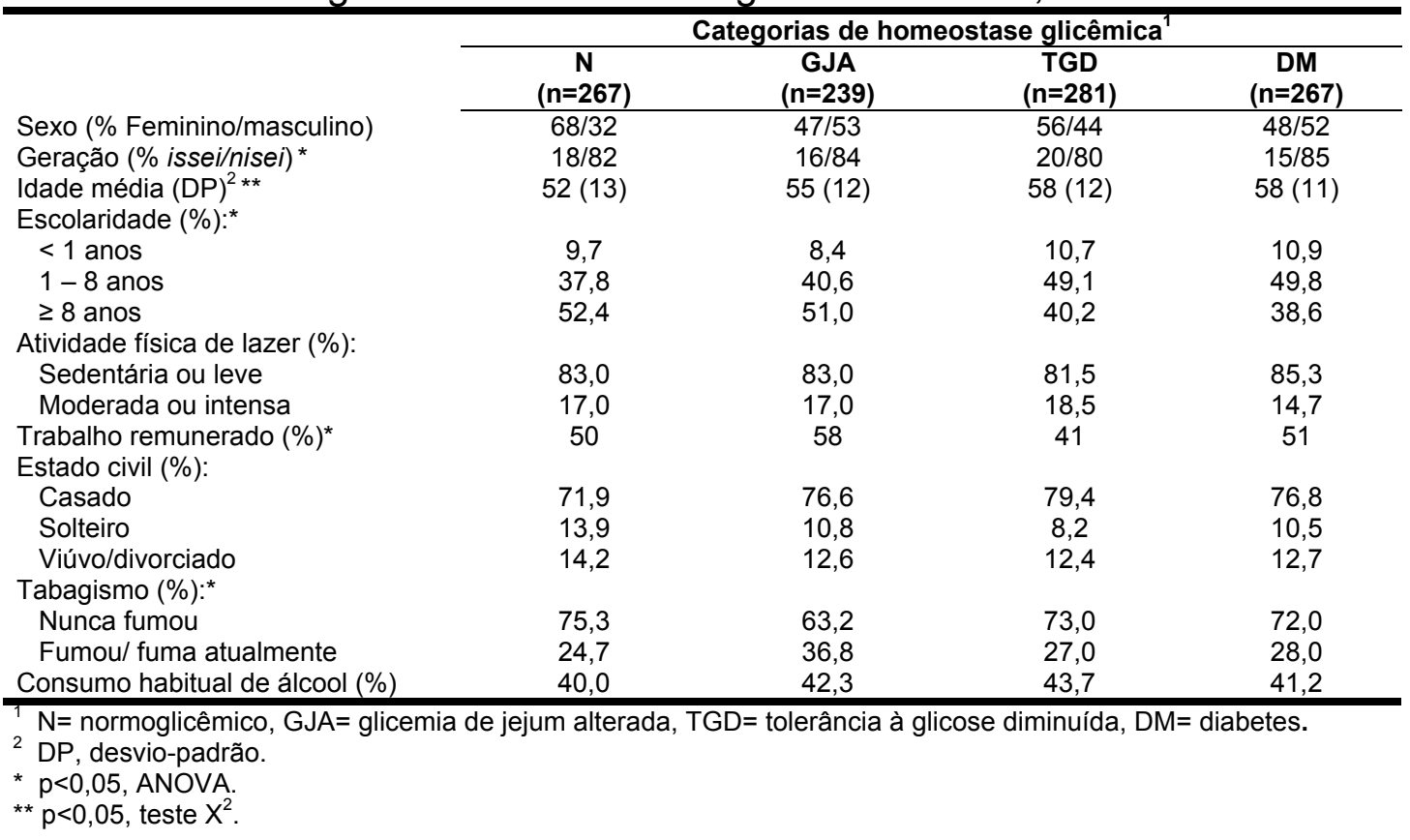

A Tabela 2 apresenta a freqüência de excesso de peso, obesidade abdominal, hipertensão arterial e dislipidemia entre nipo-brasileiros segundo categorias de homeostase glicêmica. Houve diferenças para a freqüência de 
excesso de peso, obesidade abdominal, hipertensão e dislipidemia entre as categorias de homeostase glicêmica, com uma tendência de menor ocorrência de morbidades entre os indivíduos com glicemia normal.

Tabela 2 - Freqüências de excesso de peso, obesidade abdominal, hipertensão arterial sistêmica e dislipidemia na comunidade nipo-brasileira segundo categorias de homeostase glicêmica. Bauru, 2000.

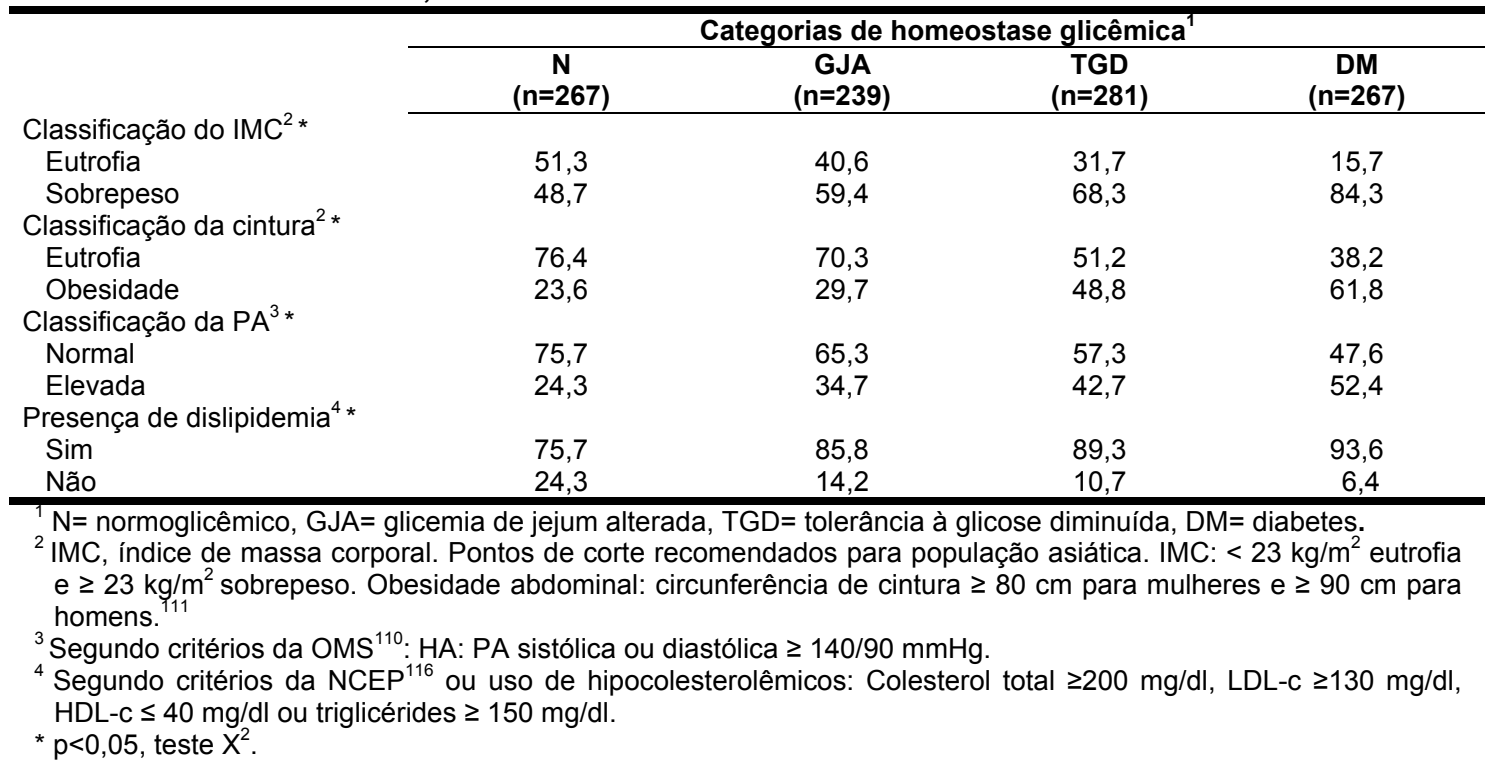

Nesta comunidade, dos 281 participantes com TGD, 189 indivíduos $(67,3 \%)$ eram também portadores de GJA. Embora os indivíduos com diagnóstico de TGD e GJA possam apresentar características metabólicas diferentes dos portadores de TGD isolada, em nosso estudo optamos pela análise de um único grupo de indivíduos portadores de TGD, dado o reduzido número de portadores de TGD isolada.

Valores médios (DP) de variáveis antropométricas, bioquímicas e níveis pressóricos segundo classificação de homeostase glicêmica na população adulta de nipo-brasileiros estão descritos na Tabela 3. Houve diferenças estatisticamente significantes entre os grupo de AHG para valores médios de peso corporal, IMC, circunferência de cintura, mediana de glicemia e insulinemia de jejum, HOMA R, PA sistólica e diastólica, colesterol total, LDL-c e triglicérides. 
Tabela 3 - Média e desvio-padrão (DP) de variáveis antropométricas e mediana de níveis pressóricos (PA) e variáveis bioquímicas segundo categorias de homeostase glicêmica. População adulta de nipo-brasileiros. Bauru, $2000(n=1.054)$.

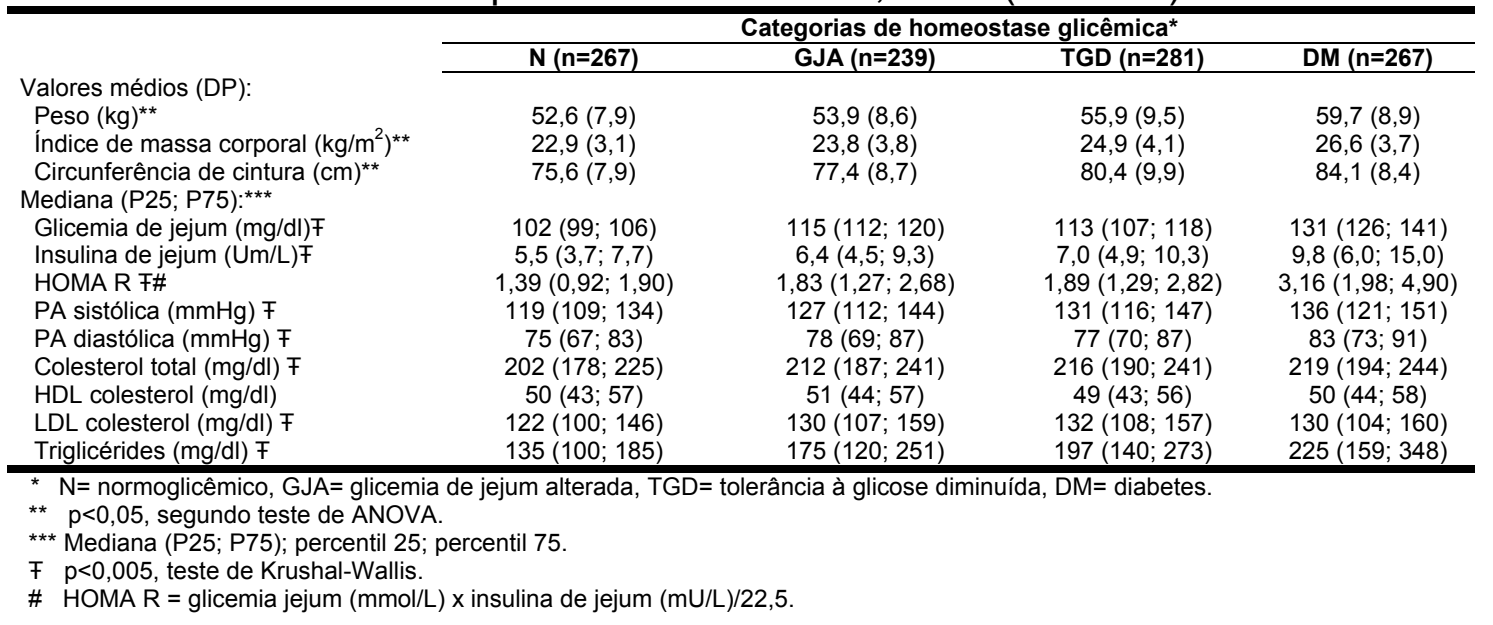

Nas Tabela 4 e 5 são apresentados os valores médios (DP) de variáveis antropométricas, bioquímicas e níveis pressóricos segundo classificação de homeostase glicêmica na população adulta feminina e masculina, respectivamente. Em mulheres observaram-se diferenças estatisticamente significantes para valores médios de idade, peso corporal, IMC e circunferência de cintura entre as categorias de AHG. Entre os homens, houve diferenças entre idade, circunferência de cintura, mediana de glicemia e insulinemia de jejum, HOMA R, PA sistólica e diastólica, colesterol total, LDL-c e triglicérides. Em relação à proporção de indivíduos do sexo feminino com obesidade abdominal e sobrepeso, observamos diferenças estatisticamente significantes entre as categorias AHG: N: 28 e 42,9\%, GJA: 32,1 e 564,5\%, TGD: 50 e 63,9\%, DM: 69,3 e 85,0\%, respectivamente. Da mesma forma, diferentes freqüências de dislipidemia e HA foram verificadas em mulheres: N: 73,1 e $24,7 \%$, GJA: 82,1 e 34,8\%, TGD: 84,5 e 41,1\%, DM: 92,1 e $55,1 \%$, respectivamente. Entre os homens, diferentes freqüências de obesidade abdominal e sobrepeso segundo AHG:N: 14,1 e 61,2\%, GJA: 27,6 e $63,8 \%$, TGD: 47,2 e 74\%, DM: 55 e 84,2\%, respectivamente. Assim como, diferentes proporções de indivíduos do sexo masculino com diagnóstico de dislipidemia e HA segundo AHG também foram observadas: 
N: 81,2 e 23,5\%, GJA: 89 e 34,6\%, TGD: 94,3 e 44,7\%, DM: 95 e 50\%, respectivamente.

Tabela 4 - Média e desvio-padrão (DP) de idade, variáveis antropométricas e mediana de níveis pressóricos (PA) e variáveis bioquímicas segundo categorias de homeostase glicêmica. População adulta feminina de nipo-brasileiros. Bauru, $2000(n=579)$.

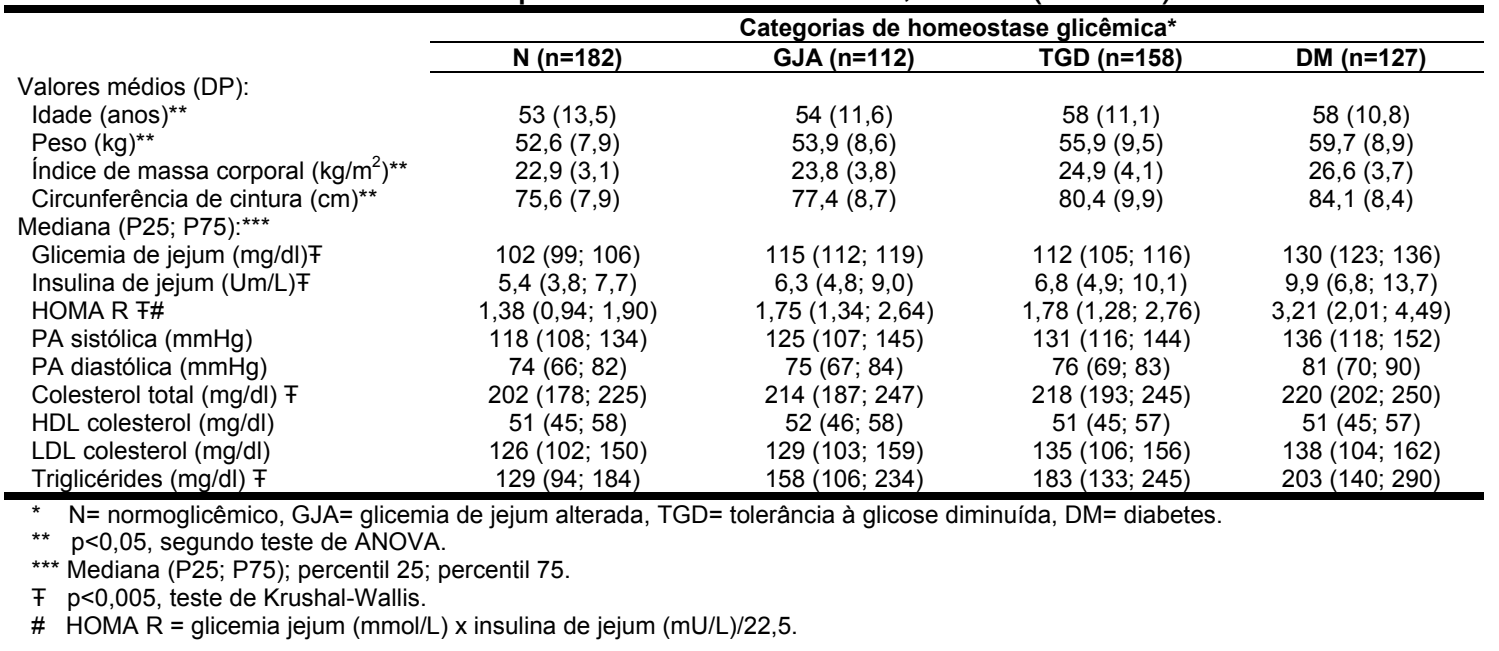

Tabela 5 - Média e desvio-padrão (DP) de idade, variáveis antropométricas e mediana de níveis pressóricos (PA) e variáveis bioquímicas segundo categorias de homeostase glicêmica. População adulta masculina de nipo-brasileiros. Bauru, $2000(n=475)$.

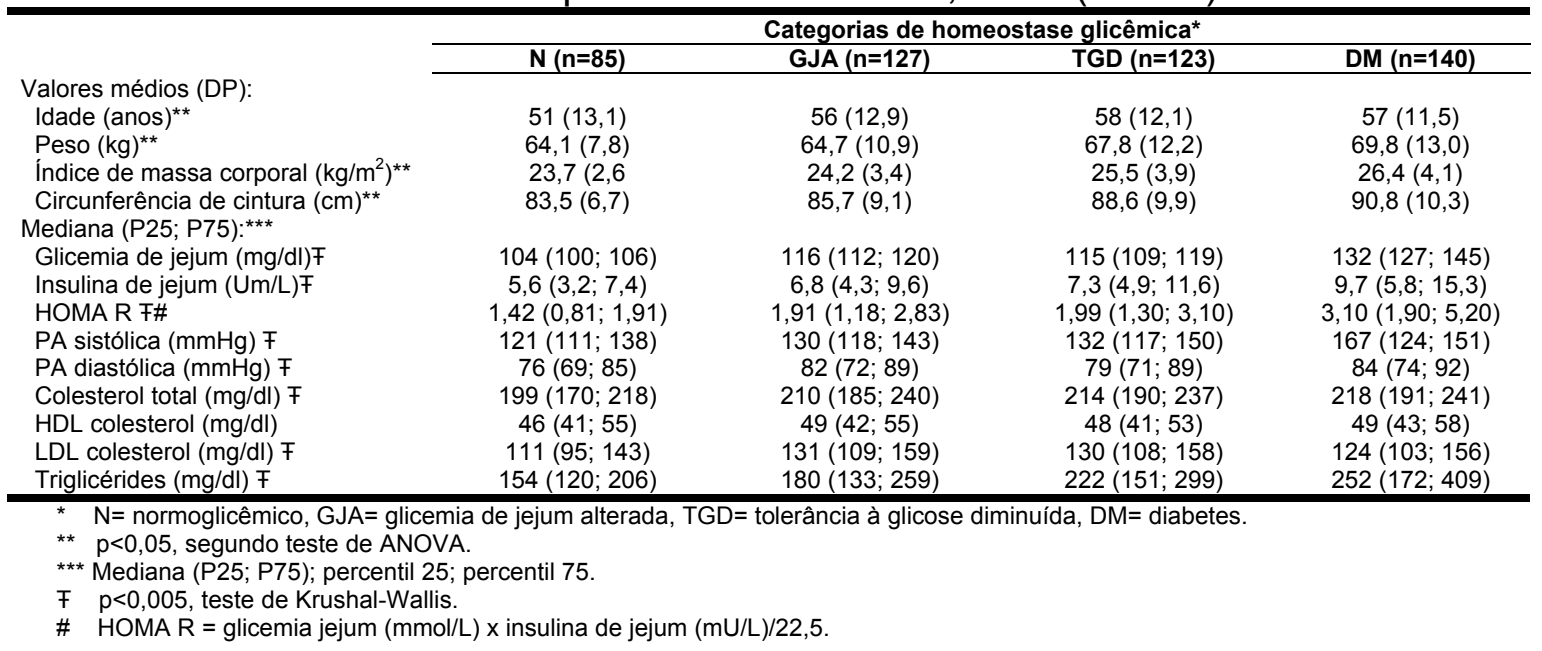




\subsection{Dieta habitual dos nipo-brasileiros de Bauru}

O consumo alimentar habitual dos nipo-brasileiros segundo categorias de homeostase glicêmica são apresentados nas Tabelas 6, 7 e 8 . Observaram-se diferenças estatisticamente significantes no consumo mediano de fibra total da dieta e vitaminas B6 e C segundo categorias de homeostase glicêmica (Tabela 6). No entanto, esta tendência não se manteve após estratificação por sexo (Tabelas 7 e 8).

Tabela 6 - Mediana do consumo diário e intervalo interquartil (P25, P75) de calorias totais (VCT) e frações, índice glicêmico, carga glicêmica, fibras e nutrientes da dieta habitual segundo classificação da homeostase glicêmica. População adulta de nipo-brasileiros. Bauru, 2000 ( $n=1.054)$.

\begin{tabular}{|c|c|c|c|c|}
\hline & \multicolumn{4}{|c|}{ Categorias de Homeostase glicêmica* } \\
\hline & $N(n=267)$ & GJA $(n=239)$ & $\operatorname{TGD}(n=281)$ & DM (n=267) \\
\hline Calorias totais - VCT (Kcal) & $1848,9(1546,3 ; 2252,4)$ & $1933,7(1592,7 ; 2248,7)$ & $1932,4(1597,2 ; 2394,5)$ & $1952,2(1622,2 ; 2310,3)$ \\
\hline Calorias de carboidratos (\% VCT) & $53,4(47,2 ; 58,0)$ & $53,5(49,0 ; 58,6)$ & $53,5(49,3 ; 58,7)$ & $53,7(48,1 ; 59,5)$ \\
\hline Calorias de proteínas (\% VCT) & $13,6(11,6 ; 15,3)$ & $13,4(11,9 ; 15,1)$ & $13,5(11,8 ; 15,1)$ & $13,7(11,9 ; 15,0)$ \\
\hline Calorias de lipídios (\% VCT) & $33,4(28,9 ; 37,9)$ & $32,3(28,4 ; 37,2)$ & $32,6(28,8 ; 37,0)$ & $31,9(27,4 ; 36,5)$ \\
\hline Proteínas (g) & $63,5(49,3 ; 77,7)$ & $65,6(51,2 ; 80,7)$ & $64,6(50,0 ; 81,9)$ & $65,2(52,5 ; 81,8)$ \\
\hline Carboidratos (g) & $243,7(198,3 ; 308,8)$ & $259,9(215,7 ; 311,8)$ & $252,4(208,2 ; 316,9)$ & $259,7(213,7 ; 323,6)$ \\
\hline Índice glicêmico & $86(82 ; 91)$ & $87(82 ; 91)$ & $86(82 ; 91)$ & $86(81 ; 90)$ \\
\hline Carga glicêmica & $217(166 ; 267)$ & $228(185 ; 268)$ & $218(182 ; 272)$ & $228(177 ; 278)$ \\
\hline Fibra total da dieta $(\mathrm{g})^{\star \star}$ & $15,3(11,1 ; 19,5)$ & $17,1(12,7 ; 21,2)$ & $16,3(12,3 ; 21,5)$ & $16,6(12,1 ; 21,7)$ \\
\hline Fibra de leguminosas $(\mathrm{g})$ & $0,13(0,05 ; 0,32)$ & $0,14(0,06 ; 0,31)$ & $0,14(0,06 ; 0,27)$ & $0,14(0,06 ; 0,28)$ \\
\hline Fibra de grãos cereais (g) & $3,1(2,4 ; 4,1)$ & $3,2(2,2 ; 4,3)$ & $3,1(2,5 ; 4,1)$ & $3,1(2,2 ; 4,0)$ \\
\hline Fibra de frutas/vegetais $(\mathrm{g})$ & $7,6(5,1 ; 10,4)$ & $7,8(5,3 ; 11,7)$ & $8,6(5,5 ; 12,4)$ & $8,5(5,7 ; 12,2)$ \\
\hline Gordura total $(\mathrm{g})$ & $68,6(54,3 ; 84,6)$ & $71,3(52,1 ; 85,2)$ & $69,6(53,4 ; 89,2)$ & $67,0(53,6 ; 87,9)$ \\
\hline Gordura saturada(g) & $16,2(12,2 ; 21,3)$ & $15,9(12,5 ; 21,5)$ & $16,5(12,4 ; 22,0)$ & $15,5(11,8 ; 20,6)$ \\
\hline Ácido graxo linoléico $(\mathrm{g})$ & $11,1(8,5 ; 13,9)$ & $10,8(8,2 ; 13,7)$ & $11,2(8,6 ; 14,6)$ & $10,8(8,6 ; 13,9)$ \\
\hline Ácido graxo oléico $(\mathrm{g})$ & $25,8(20,9 ; 32,2)$ & $26,5(19,6 ; 33,5)$ & $26,3(20,1 ; 33,2)$ & $25,4(20,6 ; 32,6)$ \\
\hline Ácido graxo trans (g) & $11,2(7,9 ; 16,1)$ & $11,0(7,7 ; 15,5)$ & $11,2(8,0 ; 16,0)$ & $11,2(7,9 ; 16,2)$ \\
\hline Colesterol (mg) & $162,2(112,5 ; 227,1)$ & $176,7(123,1 ; 233,2)$ & $180,3(120,1 ; 234,4)$ & $169,9(125,9 ; 241,6)$ \\
\hline Vitamina B6 $(\mathrm{mg})^{\star *}$ & $1,22(0,9 ; 1,5)$ & $1,29(1,0 ; 1,6)$ & $1,29(1,0 ; 1,6)$ & $1,31(1,1 ; 1,7)$ \\
\hline Niacina (mg) & $14,3(11,7 ; 18,7)$ & $16,0(12,3 ; 19,3)$ & $15,1(12,1 ; 19,5)$ & $16,0(12,8 ; 19,1)$ \\
\hline Vitamina A (UI) & $7486,3(5390,1 ; 11621,7)$ & $7623,1(5529,7 ; 11402,9)$ & $8955,9(6254,6 ; 12425,9)$ & $7790,9(5584,6 ; 11617,9)$ \\
\hline Retinol $(\mu \mathrm{g})$ & $273,0(182,1 ; 418,9)$ & $294,5(176,8 ; 435,2)$ & $298,3(191,5 ; 467,5)$ & $261,6(148,2 ; 420,5)$ \\
\hline$\beta$-caroteno $(\mu \mathrm{g})$ & $3201,2(2152,6 ; 4699,2)$ & $2936,6(2140,4 ; 4791,4)$ & $3559,1(2447,4 ; 5140,4)$ & $3145,3(2120,2 ; 4813,1)$ \\
\hline Cálcio $(\mathrm{mg})$ & $604,3(461,4 ; 810,5)$ & $609,2(470,4 ; 789,4)$ & $631,8(489,1 ; 816,9)$ & $604,1(441,1 ; 812,9)$ \\
\hline Folato $(\mu \mathrm{g})$ & $190,4(145,1 ; 252,5)$ & $207,9(155,2 ; 262,3)$ & $213,3(159,8 ; 263,4)$ & $209,9(160,7 ; 273,9)$ \\
\hline Ferro $(\mathrm{mg})$ & $12,1(9,6 ; 16,0)$ & $13,2(10,6 ; 16,4)$ & $12,6(9,9 ; 16,1)$ & $13,0(10,3 ; 16,8)$ \\
\hline Vitamina $\mathrm{C}(\mathrm{mg})^{\star *}$ & $169,2(111,6 ; 253,1)$ & $171,9(109,2 ; 262,5)$ & $186,1(127,3 ; 271,8)$ & $196,5(136,2 ; 282,5)$ \\
\hline
\end{tabular}

* $\mathrm{N}=$ normoglicêmico, GJA = glicemia de jejum alterada, TGD= tolerância à glicose diminuída, $\mathrm{DM}=$ diabetes.

${ }^{*} N=$ normoglicêmico, GJA $=$ glicemia de jej
${ }^{*} p<0,05$, segundo teste de Krushal-Wallis. 
Tabela 7 - Mediana do consumo diário e intervalo interquartil (P25, P75) de calorias totais (VCT) e frações, índice glicêmico, carga glicêmica, fibras e nutrientes da dieta habitual segundo classificação da homeostase glicêmica. População adulta feminina de nipo-brasileiros. Bauru, $2000(n=579)$.

\begin{tabular}{|c|c|c|c|c|}
\hline & \multicolumn{4}{|c|}{ Categorias de Homeostase glicêmica* } \\
\hline & $N(n=182)$ & GJA (n=112) & TGD $(n=158)$ & DM $(n=127)$ \\
\hline Calorias totais - VCT (Kcal) & $1763,8(1442,7 ; 2105,7)$ & $1776,4(1463,8 ; 2142,9)$ & $1744,4(1476,2 ; 2169,9)$ & $1783,9(1503,2 ; 2138,2)$ \\
\hline Calorias de carboidratos ( $\%$ VCT) & $53,5(48,1 ; 58,5)$ & $54,8(48,9 ; 58,7)$ & $53,9(49,8 ; 58,8)$ & $54,1(49,2 ; 59,9)$ \\
\hline Calorias de proteínas ( $\%$ VCT) & $13,6(11,9 ; 15,3)$ & $13,7(12,2 ; 15,2)$ & $13,9(11,9 ; 15,4)$ & $13,9(12,4 ; 15,1)$ \\
\hline Calorias de lipídios (\% VCT) & $33,9(29,7 ; 37,9)$ & $33,1(28,9 ; 37,7)$ & $32,6(28,9 ; 37,1)$ & $32,9(27,4 ; 36,9)$ \\
\hline Proteínas $(\mathrm{g})$ & $60,4(47,6 ; 74,5)$ & $60,6(47,1 ; 74,5)$ & $60,2(48,1 ; 74,7)$ & $59,5(50,7 ; 76,6)$ \\
\hline Carboidratos (g) & $232,7(185,0 ; 286,3)$ & $244,2(194,5 ; 288,0)$ & $241,3(197,1 ; 293,9)$ & $246,2(192,8 ; 309,9)$ \\
\hline Índice glicêmico & $86(82 ; 91)$ & $87(81 ; 91)$ & $87(82 ; 92)$ & $87(82 ; 90)$ \\
\hline Carga glicêmica & $206(160 ; 252)$ & $207(166 ; 250)$ & $209(163 ; 261)$ & $220(167 ; 163)$ \\
\hline Fibra total da dieta (g) & $14,9(10,8 ; 18,8)$ & $16,2(11,3 ; 20,6)$ & $15,8(12,1 ; 20,2)$ & $15,8(11,9 ; 20,0)$ \\
\hline Fibra de leguminosas (g) & $0,13(0,05 ; 0,33)$ & $0,16(0,08 ; 0,33)$ & $0,15(0,07 ; 0,29)$ & $0,14(0,07 ; 0,27)$ \\
\hline Fibra de grãos cereais (g) & $3,0(2,3 ; 4,0)$ & $3,1(2,2 ; 4,4)$ & $3,1(2,3 ; 4,1)$ & $3,0(2,2 ; 4,0)$ \\
\hline Fibra de frutas/vegetais ( $\mathrm{g}$ ) & $7,7(5,3 ; 10,3)$ & $8,1(5,2 ; 12,1)$ & $8,7(6,2 ; 12,2)$ & $8,9(6,1 ; 12,6)$ \\
\hline Gordura total $(\mathrm{g})$ & $66,3(51,9 ; 78,5)$ & $63,1(49,9 ; 83,4)$ & $64,2(49,9 ; 83,9)$ & $62,1(51,7 ; 77,7)$ \\
\hline Gordura saturada(g) & $14,9(11,8 ; 19,9)$ & $14,8(10,9 ; 20,1)$ & $15,1(11,3 ; 19,6)$ & $14,6(10,9 ; 18,8)$ \\
\hline Ácido graxo linoléico (g) & $10,8(8,1 ; 13,4)$ & $10,5(7,5 ; 13,4)$ & $10,4(8,0 ; 13,9)$ & $10,2(7,9 ; 13,0)$ \\
\hline Ácido graxo oléico $(\mathrm{g})$ & $24,7(19,8 ; 29,9)$ & $24,9(19,2 ; 32,3)$ & $24,8(19,1 ; 30,3)$ & $23,9(18,9 ; 29,2)$ \\
\hline Ácido graxo trans (g) & $10,3(7,8 ; 15,9)$ & $10,2(7,7 ; 13,9)$ & $9,9(7,5 ; 14,4)$ & $10,4(7,9 ; 15,8)$ \\
\hline Colesterol (mg) & $147,4(105,9 ; 203,4)$ & $160,3(102,1 ; 206,4)$ & $160,6(105,2 ; 211,2)$ & $156,8(109,2 ; 206,1)$ \\
\hline Vitamina B6 (mg) & $1,2(0,9 ; 1,4)$ & $1,2(0,9 ; 1,6)$ & $1,2(0,9 ; 1,6)$ & $1,2(0,9 ; 1,5)$ \\
\hline Niacina $(\mathrm{mg})$ & $13,9(10,7 ; 17,6)$ & $13,9(11,5 ; 17,3)$ & $14,2(11,4 ; 17,6)$ & $14,8(12,1 ; 17,7)$ \\
\hline Vitamina A (UI) & $7722,8(5336,3 ; 11852,1)$ & $7735,3(5689,7 ; 13151,5)$ & $9054,6(6221,3 ; 12805,4)$ & $8004,8(5548,1 ; 12264,8)$ \\
\hline Retinol $(\mu \mathrm{g})$ & $259,2(182,5 ; 410,8)$ & $297,4(177,8 ; 439,5)$ & $271,8(172,3 ; 415,4)$ & $254,8(149,1 ; 401,4)$ \\
\hline$\beta$-caroteno $(\mu \mathrm{g})$ & $3247,1(2144,9 ; 4794,4)$ & $2980,8(2285,5 ; 5632,5)$ & $3682,9(2513,4 ; 5517,4)$ & $3311,0(2217,9 ; 5058,3)$ \\
\hline Cálcio $(\mathrm{mg})$ & $602,4(467,1 ; 797,5)$ & $595,4(466,9 ; 823,7)$ & $641,9(502,0 ; 814,7)$ & $597,2(448,0 ; 836,9)$ \\
\hline Folato $(\mu \mathrm{g})$ & $184,4(140,5 ; 233,2)$ & $199,8(138,9 ; 260,8)$ & $193,9(148,3 ; 256,1)$ & $191,9(149,9 ; 251,5)$ \\
\hline Ferro $(\mathrm{mg})$ & $11,8(9,2 ; 15,2)$ & $12,2(9,8 ; 14,9)$ & $11,9(9,4 ; 15,3)$ & $12,2(9,9 ; 14,9)$ \\
\hline Vitamina C $(\mathrm{mg})$ & $170,9(115,4 ; 247,4)$ & $170,1(107,3 ; 280,2)$ & $185,0(130,3 ; 268,9)$ & $203,1(142,2 ; 285,4)$ \\
\hline
\end{tabular}

Não houve diferenças estatisticamente significantes entre grupos de classificação da homeostase glicêmica. Teste de Krushal-Wallis.

Tabela 8 - Mediana do consumo diário e intervalo interquartil (P25, P75) de calorias totais (VCT) e frações, índice glicêmico, carga glicêmica, fibras e nutrientes da dieta habitual segundo classificação da homeostase glicêmica. População adulta masculina de nipo-brasileiros. Bauru, $2000(n=475)$.

Calorias totais - VCT (Kcal) Calorias de carboidratos (\% VCT) Calorias de proteínas (\% VCT) Calorias de lipídios (\% VCT) Proteínas $(\mathrm{g})$

Carboidratos $(\mathrm{g})$

Índice glicêmico

Carga glicêmica

Fibra total da dieta (g)

Fibra de leguminosas $(\mathrm{g})$

Fibra de grãos cereais (g)

Fibra de frutas/vegetais $(\mathrm{g})$

Gordura total (g)

Gordura saturada(g)

Ácido graxo linoléico $(\mathrm{g})$

Ácido graxo oléico (g)

Ácido graxo trans $(\mathrm{g})$

Colesterol (mg)

Vitamina B6 $(\mathrm{mg})$

Niacina (mg)

Vitamina A (UI)

Retinol $(\mu \mathrm{g})$

$\beta$-caroteno $(\mu \mathrm{g})$

Cálcio (mg)

Folato $(\mu \mathrm{g})$

Ferro (mg)

Vitamina C $(\mathrm{mg})$
Categorias de Homeostase glicêmica*

\begin{tabular}{|c|c|c|c|}
\hline \multicolumn{4}{|c|}{ Categorias de Homeostase glicêmica* } \\
\hline$N(n=85)$ & GJA (n=127) & $\operatorname{TGD}(n=123)$ & $\mathrm{DM}(\mathrm{n}=140)$ \\
\hline $2202,3(1759,7 ; 2539,7)$ & $2061,3(1780,7 ; 2512,5)$ & $2109,4(1781,4 ; 2488,9)$ & $2129,5(1729,5 ; 2577,9)$ \\
\hline $52,8(45,9 ; 56,9)$ & $52,9(48,9 ; 58,9)$ & $53,0(47,6 ; 58,1)$ & $53,3(46,9 ; 59,2)$ \\
\hline $13,6(11,3 ; 15,2)$ & $13,4(11,5 ; 15,0)$ & $13,1(11,7 ; 14,7)$ & $13,3(11,4 ; 14,9)$ \\
\hline $32,1(28,2 ; 36,8)$ & $31,9(27,3 ; 36,2)$ & $32,6(28,5 ; 36,9)$ & $31,4(27,4 ; 36,4)$ \\
\hline $71,4(53,4 ; 86,9)$ & $69,7(54,2 ; 85,8)$ & $70,0(52,2 ; 87,9)$ & $70,4(55,8 ; 86,3)$ \\
\hline $269,2(214,6 ; 345,2)$ & $284,9(239,9 ; 330,6)$ & $269,2(240,7 ; 336,1)$ & $275,4(231,4 ; 348,7)$ \\
\hline $86(81 ; 91)$ & $86(83 ; 90)$ & $85(82 ; 89)$ & $85(80 ; 90)$ \\
\hline $230(195 ; 302)$ & $249(209 ; 291)$ & $233(200 ; 289)$ & $233(198 ; 293)$ \\
\hline $16,3(12,2 ; 22,9)$ & $17,6(13,9 ; 21,6)$ & $16,8(12,4 ; 22,5)$ & $17,4(12,5 ; 22,9)$ \\
\hline $0,13(0,05 ; 0,29)$ & $0,11(0,05 ; 0,29)$ & $0,13(0,06 ; 0,26)$ & $0,14(0,05 ; 0,29)$ \\
\hline $3,1(2,4 ; 4,3)$ & $3,2(2,2 ; 4,2)$ & $3,2(2,6 ; 4,1)$ & $3,1(2,2 ; 4,3)$ \\
\hline $7,2(4,7 ; 10,5)$ & $7,7(5,4 ; 11,5)$ & $7,9(5,0 ; 12,5)$ & $8,0(5,3 ; 11,2)$ \\
\hline $76,9(61,3 ; 95,6)$ & $74,5(58,6 ; 92,7)$ & $77,2(59,2 ; 96,7)$ & $74,6(55,9 ; 96,7)$ \\
\hline $19,0(13,5 ; 23,6)$ & $16,7(13,2 ; 22,4)$ & $18,0(13,7 ; 24,5)$ & $16,5(12,6 ; 22,4)$ \\
\hline $11,7(9,4 ; 14,7)$ & $11,3(8,9 ; 14,3)$ & $11,9(9,2 ; 15,6)$ & $11,4(8,7 ; 14,5)$ \\
\hline $29,0(22,9 ; 36,3)$ & $27,8(20,5 ; 34,3)$ & $28,5(21,8 ; 36,9)$ & $27,8(21,3 ; 36,6)$ \\
\hline $12,9(8,9 ; 16,8)$ & $12,5(7,7 ; 17,4)$ & $11,9(8,9 ; 17,6)$ & $11,9(8,2 ; 17,3)$ \\
\hline $192,8(134,1 ; 257,1)$ & $195,4(141,9 ; 254,8)$ & $195,1(143,9 ; 268,5)$ & $187,2(134,3 ; 267,3)$ \\
\hline $1,4(1,1 ; 1,8)$ & $1,4(1,1 ; 1,6)$ & $1,4(1,1 ; 1,8)$ & $1,4(1,1 ; 1,8)$ \\
\hline $17,2(12,6 ; 21,7)$ & $17,4(13,3 ; 20,6)$ & $16,8(13,1 ; 21,5)$ & $17,4(14,3 ; 20,9)$ \\
\hline $7265,4(5532,3 ; 10955,5)$ & $7669,9(5194,4 ; 10970,8)$ & $8863,6(6259,1 ; 11792,3)$ & $7720,4(5594,2 ; 11160,5)$ \\
\hline $309,6(169,8 ; 437,4)$ & $280,4(175,2 ; 399,1)$ & $326,9(203,6 ; 510,9)$ & $262,8(151,9 ; 428,9)$ \\
\hline $3121,5(2154,2 ; 4636,9)$ & $2893,3(1975,1 ; 4402,3)$ & $3434,6(2408,4 ; 4986,5)$ & $2966,2(1913,8 ; 4575,1)$ \\
\hline $610,6(432,1 ; 833,8)$ & $614,6(473,0 ; 782,6)$ & $608,7(460,3 ; 826,4)$ & $606,0(434,8 ; 772,0)$ \\
\hline $209,3(153,2 ; 272,2)$ & $214,6(163,1 ; 264,9)$ & $221,6(172,9 ; 276,0)$ & $217,4(165,3 ; 287,4)$ \\
\hline $13,2(10,4 ; 16,9)$ & $13,9(11,4 ; 17,9)$ & $13,6(10,5 ; 16,5)$ & $13,8(10,8 ; 18,2)$ \\
\hline $165,5(106,7 ; 257,0)$ & $175,8(115,7 ; 261,6)$ & $187,7(124,7 ; 274,4)$ & $189,5(132,5 ; 280,9)$ \\
\hline
\end{tabular}

* $\mathrm{N}=$ normoglicêmico, $\mathrm{GJA}=$ glicemia de jejum alterada, TGD= tolerância à glicose diminuída, $\mathrm{DM}=$ diabetes

Não houve diferenças estatisticamente significantes entre grupos de classificação da homeostase glicêmica. Teste de Krushal-Wallis.

$\mathrm{Na}$ população total, independente da classificação de homeostase glicêmica, o padrão alimentar caracterizou-se por uma dieta normoglicídica, 
normoprotéica e hiperlipídica (acima de 30\% das calorias totais). Observaram-se teores moderados de consumo de fibras e um consumo de vitamina C acima de recomendações nutricionais para população adulta (65 $\mathrm{mg} / \mathrm{dia})$.

Os valores de mediana de consumo diário de grupos de alimentos da dieta habitual de nipo-brasileiros segundo categorias de homeostase glicêmica estão apresentados nas Tabelas 9, 10 e 11. Na população total, observaram-se diferenças estatisticamente significantes entre as categorias de homeostase glicêmica para valores medianos de consumo de frutas/sucos, frutas cítricas, carnes vermelhas e do grupo de pescados. Em análise estratificada por sexo, consumos medianos diferenciados entre categorias de homeostase glicêmica para frutas/sucos e frutas cítricas permaneceram significantes no sexo feminino. Em homens não houve diferenças significantes de consumo destes alimentos segundo categorias de homeostase glicêmica (Tabela 11).

Tabela 9 - Mediana e intervalo interquartil (P25, P75) de consumo diário de grupos de alimentos $(\mathrm{g})$ da dieta habitual segundo classificação da homeostase glicêmica. População adulta de nipo-brasileiros. Bauru, $2000(n=1.054)$.

\begin{tabular}{|c|c|c|c|c|}
\hline & \multicolumn{4}{|c|}{ Categorias de Homeostase glicêmica* } \\
\hline & $N(n=267)$ & GJA (n=239) & TGD (n=281) & DM (n=267) \\
\hline Leguminosas $(\mathrm{g})$ & $6,5(2,7 ; 15,3)$ & $6,8(3,2 ; 13,4)$ & $7,1(3,6 ; 14,0)$ & $7,4(3,2 ; 12,9)$ \\
\hline Frutas cítricas $(\mathrm{g})^{* *}$ & $170(64 ; 261)$ & $175(60 ; 350)$ & $175(85 ; 350)$ & $196(93 ; 353)$ \\
\hline Vegetais $(\mathrm{g})$ & $180(131 ; 227)$ & $180(134 ; 235)$ & $184(130 ; 244)$ & $182(124 ; 232)$ \\
\hline Laticínios integrais $(\mathrm{g})$ & $70(9 ; 167)$ & $59(9 ; 164)$ & $69(6 ; 170)$ & $43(4 ; 154)$ \\
\hline Laticínios pobres em gordura (g) & $6(1 ; 81)$ & $6(1 ; 150)$ & $6(1 ; 119)$ & $6(0 ; 81)$ \\
\hline Óleos e frituras $(\mathrm{g})$ & $25(17 ; 34)$ & $25(17 ; 37)$ & $25(17 ; 35)$ & $24(17 ; 34)$ \\
\hline Doces $(g)$ & $105(60 ; 193)$ & $110(53 ; 228)$ & $95(50 ; 173)$ & $95(44 ; 219)$ \\
\hline Miso-shiru (g) & $13(3 ; 40)$ & $13(3 ; 57)$ & $13(5 ; 57)$ & $13(3 ; 29)$ \\
\hline
\end{tabular}


Tabela 10 - Mediana e intervalo interquartil (P25, P75) de consumo diário de grupos de alimentos $(\mathrm{g})$ da dieta habitual segundo classificação da homeostase glicêmica. População adulta feminina de nipobrasileiros. Bauru $2000(n=579)$.

\begin{tabular}{|c|c|c|c|c|}
\hline & & Categorias de $\mathrm{H}$ & stase glicêmica* & \\
\hline & $N(n=182)$ & GJA (n=112) & TGD (n=158) & $\mathrm{DM}(\mathrm{n}=127)$ \\
\hline Cereais/pães/massas (g) & $401(242 ; 504)$ & $389(232 ; 521)$ & $443(275 ; 523)$ & $472(265 ; 529)$ \\
\hline Leguminosas (g) & $6,9(2,7 ; 13,1)$ & $6,9(3,6 ; 15,4)$ & $7,5(3,6 ; 15,0)$ & $7,4(3,5 ; 13,0)$ \\
\hline Frutas cítricas $(\mathrm{g})^{\star \star}$ & $170(64 ; 270)$ & $173(56 ; 325)$ & $175(80 ; 350)$ & $200(103 ; 360)$ \\
\hline Vegetais (g) & $179(130 ; 219)$ & $179(136 ; 236)$ & $184(128 ; 246)$ & $173(119 ; 226)$ \\
\hline Laticínios integrais (g) & $58(7 ; 164)$ & $51(11 ; 166)$ & $68(4 ; 161)$ & $45(7 ; 154)$ \\
\hline Laticínios pobres em gordura (g) & $9(1 ; 150)$ & $19(1 ; 150)$ & $11(1 ; 151)$ & $9(1 ; 151)$ \\
\hline Óleos e frituras (g) & $23(17 ; 33)$ & $26(17 ; 36)$ & $25(16 ; 33)$ & $23(18 ; 32)$ \\
\hline Doces $(\mathrm{g})$ & $89(52 ; 155)$ & $90(40 ; 174)$ & $81(43 ; 138)$ & $82(40 ; 159)$ \\
\hline Miso-shiru (g) & $13(3 ; 40)$ & $13(4 ; 57)$ & $17(7 ; 57)$ & $13(7 ; 29)$ \\
\hline
\end{tabular}

** Teste de Krushal-Wallis, $p<0,05$

Tabela 11 - Mediana e intervalo interquartil (P25, P75) de consumo diário de grupos de alimentos $(\mathrm{g})$ da dieta habitual segundo classificação da homeostase glicêmica. População adulta masculina de nipobrasileiros. Bauru, 2000 ( $n=475)$.

\begin{tabular}{|c|c|c|c|c|}
\hline & \multicolumn{4}{|c|}{ Categorias de Homeostase Glicêmica* } \\
\hline Leguminosas (g) & $6,1(2,5 ; 15,9)$ & $6,8(3,0 ; 13,3)$ & $7,0(3,4 ; 12,9)$ & $7,4(2,7 ; 12,5)$ \\
\hline Frutas cítricas $(\mathrm{g})$ & $171(65 ; 275)$ & $175(61 ; 354)$ & $175(90 ; 325)$ & $196(78 ; 350)$ \\
\hline Vegetais (g) & $180(138 ; 235)$ & $182(130 ; 234)$ & $183(130 ; 242)$ & $187(135 ; 242)$ \\
\hline Laticínios integrais $(\mathrm{g})$ & $108(13 ; 187)$ & $62(7 ; 163)$ & $69(9 ; 161)$ & $33(4 ; 154)$ \\
\hline Laticínios pobres em gordura (g) & $2(0 ; 18)$ & $6(0 ; 40)$ & $6(1 ; 23)$ & $4(0 ; 26)$ \\
\hline Óleos e frituras $(\mathrm{g})$ & $27(20 ; 37)$ & $25(17 ; 38)$ & $27(18 ; 38)$ & $27(17 ; 37)$ \\
\hline Doces $(g)$ & $153(82 ; 274)$ & $123(69 ; 273)$ & $115(61 ; 229)$ & $114(47 ; 281)$ \\
\hline Miso-shiru (g) & $13(1 ; 31)$ & $13(2 ; 57)$ & $13(2 ; 40)$ & $8(1 ; 32)$ \\
\hline
\end{tabular}

${ }^{*} \mathrm{~N}=$ normoglicêmico, GJA= glicemia de jejum alterada, TGD= tolerância à glicose diminuída, $\mathrm{DM}=$ diabetes.

Não houve diferenças estatisticamente significantes. Teste de Krushal-Wallis.

\subsection{Associação entre IG, CG, dieta habitual e glicemia de jejum, insulinemia de jejum e HOMA R}

Os coeficientes de correlação de Pearson entre fatores dietéticos, IG,

CG e a glicemia e insulinemia de jejum e HOMA $R$ são mostrados nas

Tabela 12 e 13. 
Tabela 12 - Coeficientes de correlação de Pearson (r) entre o consumo de calorias totais, índice glicêmico, carga glicêmica, demais variáveis dietéticas e glicemia e insulinemia de jejum e HOMA R. População adulta de nipo-brasileiros. Bauru, 2000 ( $n=1.054)$.

\begin{tabular}{|c|c|c|c|c|c|c|}
\hline & \multicolumn{2}{|c|}{ Glicemia jejum (mg/dl)* $^{*}$} & \multicolumn{2}{|c|}{ Insulina jejum (uM/L)* } & \multicolumn{2}{|c|}{ HOMA R*干 } \\
\hline & $\mathbf{r}$ & p & $\mathbf{r}$ & $p$ & $\mathbf{r}$ & $p$ \\
\hline Carboidratos (g) & 0,041 & 0,183 & 0,003 & 0,913 & 0,013 & 0,682 \\
\hline Índice glicêmico & $-0,110$ & 0,000 & $-0,082$ & 0,009 & $-0,097$ & 0,002 \\
\hline Ajustado** & $-0,108$ & 0,000 & $-0,081$ & 0,010 & $-0,095$ & 0,002 \\
\hline Carga Glicêmica & 0,017 & 0,586 & $-0,015$ & 0,629 & $-0,009$ & 0,770 \\
\hline Ajustado** & $-0,003$ & 0,932 & $-0,041$ & 0,191 & $-0,038$ & 0,227 \\
\hline Fibra de frutas e vegetais $(\mathrm{g})$ & 0,022 & 0,469 & 0,008 & 0,791 & 0,038 & 0,682 \\
\hline Ajustado** & $-0,005$ & 0,880 & $-0,005$ & 0,872 & $-0,006$ & 0,860 \\
\hline Fibra de leguminosas $(\mathrm{g})^{*}$ & 0,022 & 0,478 & $-0,023$ & 0,458 & $-0,016$ & 0,615 \\
\hline Ajustado** & 0,003 & 0,918 & $-0,034$ & 0,274 & $-0,030$ & 0,334 \\
\hline Gordura total (g) & 0,060 & 0,052 & 0,079 & 0,011 & 0,087 & 0,005 \\
\hline Ajustado** & $-0,002$ & 0,948 & 0,095 & 0,002 & 0,088 & 0,005 \\
\hline Gordura saturada(g) & 0,039 & 0,205 & 0,067 & 0,031 & 0,071 & 0,022 \\
\hline Ajustado** & $-0,029$ & 0,345 & 0,065 & 0,037 & 0,055 & 0,081 \\
\hline Ácido graxo linoléico (g) & 0,027 & 0,388 & 0,067 & 0,031 & 0,070 & 0,024 \\
\hline Ajustado** & $-0,037$ & 0,228 & 0,061 & 0,049 & 0,052 & 0,097 \\
\hline Ácido graxo oléico (g) & 0,066 & 0,033 & 0,076 & 0,015 & 0,086 & 0,006 \\
\hline Ajustado** & 0,015 & 0,617 & 0,079 & 0,011 & 0,077 & 0,013 \\
\hline Ácido graxo trans $(\mathrm{g})^{*}$ & 0,001 & 0,976 & 0,066 & 0,035 & 0,063 & 0,045 \\
\hline Ajustado** & $-0,042$ & 0,175 & 0,058 & 0,065 & 0,046 & 0,143 \\
\hline Colesterol (mg) & 0,095 & 0,002 & 0,073 & 0,019 & 0,086 & 0,006 \\
\hline Ajustado** & 0,064 & 0,038 & 0,066 & 0,036 & 0,072 & 0,022 \\
\hline
\end{tabular}

Tabela 13 - Coeficientes de correlação de Pearson ( $r$ ) entre o consumo diário de grupos de alimentos (g) e glicemia e insulinemia de jejum e HOMA R. População adulta de nipo-brasileiros. Bauru, $2000(n=1.054)$.

\begin{tabular}{|c|c|c|c|c|c|c|}
\hline & \multicolumn{2}{|c|}{ Glicemia jejum (mg/dl)* } & \multicolumn{2}{|c|}{ Insulina jejum (uM/L)* } & \multicolumn{2}{|c|}{ HOMA R* $\mp$} \\
\hline & $\mathbf{r}$ & p & $\mathbf{r}$ & p & $\mathbf{r}$ & $\mathbf{p}$ \\
\hline Cereais/pães/massas (g) & 0,03 & 0,326 & $-0,031$ & 0,316 & $-0,022$ & 0,475 \\
\hline Ajustado** & $-0,02$ & 0,517 & $-0,070$ & 0,026 & $-0,069$ & 0,027 \\
\hline Leguminosas $(\mathrm{g})^{*}$ & $-0,02$ & 0,960 & $-0,055$ & 0,077 & $-0,051$ & 0,106 \\
\hline Ajustado** & $-0,02$ & 0,517 & $-0,066$ & 0,033 & $-0,065$ & 0,037 \\
\hline Frutas e sucos de frutas $(\mathrm{g})$ & 0,050 & 0,105 & 0,016 & 0,598 & 0,025 & 0,419 \\
\hline Ajustado** & 0,028 & 0,370 & 0,005 & 0,871 & 0,010 & 0,756 \\
\hline Frutas cítricas (g) & 0,062 & 0,045 & 0,006 & 0,845 & 0,017 & 0,586 \\
\hline Ajustado** & 0,043 & 0,168 & $-0,004$ & 0,891 & 0,003 & 0,923 \\
\hline Vegetais (g) & $-0,016$ & 0,604 & 0,035 & 0,263 & 0,031 & 0,328 \\
\hline Ajustado** & $-0,052$ & 0,094 & 0,022 & 0,475 & 0,011 & 0,720 \\
\hline Laticínios integrais (g) & $-0,106$ & 0,001 & $-0,034$ & 0,283 & $-0,052$ & 0,096 \\
\hline Ajustado** & $-0,123$ & 0,000 & $-0,041$ & 0,186 & $-0,063$ & 0,044 \\
\hline Laticínios pobres em gordura (g) & $-0,021$ & 0,493 & $-0,010$ & 0,752 & $-0,012$ & 0,706 \\
\hline Ajustado** & $-0,017$ & 0,571 & $-0,008$ & 0,796 & $-0,009$ & 0,766 \\
\hline Carnes vermelhas, embutidos, miúdos e aves $(\mathrm{g})^{*}$ & 0,124 & 0,000 & 0,076 & 0,015 & 0,095 & 0,002 \\
\hline Ajustado** & 0,106 & 0,001 & 0,069 & 0,027 & 0,084 & 0,007 \\
\hline Pescados e frutos do mar $(\mathrm{g})^{*}$ & 0,035 & 0,253 & $-0,015$ & 0,622 & $-0,007$ & 0,818 \\
\hline Ajustado** & 0,021 & 0,486 & $-0,023$ & 0,461 & $-0,017$ & 0,576 \\
\hline Óleos e frituras $(\mathrm{g})^{*}$ & 0,028 & 0,357 & 0,078 & 0,013 & 0,079 & 0,011 \\
\hline Ajustado** & $-0,003$ & 0,922 & 0,070 & 0,025 & 0,065 & 0,037 \\
\hline Doces $(g)^{*}$ & $-0,053$ & 0,085 & 0,046 & 0,144 & 0,034 & 0,283 \\
\hline Ajustado** & $-0,083$ & 0,007 & 0,036 & 0,244 & 0,018 & 0,559 \\
\hline Missoshiro $(g)^{*}$ & $-0,039$ & 0,208 & $-0,049$ & 0,117 & $-0,053$ & 0,092 \\
\hline Ajustado** & $-0,049$ & 0,112 & $-0,054$ & 0,082 & $-0,060$ & 0,055 \\
\hline
\end{tabular}

* Variáveis que sofreram transformação logarítmica.

** Ajustado: valores de coeficientes de correlação com consumo ajustado pelas calorias totais pelo método residual.

$\mp$ HOMA R = glicemia jejum $(\mathrm{mmol} / \mathrm{L}) \mathrm{x}$ insulina de jejum $(\mathrm{mU} / \mathrm{L}) / 22,5$. 
Os coeficientes de regressão ß1 (IC 95\%) do IG, CG e nutrientes selecionados em modelos de regressão linear múltiplos com os valores de glicemia e insulinemia de jejum e HOMA R são mostrados nas Tabelas 14, 15 e 16. Verificou-se uma relação inversa entre o IG da dieta e a glicemia de jejum na população total após ajuste múltiplo. Em modelos estratificados por sexo, a mesma tendência de relação inversa entre o IG da dieta e glicemia de jejum foi verificado entre os homens. Nas mulheres, associação positiva entre o colesterol dietético e glicemia de jejum foi observada. Os modelos múltiplos explicaram $47 \%$ da variação de glicemia de jejum.

Tabela 14 - Coeficientes de regressão ß1 (IC 95\%) entre o índice glicêmico, carga glicêmica e nutrientes selecionados em modelos de regressão linear múltiplos e valores de glicemia e insulinemia de jejum e HOMA R. População adulta de nipo-brasileiros. Bauru, $2000(n=1054)$.

\begin{tabular}{|c|c|c|c|}
\hline & Glicemia jejum (mg/dl) $^{* 1}$ & Insulina jejum (um/L)* ${ }^{* 2}$ & HOMA R* $^{*}{ }^{2}$ \\
\hline Índice glicêmico & $-0,0017105(-0,003025 ;-0,000396)$ & $-0,0056063(-0,011997 ; 0,000784)$ & $-0,0074259(-0,014186 ;-0,000666)$ \\
\hline Carboidratos (g) & $-0,0001510(-0,000400 ; 0,000098)$ & $0,0008545(-0,000937 ; 0,002646)$ & $0,0003635(-0,001533 ; 0,002260)$ \\
\hline Fibra de cereais $(\mathrm{g})$ & $0,0014781(-0,004306 ; 0,007262)$ & $-0,0096217(-0,037098 ; 0,017855)$ & $-0,0069727(-0,036064 ; 0,022118)$ \\
\hline Fibra de leguminosas $(\mathrm{g})^{*}$ & $0,0048422(-0,001994 ; 0,011679)$ & $0,0003372(-0,032137 ; 0,032811)$ & $0,0061795(-0,028196 ; 0,040555)$ \\
\hline Fibra vegetais/frutas (g) & $-0,0010247(-0,003755 ; 0,001706)$ & $0,0051237(-0,007913 ; 0,018160)$ & $0,0038477(-0,009955 ; 0,017650)$ \\
\hline Gordura total (g) & $-0,0000110(-0,000627 ; 0,000605)$ & $0,0023240(-0,000512 ; 0,005160)$ & $0,0024694(-0,000532 ; 0,005471)$ \\
\hline Ácido graxo linoléico $(\mathrm{g})$ & $-0,0002455(-0,002722 ; 0,002231)$ & $0,0053626(-0,011989 ; 0,022714)$ & $0,0044872(-0,013883 ; 0,022857)$ \\
\hline Ácido graxo trans $(\mathrm{g})^{*}$ & $-0,0128711(-0,030225 ; 0,004483)$ & $0,0172509(-0,065267 ; 0,099768)$ & $0,0036450(-0,083717 ; 0,091008)$ \\
\hline Colesterol dietético $(\mathrm{g})$ & $0,0000979(-0,000001 ; 0,000197)$ & $0,0000372(-0,000442 ; 0,000516)$ & $0,0001243(-0,000383 ; 0,000631)$ \\
\hline
\end{tabular}

Tabela 15 - Coeficientes de regressão ß1 (IC 95\%) entre o índice glicêmico, carga glicêmica e nutrientes selecionados em modelos de regressão linear múltiplos e valores de glicemia e insulinemia de jejum e HOMA R. População adulta feminina de nipobrasileiros. Bauru, $2000(n=579)$.

Índice glicêmico
Carga Glicêmica
Carboidratos $(\mathrm{g})$
Fibra total $(\mathrm{g})$
Fibra de cereais $(\mathrm{g})$
Fibra de leguminosas $(\mathrm{g})^{\star}$
Fibra vegetais/frutas $(\mathrm{g})$
Gordura total $(\mathrm{g})$
Gordura saturada $(\mathrm{g})$
Ácido graxo oléico $(\mathrm{g})$
Ácido graxo linoléico $(\mathrm{g})$
Ácido graxo trans $(\mathrm{g})^{*}$
Colesterol dietético $(\mathrm{g})$

Glicemia jejum (mg/dl)* $-0,0008278(-0,002670 ; 0,001014)$ $-0,0000837(-0,000425 ; 0,000257)$ $-0,0000793(-0,000463 ; 0,000304)$ $-0,0002014(-0,002351 ; 0,001948)$ $0,0018664(-0,006833 ; 0,010566)$ $0,0032888(-0,006416 ; 0,012994)$ $-0,0009451(-0,005113 ; 0,003223)$ $-0,0000429(-0,000966 ; 0,000881)$ $-0,0010330(-0,003954 ; 0,001888)$ $0,0001348(-0,001826 ; 0,002095)$ $0,0002728(-0,003199 ; 0,003745)$ $0,0106199(-0,034702 ; 0,013462)$ $0,0001845(0,000027 ; 0,000342)$ Insulina jejum (um/L)* $-0,0024272(-0,012322 ; 0,007468)$ $-0,0014651(-0,004378 ; 0,001448)$ $-0,0017591(-0,005333 ; 0,001814)$ $0,0091154(-0,001914 ; 0,020145)$ $0,0104815(-0,032976 ; 0,053939)$ $-0,0008627(-0,045981 ; 0,044256)$ $-0,0173539(-0,037944 ; 0,003236)$ $0,0020216(-0,002410 ; 0,006453)$ $-0,0040435(-0,021656 ; 0,013569)$ $0,0008114(-0,025957 ; 0,027580)$ $0,0185269(-0,006882 ; 0,043936)$ $0,0440090(-0,076959 ; 0,164977)$ $-0,0002004(-0,000997 ; 0,000597)$

\section{HOMA R $^{*} \mathbf{F}^{2}$}

$-0,0034280(-0,013844 ; 0,006988)$ $-0,0020061(-0,005071 ; 0,001059)$ $-0,0025401(-0,006300 ; 0,001219)$ $0,0087292(-0,002883 ; 0,020341)$ $0,0136170(-0,032131 ; 0,059365)$ $0,0065875(-0,040911 ; 0,054086)$ $-0,0187025(-0,040377 ; 0,002972)$ $0,0022982(-0,002368 ; 0,006964)$ $-0,0040968(-0,022640 ; 0,014446)$ $0,0021044(-0,026078 ; 0,030287)$ $0,0189193(-0,007835 ; 0,045673)$ $0,0318175(-0,095572 ; 0,159207)$ $-0,0000230(-0,000862 ; 0,000816)$

\footnotetext{
1 Ajuste múltiplo por idade (anos), geração (1a ou $2^{\mathrm{a}}$ geração), escolaridade (não freqüentou a escola, até $1^{\circ} \mathrm{grau},>=2^{\circ} \mathrm{grau}$ ), presença de HA e/ou dislipidemiá), tabảgismo (sim/não), consumo habitual de álcool (sim/não), atividade física de lazer (sim/não), circunferência de cintura (cm) e consumo de fibras totais (g/dia), colesterol dietético (mg/dia) e VCT (kcal/dia). Os nutrientes/alimentos foram ajustados pelas calorias totais pelo método residual.

Ajuste múltiplo semelhante ao modelo 1 substituindo o colesterol dietético por gordura total da dieta (g/dia).
}

Ғ HOMA R $=$ glicemia jejum $(\mathrm{mmol} / \mathrm{L}) \mathrm{x}$ insulina $(\mathrm{mU} / \mathrm{L}) / 22,5$ 
Tabela 16 - Coeficientes de regressão ß1 (IC 95\%) entre o índice glicêmico, carga glicêmica e nutrientes selecionados em modelos de regressão linear múltiplos e valores de glicemia e insulinemia de jejum e HOMA R. População adulta masculina de nipobrasileiros. Bauru, 2000 ( $n=475)$.

\begin{tabular}{|c|c|c|c|}
\hline & Glicemia jejum (mg/dl)* & Insulina jejum (um/L) ${ }^{* 2}$ & HOMA R $^{*} \mp^{2}$ \\
\hline Índice glicêmico & $-0,0026884(-0,004639 ;-0,000738)$ & $-0,0080718(-0,016926 ; 0,000783)$ & $-0,0109050(-0,020323 ;-0,001487)$ \\
\hline Carboidratos (g) & $-0,0001585(-0,000498 ; 0,000181)$ & $0,0016810(-0,000441 ; 0,003804)$ & $0,0012667(-0,000999 ; 0,003532)$ \\
\hline Fibra de cereais $(\mathrm{g})$ & $0,0002674(-0,007661 ; 0,008196)$ & $-0,0251498(-0,061185 ; 0,010885)$ & $-0,0229278(-0,061364 ; 0,015508)$ \\
\hline Fibra de leguminosas $(\mathrm{g})^{*}$ & $-0,0009601(-0,011877 ; 0,009957)$ & $0,0014758(-0,046008 ; 0,048960)$ & $-0,0229278(-0,061364 ; 0,015508)$ \\
\hline Fibra vegetais/frutas (g) & $-0,0017845(-0,005498 ; 0,001929)$ & $0,0185832(0,001572 ; 0,035595)$ & $0,0165919(-0,001571 ; 0,034755)$ \\
\hline Gordura total $(\mathrm{g})$ & $-0,0001182(-0,000969 ; 0,000733)$ & $0,0026409(-0,001097 ; 0,006379)$ & $0,0026068(-0,001378 ; 0,006592)$ \\
\hline Ácido graxo linoléico $(\mathrm{g})$ & $-0,0013352(-0,004913 ; 0,002243)$ & $-0,0072885(-0,031187 ; 0,016610)$ & $-0,0099697(-0,035439 ; 0,015499)$ \\
\hline Ácido graxo trans $(\mathrm{g})^{*}$ & $-0,0202293(-0,045570 ; 0,005112)$ & $-0,0027767(-0,116787 ; 0,111234)$ & $-0,0219996(-0,143519 ; 0,099519)$ \\
\hline Colesterol dietético $(\mathrm{g})$ & $0,0000505(-0,000079 ; 0,000180)$ & $0,0001543(-0,000441 ; 0,000750)$ & $0,0001966(-0,000438 ; 0,000831)$ \\
\hline
\end{tabular}

Associação inversa entre o IG da dieta e HOMA R na população total foi verificada, sendo que a mesma tendência foi observada entre os homens. Os modelos múltiplos explicaram 32\% da variação de HOMA R. Em relação à insulina de jejum, nenhuma relação estatisticamente significante foi observada entre o consumo de IG, CG e demais nutrientes na população total. No entanto, em análises estratificadas por sexo, observou-se uma associação positiva entre o consumo de fibra de vegetais/ frutas e insulina de jejum nos homens. Os modelos explicaram cerca de $26 \%$ da variação da insulina de jejum.

Os coeficientes de regressão $ß 1$ do consumo diário de grupos de alimentos selecionados em modelos de regressão linear múltiplos com os valores de glicemia e insulinemia de jejum e HOMA R são mostrados nas Tabelas 17 a 19. Na população total, observou-se associação inversa entre o consumo dos grupos de laticínios integrais, doces e glicemia de jejum após ajuste múltiplo. A mesma tendência de associação inversa entre o consumo de doces e glicemia de jejum foi verificada nas mulheres, assim como na relação inversa entre o consumo de laticínios e glicemia de jejum nos homens após ajuste múltiplo. 
Tabela 17 - Coeficientes de regressão ß1 (IC 95\%) entre o consumo diário de grupos de alimentos em modelos de regressão linear múltiplos e valores de glicemia e insulinemia de jejum e HOMA R. População adulta de nipo-brasileiros. Bauru, 2000 ( $n=1.054)$.

Cereais/pães/massas $(\mathrm{g})$
Leguminosas $(\mathrm{g})^{*}$
Vegetais $(\mathrm{g})$
Frutas e sucos de frutas $(\mathrm{g})$
Frutas cítricas $(\mathrm{g})$
Miso-shiru $(\mathrm{g})^{*}$
Laticínios integrais $(\mathrm{g})$
Carnes $(\mathrm{g})^{*}$
Óleos e frituras $(\mathrm{g})$
Doces $(\mathrm{g})^{*}$

Glicemia jejum (mg/dl)* Insulina jejum (um/L)*2

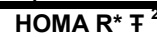

\begin{tabular}{rrr}
$-0,0000080(-0,000064 ; 0,000048)$ & $-0,0002491(-0,000549 ; 0,000051)$ & $-0,0002627(-0,000580 ; 0,000055)$ \\
$0,0011890(-0,006049 ; 0,008427)$ & $-0,0070190(-0,041208 ; 0,027170)$ & $-0,0048622(-0,041057 ; 0,031333)$ \\
$-0,0000577(-0,000162 ; 0,000046)$ & $0,0002167(-0,000271 ; 0,000704)$ & $0,0001656(-0,000351 ; 0,000682)$ \\
$0,0000137(-0,000031 ; 0,000059)$ & $0,0001292(-0,000089 ; 0,000347)$ & $0,0001380(-0,000093 ; 0,000369)$ \\
$0,0000266(-0,000019 ; 0,000073)$ & $0,0001292(-0,000089 ; 0,000347)$ & $0,0000123(-0,000222 ; 0,000247)$ \\
$-0,0009934(-0,005832 ; 0,003846)$ & $0,0021138(-0,020747 ; 0,024975)$ & $0,0018706(-0,022331 ; 0,026072)$ \\
$-\mathbf{0 , 0 0 0 1 0 7 5}(-0,000183 ;-0,000032)$ & $0,0001154(-0,000242 ; 0,000472)$ & $0,0000078(-0,000370 ; 0,000386)$ \\
$0,0133554(-0,001935 ; 0,028646)$ & $0,0053545(-0,060740 ; 0,071449)$ & $-0,0187237(-0,094206 ; 0,056758)$ \\
$-0,0000457(-0,000724 ; 0,000632)$ & $0,0016615(-0,001957 ; 0,005280)$ & $0,0014816(-0,002350 ; 0,005313)$ \\
$-\mathbf{0 , 0 1 2 3 5 5 6 ( - 0 , 0 2 0 0 2 3 ; - 0 , 0 0 4 6 8 9 )}$ & $0,0098191(-0,026625 ; 0,046263)$ & $-0,0031239(-0,041709 ; 0,035461)$ \\
\hline
\end{tabular}

* Variáveis que sofreram transformação logarítmica

${ }^{1}$ Ajuste múltiplo por sexo (feminino ou masculino), idade (anos), geração (1 ${ }^{\mathrm{a}}$ ou $2^{\mathrm{a}}$ geração), escolaridade (não freqüentou a escola, até $1^{\circ} \mathrm{grau},>=2^{\circ} \mathrm{grau}$ ), presença de $\mathrm{HA}$ e/ou dislipidemia), tabagismo (sim/não), consumo habitual de álcool (sim/não), atividade física de lazer ( $\operatorname{sim} /$ não), circunferência de cintura $(\mathrm{cm})$ e consumo de fibras totais ( $\mathrm{g} / \mathrm{dia})$, colesterol dietético (mg/dia) e VCT (kcal/dia). Os nutrientes/alimentos foram ajustados pelas calorias totais pelo método residual.

2 Ajuste múltiplo semelhante ao modelo 1 substituindo o colesterol dietético por gordura total da dieta (g/dia).

$\mp$ HOMA R = glicemia jejum $(\mathrm{mmol} / \mathrm{L}) \mathrm{x}$ insulina de jejum $(\mathrm{mU} / \mathrm{L}) / 22,5$.

Tabela 18 - Coeficientes de regressão ß1 (IC 95\%) entre o consumo diário de grupos de alimentos em modelos de regressão linear múltiplos e valores de glicemia e insulinemia de jejum e HOMA R. População adulta feminina de nipo-brasileiros. Bauru, 2000 $(n=579)$.

\begin{tabular}{|c|c|c|c|}
\hline & Glicemia jejum $(\mathrm{mg} / \mathrm{dl})^{\star 1}$ & Insulina jejum (um/L) $)^{* 2}$ & $\mathrm{HOMA} \mathrm{R}^{*} \mp^{2}$ \\
\hline Cereais/pães/massas (g) & $0,0000429(-0,000032 ; 0,000118)$ & $-0,0001800(-0,000640 ; 0,000280)$ & $-0,0001170(-0,000602 ; 0,000368)$ \\
\hline Leguminosas $(\mathrm{g})^{\star}$ & $0,0032888(-0,006416 ; 0,012994)$ & $-0,0236498(-0,071459 ; 0,024159)$ & $-0,0179635(-0,068318 ; 0,032391)$ \\
\hline Vegetais (g) & $-0,0000197(-0,000163 ; 0,000123)$ & $-0,0000394(-0,000741 ; 0,000662)$ & $-0,0000382(-0,000777 ; 0,000700)$ \\
\hline Frutas e sucos de frutas $(\mathrm{g})$ & $0,0000075(-0,000060 ; 0,000075)$ & $-0,0001919(-0,000532 ; 0,000148)$ & $-0,0001946(-0,000553 ; 0,000164)$ \\
\hline Frutas cítricas (g) & $0,0000187(-0,000047 ; 0,000085)$ & $-0,0003399(-0,000673 ;-0,000007)$ & $-0,0003355(-0,000686 ; 0,000015)$ \\
\hline Miso-shiru $(\mathrm{g})^{*}$ & $0,0001091(-0,006362 ; 0,006580)$ & $-0,0065939(-0,038629 ; 0,025441)$ & $-0,0058150(-0,039544 ; 0,027914)$ \\
\hline Laticínios integrais (g) & $-0,0000917(-0,000191 ; 0,000007)$ & $-0,0001983(-0,000688 ; 0,000291)$ & $-0,0002877(-0,000803 ; 0,000228)$ \\
\hline Carnes $(g)^{*}$ & $0,0087895(-0,009646 ; 0,027225)$ & $0,0550880(-0,032969 ; 0,143145)$ & $0,0039953(-0,089933 ; 0,097923)$ \\
\hline Óleos e frituras $(\mathrm{g})$ & $0,0001110(-0,000819 ; 0,001041)$ & $0,0004117(-0,004938 ; 0,005761)$ & $0,0003180(-0,005314 ; 0,005950)$ \\
\hline Doces $(g)^{*}$ & $-0,0143326(-0,024303 ;-0,004362)$ & $-0,0078083(-0,057555 ; 0,041938)$ & $-0,0239213(-0,076262 ; 0,028419)$ \\
\hline
\end{tabular}

Tabela 19 - Coeficientes de regressão ß1 (IC 95\%) entre o consumo diário de grupos de alimentos em modelos de regressão linear múltiplos e valores de glicemia e insulinemia de jejum e HOMA R. População adulta masculina de nipo-brasileiros. Bauru, 2000 $(n=475)$.

\begin{tabular}{|c|c|c|c|}
\hline & Glicemia jejum (mg/dl) ${ }^{\star}$ & Insulina jejum (um/L)* ${ }^{* 2}$ & HOMA R* $^{*} \mp^{2}$ \\
\hline Cereais/pães/massas (g) & $-0,0000676(-0,000152 ; 0,000017)$ & $-0,0002967(-0,000711 ; 0,000118)$ & $-0,0003846(-0,000826 ; 0,000057)$ \\
\hline Leguminosas $(\mathrm{g})^{*}$ & $-0,0009601(-0,011877 ; 0,009957)$ & $0,0100080(-0,039312 ; 0,059328)$ & $0,0084178(-0,044161 ; 0,060997)$ \\
\hline Vegetais $(\mathrm{g})$ & $-0,0000953(-0,000250 ; 0,000059)$ & $0,0004179(-0,000271 ; 0,001107)$ & $0,0003243(-0,000411 ; 0,001060)$ \\
\hline Frutas e sucos de frutas $(\mathrm{g})$ & $0,0000084(-0,000053 ; 0,000070)$ & $0,0003296(0,000045 ; 0,000614)$ & $0,0003360(0,000032 ; 0,000640)$ \\
\hline Frutas cítricas $(\mathrm{g})$ & $0,0000269(-0,000038 ; 0,000091)$ & $0,0002377(-0,000058 ; 0,000534)$ & $0,0002596(-0,000056 ; 0,000575)$ \\
\hline Miso-shiru $(\mathrm{g})^{*}$ & $-0,0013109(-0,008598 ; 0,005976)$ & $0,0144195(-0,018320 ; 0,047159)$ & $0,0139416(-0,020965 ; 0,048848)$ \\
\hline Laticínios integrais $(\mathrm{g})$ & $-0,0001369(-0,000255 ;-0,000018)$ & $0,0005533(0,000018 ; 0,001089)$ & $0,0004211(-0,000151 ; 0,000993)$ \\
\hline Carnes $(\mathrm{g})^{*}$ & $0,0202997(-0,007426 ; 0,048026)$ & $-0,0899612(-0,213793 ; 0,033871)$ & $-0,0700287(-0,202178 ; 0,062120)$ \\
\hline Óleos e frituras $(\mathrm{g})$ & $-0,0002257(-0,001223 ; 0,000772)$ & $0,0029179(-0,002114 ; 0,007950)$ & $0,0026160(-0,002751 ; 0,007983)$ \\
\hline Doces $(g)^{*}$ & $-0,0055952(-0,017923 ; 0,006733)$ & $0,0346540(-0,021112 ; 0,090420)$ & $0,0292643(-0,030221 ; 0,088750)$ \\
\hline
\end{tabular}

* Variáveis que sofreram transformação logarítmica

${ }^{1}$ Ajuste múltiplo por idade (anos), geração ( $1^{\mathrm{a}}$ ou $2^{\mathrm{a}}$ geração), escolaridade (não freqüentou a escola, até $1^{\circ} \mathrm{grau},>=2^{\circ} \mathrm{grau}$ ), presença de HA e/ou dislipidemia), tabagismo (sim/não), consumo habitual de álcool (sim/não), atividade física de lazer (sim/não), circunferência de cintura $(\mathrm{cm})$ e consumo de fibras totais (g/dia), colesterol dietético (mg/dia) e VCT (kcal/dia). O consumo dos alimentos foi ajustado pelas calorias totais pelo método residual.

2 Ajuste múltiplo semelhante ao modelo 1 substituindo o colesterol dietético por gordura total da dieta (g/dia).

$\mp$ HOMA R = glicemia jejum $(\mathrm{mmol} / \mathrm{L}) \mathrm{x}$ insulina de jejum $(\mathrm{mU} / \mathrm{L}) / 22,5$. 
Nos modelos múltiplos com a insulinemia de jejum e HOMA R não houve associações estatisticamente significantes com o consumo alimentar na população total. Em análises estratificadas por sexo, observou-se associação inversa entre o consumo de frutas cítricas e insulina de jejum em mulheres. Por outro lado, nos homens associações positivas entre o consumo dos grupos de frutas/sucos, laticínios integrais e insulina de jejum, assim como associação positiva entre o consumo de frutas/sucos e HOMA foram verificadas. Estes dados sugerem que o padrão de consumo alimentar e sua relação com desfechos metabólicos diferem segundo sexo em nipobrasileiros.

Em nossa população de estudo, as principais fontes alimentares do IG da dieta habitual foram os cereais, compostos principalmente pelo arroz polido e pão branco do tipo "francês". As medianas de consumo dos grupos de doces, frutas e cereais nos tercis de IG da dieta habitual são mostradas na Figura 3. A Figura 4 apresenta as medianas de consumo dos grupos de doces, frutas e cereais nos tercis de CG da dieta habitual. 
Figura 3 - Mediana de consumo de alimentos segundo tercil de índice glicêmico da dieta em nipo-brasileiros. Bauru, 2000.

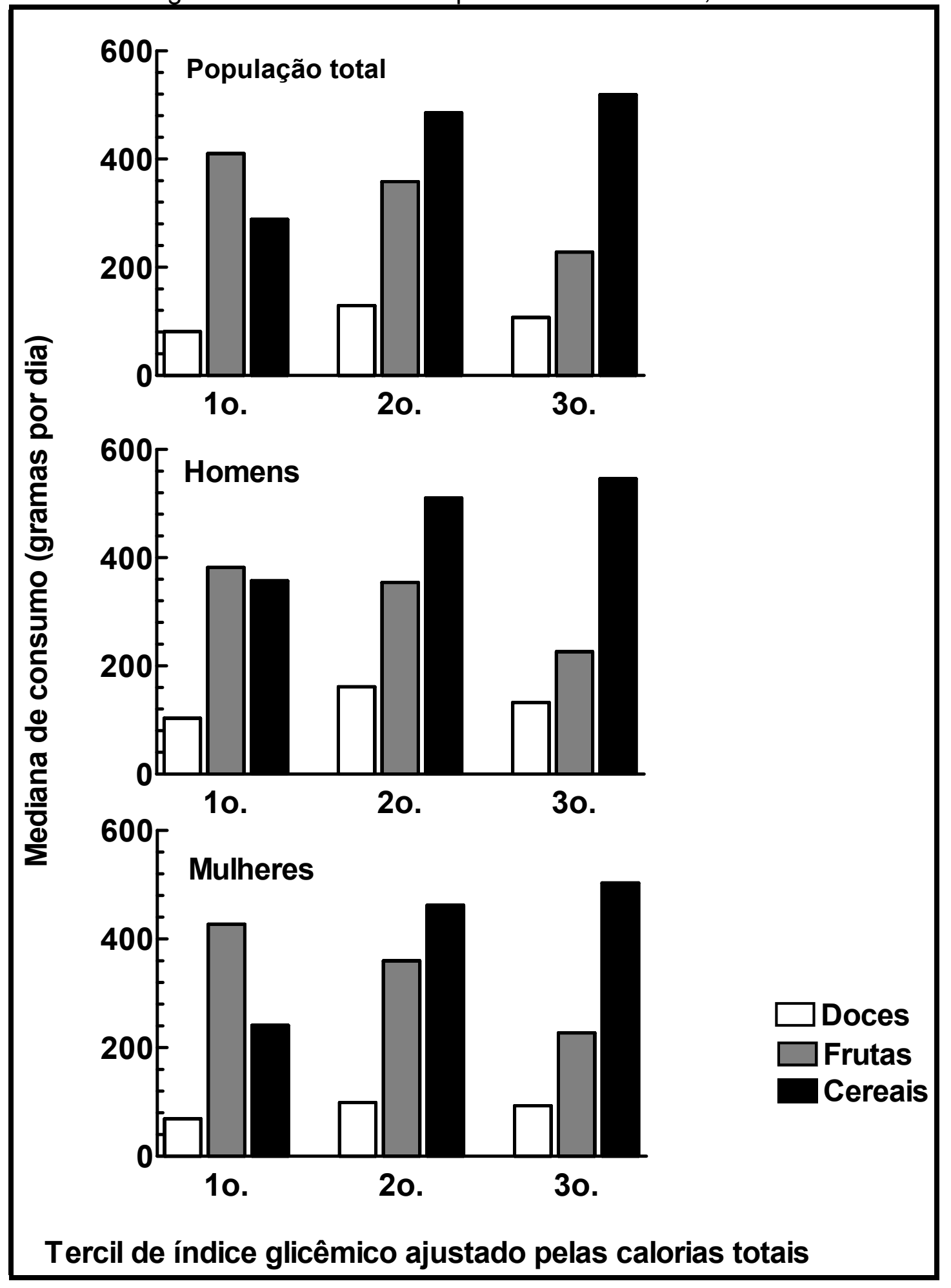


Figura 4 - Mediana de consumo de alimentos segundo tercil de carga glicêmica da dieta em nipo-brasileiros. Bauru, 2000.

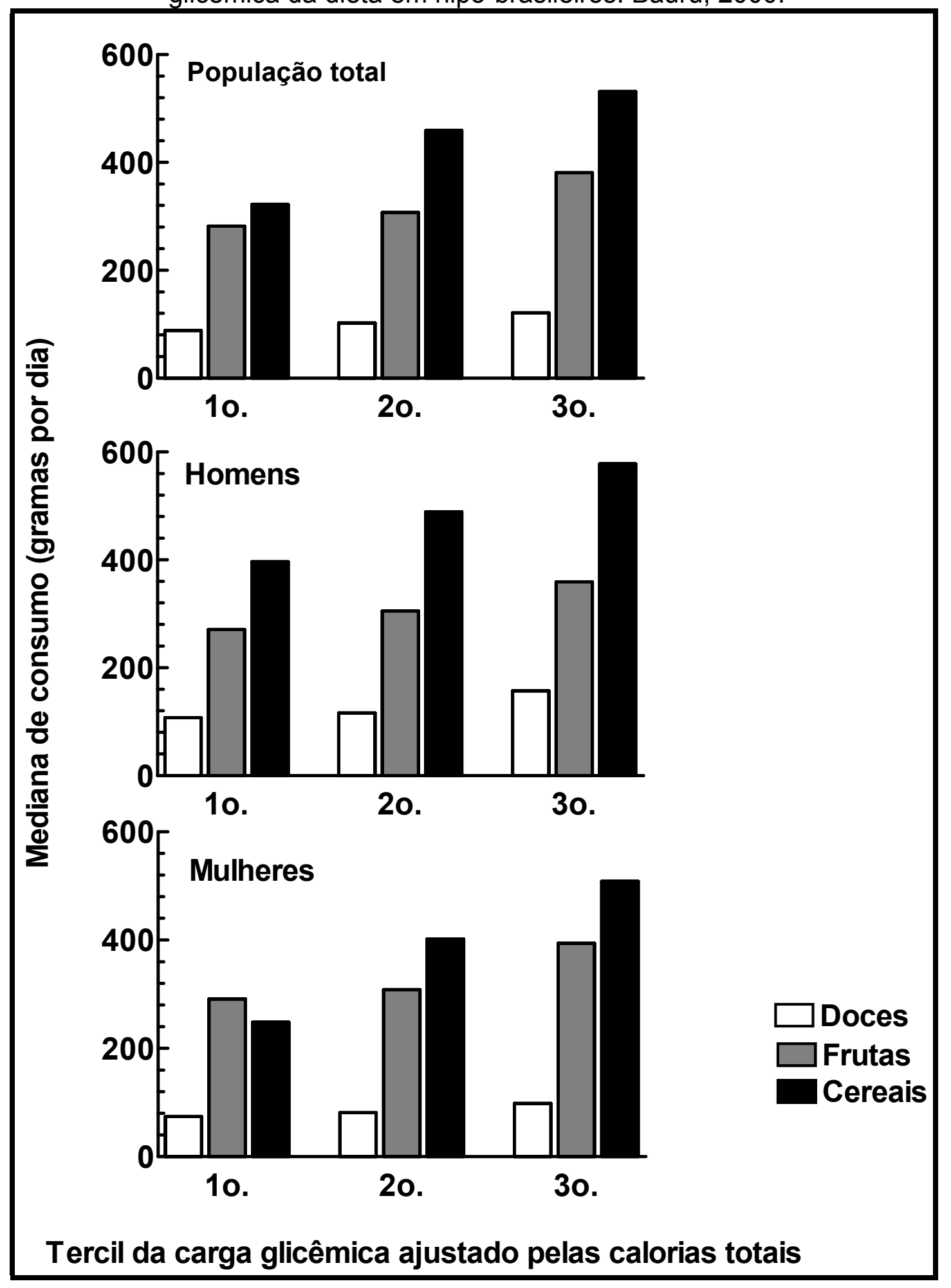




\subsection{Associação entre IG, CG, dieta habitual e homeostase glicêmica}

A Tabela 20 apresenta os valores brutos da RC para co-variáveis não dietéticas incluídas nos modelos de regressão logística em relação às categorias de AHG. Observou-se que a presença de co-morbidades (HA e/ou dislipidemia) e ser do sexo masculino foram fatores de risco para a AHG. O hábito de fumar (atual ou passado) representou fator de risco para GJA. Além disso, a presença de obesidade abdominal e envelhecimento foram associados ao risco de TGD e DM.

Tabela 20 - Razão de chances bruta (IC 95\%) para co-variáveis segundo categorias de alteração de homeostase glicêmica em nipobrasileiros (AHG). Bauru, 2000.

\begin{tabular}{|c|c|c|c|}
\hline & \multicolumn{3}{|c|}{ RC (IC 95\%) segundo categorias de AHG* } \\
\hline & GJA & TGD & DM \\
\hline & \multicolumn{3}{|c|}{ Sexo } \\
\hline Masculino & 1,00 & 1,00 & 1,00 \\
\hline Feminino & $0,41(0,29-0,59)$ & $0,60(0,42-0,85)$ & $0,42(0,29-0,60)$ \\
\hline \multicolumn{4}{|l|}{ Geração } \\
\hline $1^{a}$ & 1,00 & 1,00 & 1,00 \\
\hline $2^{a}$ & $1,15(0,72-1,83)$ & $0,88(0,57-1,35)$ & $1,26(0,79-2,01)$ \\
\hline \multicolumn{4}{|l|}{ Faixa etária } \\
\hline $30-44$ anos & 1,00 & 1,00 & 1,00 \\
\hline $45-59$ anos & $1,46(0,95-2,45)$ & $3,27(2,03-5,28)$ & $3,30(2,03-5,37)$ \\
\hline$\geq 60$ anos & $1,46(0,93-2,28)$ & $4,05(2,50-6,57)$ & $4,10(2,51-6,71)$ \\
\hline \multicolumn{4}{|l|}{ Escolaridade } \\
\hline não freqüentou a escola & 1,00 & 1,00 & 1,00 \\
\hline até $1^{\circ}$ grau completo & $1,25(0,65-2,38)$ & $1,18(0,66-2,13)$ & $1,18(0,66-2,13)$ \\
\hline$\geq 2^{\circ} \mathrm{grau}$ & $1,13(0,60-2,13)$ & $0,70(0,39-1,25)$ & $0,66(0,37-1,19)$ \\
\hline \multicolumn{4}{|c|}{ Presença de co-morbidades** } \\
\hline Não & 1,00 & 1,00 & 1,00 \\
\hline Sim & $2,32(1,39-3,89)$ & $3,39(1,97-5,83)$ & $5,51(2,88-10,57)$ \\
\hline \multicolumn{4}{|l|}{ Tabagismo } \\
\hline Não & 1,00 & 1,00 & 1,00 \\
\hline Sim & $1,78(1,21-2,60)$ & $1,13(0,77-1,66)$ & $1,17(0,79-1,28)$ \\
\hline \multicolumn{4}{|l|}{ Obesidade abdominal $^{* * *}$} \\
\hline Não & 1,00 & 1,00 & 1,00 \\
\hline Sim & $1,37(0,92-2,03)$ & $3,08(2,13-4,15)$ & $5,24(3,59-7,62)$ \\
\hline \multicolumn{4}{|c|}{ Pratica atividade física de lazer } \\
\hline Não & 1,00 & 1,00 & 1,00 \\
\hline Sim & $0,99(0,62-1,58)$ & $1,12(0,72-1,74)$ & $0,84(0,53-1,34)$ \\
\hline \multicolumn{4}{|l|}{ Consumo habitual de álcool } \\
\hline Não & 1,00 & 1,00 & 1,00 \\
\hline Sim & $1,13(0,79-1,61)$ & $1,19(0,84-1,66)$ & $0,97(0,77-1,53)$ \\
\hline
\end{tabular}

Os valores da RC segundo tercis de consumo de IG, CG, nutrientes e grupos de alimentos selecionados da dieta habitual ajustados pelas calorias totais estão apresentados nas Tabelas 21 e 22. Após ajuste múltiplo, 
observou-se maior RC para GJA entre os indivíduos do $2^{\circ}$ e $3^{\circ}$ tercis de consumo de fibras totais, cujo efeito de dose-resposta foi estatisticamente significante. Entretanto, após a inclusão do consumo diário de frutas no modelo, este efeito foi mantido apenas no tercil intermediário de fibras [1,79 $(1,09-2,91)] \mathrm{com} G J A$, sem efeito de dose-resposta $(p$ de tendência $=$ 0,62 ). Avaliando-se o consumo agrupado de cereais e frutas, observamos um elevado risco para GJA no tercil superior de consumo $1,99(1,11-3,57)$ com efeito dose-resposta significante $(p=0,03)$, além disso apenas o tercil intermediário de fibras manteve-se significante 1,59 $(1,00-2,5)$ e sem efeito dose-resposta $(p=0,27)$. Quando considerado nas análises o efeito conjunto de consumo de cereais, frutas e leguminosas, o tercil intermediário de consumo deste grupo foi risco para GJA 1,82 (1,01 - 3,30), com valor de $p$ de tendência de $p=0,059$, e o efeito da fibra com GJA não se manteve significante $1,31(0,76-2,26)$, sugerindo que o efeito observado para $\circ$ consumo de fibras em relação à GJA possa ser atribuído ao consumo de arroz, feijão e frutas. O tercil intermediário do consumo de doces foi um fator protetor para GJA, sem evidências de efeito dose-resposta. As principais fontes alimentares de fibra total da dieta na população estudada foram os grupos de frutas e cereais representados principalmente pelo consumo de arroz polido e pão branco, cujos valores brutos medianos de consumo segundo tercil de fibras, conforme categoria de homeostase glicêmica são mostrados na Figura 5. Apesar do elevado consumo de cereais, o principal contribuinte no incremento do consumo de fibra em cada tercil foi o grupo de frutas e sucos em todas as condições metabólicas avaliadas. No tercil superior de fibra, o consumo mediano de frutas foi de aproximadamente $500 \mathrm{~g} /$ dia, com valor máximo de consumo diário de $1400 \mathrm{~g}$ de frutas. 
Tabela 21 - Razão de chances (IC 95\%) para alteração de homeostase glicêmica (AHG) entre tercis de índice glicêmico, carga glicêmica e nutientes da dieta habitual em nipo-brasileiros. Bauru, 2000.

\begin{tabular}{|c|c|c|c|c|}
\hline \multirow[b]{2}{*}{ Variáveis Independentes** } & \multirow[b]{2}{*}{ Mediana de consumo } & \multicolumn{3}{|c|}{$\begin{array}{c}\text { Variáveis dependentes } \\
\text { RC (IC } 95 \%) \text { segundo categorias de } \text { AHG }^{*}\end{array}$} \\
\hline & & GJA & TGD & DM \\
\hline \multicolumn{5}{|l|}{ Índice glicêmico } \\
\hline $1^{\circ}$ tercil & 80,1 & 1,00 & 1,00 & 1,00 \\
\hline $2^{\circ}$ tercil & 86,2 & $1,26(0,79-2,01)$ & $0,97(0,61-1,53)$ & $0,97(0,59-1,61)$ \\
\hline $3^{\circ}$ tercil & 92,3 & $1,34(0,83-2,16)$ & $1,14(0,71-1,82)$ & $0,96(0,57-1,61)$ \\
\hline $\mathrm{p}$ de tendência & & 0,24 & 0,61 & 0,94 \\
\hline \multicolumn{5}{|l|}{ Carga glicêmica } \\
\hline $1^{\circ}$ tercil & 181,0 & 1,00 & 1,00 & 1,00 \\
\hline $2^{\circ}$ tercil & 216,8 & $1,17(0,74-1,87)$ & $1,11(0,70-1,75)$ & $1,14(0,68-1,92)$ \\
\hline $3^{\circ}$ tercil & 269,8 & $1,33(0,80-2,22)$ & $1,06(0,64-1,74)$ & $1,38(0,81-2,36)$ \\
\hline$p$ de tendência & & 0,27 & 0,81 & 0,20 \\
\hline \multicolumn{5}{|l|}{ Carboidratos (g) } \\
\hline $1^{\circ}$ tercil & 221,8 & 1,00 & 1,00 & 1,00 \\
\hline $2^{\circ}$ tercil & 243,2 & $1,35(0,85-2,15)$ & $1,40(0,88-2,23)$ & $1,47(0,88-2,47)$ \\
\hline $3^{\circ}$ tercil & 310,7 & $1,17(0,69-1,98)$ & $1,11(0,66-1,87)$ & $1,59(0,93-2,79)$ \\
\hline$p$ de tendência & & 0,54 & 0,61 & 0,07 \\
\hline \multicolumn{5}{|l|}{ Fibra total $(\mathrm{g})$} \\
\hline $1^{\circ}$ tercil & 11,8 & 1,00 & 1,00 & 1,00 \\
\hline $2^{\circ}$ tercil & 15,5 & $1,71(1,09-2,69)$ & $1,16(0,74-1,83)$ & $1,42(0,86-2,33)$ \\
\hline $3^{\circ}$ tercil & 22,6 & $1,70(1,06-2,74)$ & $1,49(0,94-2,38)$ & $1,39(0,83-2,32)$ \\
\hline$p$ de tendência & & 0,024 & 0,08 & 0,24 \\
\hline \multicolumn{5}{|l|}{ Fibra de cereais $(\mathrm{g})$} \\
\hline $1^{\circ}$ tercil & 2,12 & 1,00 & 1,00 & 1,00 \\
\hline $2^{\circ}$ tercil & 2,97 & $0,75(0,47-1,19)$ & $0,99(0,62-1,59)$ & $0,82(0,49-1,36)$ \\
\hline $3^{\circ}$ tercil & 4,52 & $1,05(0,65-1,67)$ & $1,38(0,86-2,21)$ & $1,34(0,79-2,25)$ \\
\hline$p$ de tendência & & 0,80 & 0,17 & 0,24 \\
\hline \multicolumn{5}{|l|}{ Fibra de leguminosas $(\mathrm{g})^{* \star *}$} \\
\hline $1^{\circ}$ tercil & 0,05 & 1,00 & 1,00 & 1,00 \\
\hline $2^{\circ}$ tercil & 0,15 & $1,21(0,77-1,93)$ & $0,78(0,50-1,22)$ & $0,89(0,53-1,50)$ \\
\hline $3^{\circ}$ tercil & 0,39 & $1,28(0,80-2,06)$ & $0,86(0,54-1,35)$ & $0,90(0,55-1,48)$ \\
\hline $\mathrm{p}$ de tendência & & 0,31 & 0,49 & 0,65 \\
\hline \multicolumn{5}{|l|}{ Fibra de frutas e vegetais $(\mathrm{g})$} \\
\hline $1^{\circ}$ tercil & 4,59 & 1,00 & 1,00 & 1,00 \\
\hline $2^{\circ}$ tercil & 7,76 & $0,79(0,48-1,31)$ & $0,70(0,41-1,19)$ & $0,67(0,38-1,18)$ \\
\hline $3^{\circ}$ tercil & 13,68 & $0,86(0,45-1,65)$ & $0,92(0,47-1,78)$ & $0,77(0,38-1,58)$ \\
\hline$p$ de tendência & & 0,63 & 0,79 & 0,55 \\
\hline \multicolumn{5}{|l|}{ Gordura total (g) } \\
\hline $1^{\circ}$ tercil & 58,8 & 1,00 & 1,00 & 1,00 \\
\hline $2^{\circ}$ tercil & 66,4 & $1,26(0,77-2,05)$ & $1,49(0,92-2,43)$ & $1,00(0,60-1,69)$ \\
\hline $3^{\circ}$ tercil & 85,7 & $1,01(0,61-1,69)$ & $1,32(0,81-2,16)$ & $0,77(0,46-1,30)$ \\
\hline$p$ de tendência & & 0,97 & 0,33 & 0,31 \\
\hline \multicolumn{5}{|l|}{ Gordura saturada (g) } \\
\hline $1^{\circ}$ tercil & 12,9 & 1,00 & 1,00 & 1,00 \\
\hline $2^{\circ}$ tercil & 15,3 & $0,97(0,59-1,60)$ & $1,09(0,67-1,79)$ & $0,59(0,35-1,01)$ \\
\hline $3^{\circ}$ tercil & 21,6 & $0,91(0,52-1,60)$ & $1,26(0,73-2,15)$ & $0,48(0,27-0,88)$ \\
\hline$p$ de tendência & & 0,72 & 0,40 & 0,016 \\
\hline \multicolumn{5}{|l|}{ Colesterol dietético $(\mathrm{mg})$} \\
\hline $1^{\circ}$ tercil & 117,7 & 1,00 & 1,00 & 1,00 \\
\hline $2^{\circ}$ tercil & 160,3 & $1,22(0,77-1,93)$ & $1,05(0,67-1,66)$ & $0,87(0,52-1,45)$ \\
\hline $3^{\circ}$ tercil & 243,9 & $1,21(0,75-1,94)$ & $1,29(0,81-2,04)$ & $1,22(0,74-2,03)$ \\
\hline$p$ de tendência & & 0,39 & 0,29 & 0,39 \\
\hline
\end{tabular}


Tabela 22 - Razão de chances (IC 95\%) para alteração de homeostase glicêmica (AHG) entre tercis de consumo habitual de grupos de alimentos em nipo-brasileiros. Bauru, 2000.

\begin{tabular}{|c|c|c|c|c|}
\hline \multirow[b]{3}{*}{ Variáveis Independentes $* *$} & \multirow[b]{3}{*}{ Mediana de consumo } & \multicolumn{3}{|c|}{ Variáveis dependentes } \\
\hline & & \multicolumn{3}{|c|}{ RC (IC 95\%) segundo categorias de $\mathrm{AHG}^{*}$} \\
\hline & & GJA & TGD & DM \\
\hline \multicolumn{5}{|l|}{ Frutas e suco de frutas (g/dia) } \\
\hline $1^{\circ}$ tercil & 131,5 & 1,00 & 1,00 & 1,00 \\
\hline $2^{\circ}$ tercil & 306,3 & $0,87(0,53-1,41)$ & $0,98(0,59-1,62)$ & $0,90(0,53-1,54)$ \\
\hline $3^{\circ}$ tercil & 576,2 & $1,02(0,56-1,86)$ & $1,31(0,72-2,39)$ & $1,34(0,69-2,59)$ \\
\hline$p$ de tendência & & 0,96 & 0,38 & 0,34 \\
\hline \multicolumn{5}{|l|}{ Frutas cítricas (g/dia) } \\
\hline $1^{\circ}$ tercil & 47,1 & 1,00 & 1,00 & 1,00 \\
\hline $2^{\circ}$ tercil & 175,0 & $0,29(0,49-1,26)$ & $0,78(0,48-1,25)$ & $0,83(0,48-1,44)$ \\
\hline $3^{\circ}$ tercil & 371,0 & $0,91(0,53-1,55)$ & $0,87(0,50-1,51)$ & $1,34(0,74-2,44)$ \\
\hline$p$ de tendência & & 0,64 & 0,61 & 0,24 \\
\hline \multicolumn{5}{|l|}{ Vegetais (g/dia) } \\
\hline $1^{\circ}$ tercil & 115,6 & 1,00 & 1,00 & 1,00 \\
\hline $2^{\circ}$ tercil & 180,1 & $0,95(0,59-1,51)$ & $0,61(0,38-0,98)$ & $0,62(0,37-1,02)$ \\
\hline $3^{\circ}$ tercil & 260,0 & $1,28(0,79-2,08)$ & $1,30(0,80-2,10)$ & $0,85(0,51-1,44)$ \\
\hline p de tendência & & 0,34 & 0,22 & 0,49 \\
\hline \multicolumn{5}{|l|}{ Cereais/pães/massas (g/dia) } \\
\hline $1^{\circ}$ tercil & 265,4 & 1,00 & 1,00 & 1,00 \\
\hline $2^{\circ}$ tercil & 474,5 & $1,24(0,78-1,96)$ & $1,02(0,65-1,61)$ & $1,02(0,62-1,68)$ \\
\hline $3^{\circ}$ tercil & 551,3 & $1,52(0,94-2,46)$ & $1,45(0,91-2,32)$ & $1,54(0,92-2,58)$ \\
\hline$p$ de tendência & & 0,07 & 0,13 & 0,08 \\
\hline \multicolumn{5}{|l|}{ Doces (g/dia) } \\
\hline $1^{\circ}$ tercil & 37,5 & 1,00 & 1,00 & 1,00 \\
\hline $2^{\circ}$ tercil & 102,4 & $0,58(0,36-0,93)$ & $0,69(0,43-1,09)$ & $0,58(0,35-0,96)$ \\
\hline $3^{\circ}$ tercil & 259,6 & $0,82(0,51-1,32)$ & $0,71(0,43-1,15)$ & $0,68(0,40-1,15)$ \\
\hline $\mathrm{p}$ de tendência & & 0,52 & 0,17 & 0,15 \\
\hline \multicolumn{5}{|l|}{ Leguminosas (g/dia) } \\
\hline $1^{\circ}$ tercil & 2,0 & 1,00 & 1,00 & 1,00 \\
\hline $2^{\circ}$ tercil & 7,1 & $1,38(0,86-2,22)$ & $1,48(0,93-2,35)$ & $1,31(0,79-2,17)$ \\
\hline $3^{\circ}$ tercil & 17,6 & $1,29(0,82-2,06)$ & $1,25(0,78-2,00)$ & $0,91(0,55-1,51)$ \\
\hline p de tendência & & 0,27 & 0,35 & 0,74 \\
\hline \multicolumn{5}{|l|}{ Laticínios integrais (g/dia) } \\
\hline $1^{\circ}$ tercil & 4,3 & 1,00 & 1,00 & 1,00 \\
\hline $2^{\circ}$ tercil & 57,1 & $1,06(0,65-1,73)$ & $0,91(0,56-1,47)$ & $0,84(0,51-1,40)$ \\
\hline $3^{\circ}$ tercil & 200,0 & $0,96(0,61-1,54)$ & $0,94(0,59-1,49)$ & $0,59(0,35-1,00)$ \\
\hline $\mathrm{p}$ de tendência & & 0,81 & 0,81 & 0,04 \\
\hline
\end{tabular}

Figura 5 - Mediana de consumo de alimentos segundo tercil de fibra total da dieta, segundo classificação de homeostase glicêmica. Bauru, 2000.

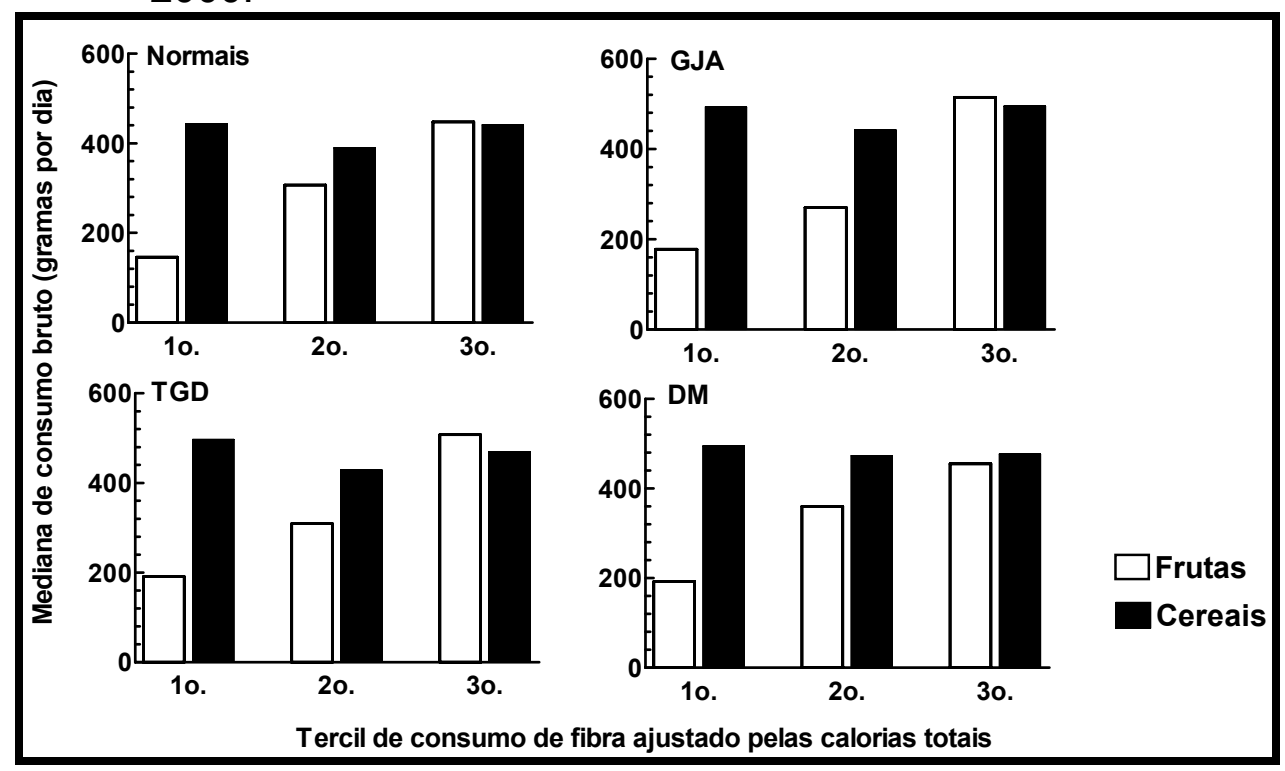


Em relação à TGD, observou-se uma relação protetora e estatisticamente significante no tercil intermediário de consumo diário do grupo de vegetais nos modelos de regressão logística múltiplo, mas esta relação não foi observada nos outros estratos de consumo, sem evidências de tendência dose-resposta. O tercil superior de consumo agrupado de frutas e cereais foi associado a risco para TGD: 2,50 (1,42-4,41), com efeito dose-resposta significante $(p=0,002)$. O consumo agrupado de cereais, leguminosas e frutas foi risco para TGD $[2,57(1,45-4,58)]$, com efeito dose-resposta $(p=0,001)$.

Em relação ao diabetes, observamos proteção entre o consumo do tercil superior de gorduras saturadas com efeito dose-reposta. Entretanto, esta associação perdeu significância estatística após ajuste por laticínios. Da mesma forma, após a substituição do colesterol total por gordura total da dieta no modelo múltiplo, os valores de RC para diabetes no tercil superior de gordura saturada perdem significância estatística. A principal fonte dietética de gorduras saturadas na população estudada foi o grupo de laticínios integrais. Entre os indivíduos portadores de diabetes, as medianas de consumo do grupo de laticínios integrais segundo tercis de gorduras saturadas ajustadas pelas calorias totais foram: 15, 75 e 112g/dia, respectivamente, sugerindo que o papel protetor do consumo de gorduras saturadas em relação ao diabetes pode ser atribuído ao consumo de laticínios, cujo efeito dose-resposta de consumo foi estatisticamente significante. Semelhante ao observado entre os indivíduos com GJA, observou-se menor valor de RC para diabetes no tercil intermediário do consumo do grupo de doces. Não foi possível avaliar o efeito do consumo conjunto de cereais, leguminosas e frutas com diabetes (teste de HosmerLemeshow $p<0,05$ ). 


\section{DISCUSSÃO}

No presente estudo investigamos os hábitos alimentares com ênfase na qualidade dos carboidratos da dieta e sua associação com distúrbios do metabolismo da glicose entre nipo-brasileiros, cuja prevalência de AHG é considerada uma das maiores do mundo. ${ }^{7}$

Semelhante ao observado entre migrantes japoneses residentes no Havaí, diferentes hábitos alimentares e estilo de vida foram relatados pelos nipo-brasileiros em relação ao padrão alimentar típico japonês, com maior predominância do consumo de frutas/sucos, cereais refinados e carnes vermelhas em detrimento do hábito de peixes, laticínios e vegetais, cujas divergências estavam relacionadas com as alterações do metabolismo da glicose investigadas, concordando com a hipótese que o grau e incorporação do estilo de vida local possa constituir em um dos fatores envolvidos na diferença do perfil antropométrico e freqüência de morbidades em populações migrantes.

Evidências científicas relacionadas ao estilo de vida característico de países em desenvolvimento, como o Brasil, e risco para DCNT são ainda escassas na literatura. O papel da qualidade dos carboidratos na determinação de AHG permanece pouco esclarecido e os dados disponíveis são inconsistentes. ${ }^{86}$

Estudos de corte transversal sobre fatores associados à ocorrência de doenças necessitam de interpretação cautelosa, já que uma limitação inerente ao desenho do estudo é a impossibilidade de identificar a relação temporal entre causa e efeito. Em nosso estudo, parte dos participantes da pesquisa em 2000 (37,4\%) foram também avaliados no inquérito de saúde e nutrição em 1993, podendo contribuir para a alteração do estilo de vida desses indivíduos. Por este motivo, um dos critérios de exclusão na presente análise foi apresentar diagnóstico prévio de GJA, TGD, DM ou uso de 
hipoglicemiantes orais e/ou insulina, analisando-se somente os casos recém-diagnosticados de $\mathrm{AHG}$.

A carência de dados sobre os teores de IG dos alimentos/preparações tipicamente nacionais, assim como a ausência de instrumentos específicos para avaliação do IG da dieta habitual é uma limitação de estudos epidemiológicos sobre a relação entre o IG da dieta e a ocorrência de doenças crônicas. No entanto, consideramos que a adaptação do teor de IG de alguns alimentos baseado em valores de outros alimentos com composição química semelhante, especialmente em relação à quantidade/qualidade dos carboidratos, fibras e lipídeos totais, permite a comparação dos nossos resultados com estudos internacionais que utilizaram a mesma fonte de dados. Em relação às limitações do QQFA para a avaliação do IG da dieta habitual, o procedimento adotado no presente estudo foi o mesmo utilizado em por estudos internacionais prévios. ${ }^{72,76,90,91}$ Apesar de sua menor exatidão em relação a outros instrumentos de avaliação do consumo alimentar, como o inquérito recordatório de 24 horas e diário alimentar, O QQFA reflete o consumo alimentar habitual dos indivíduos e permite classificar os indivíduos segundo níveis de ingestão para avaliar a associação entre dieta e risco para desfechos de interesse. Neste aspecto em particular, por ser capaz de medir variação de consumo entre indivíduos, o QQFA tem sido considerado mais adequado à estimativa de riscos. ${ }^{119}$

No presente estudo, a proporção de indivíduos considerados sedentários, acima de $80 \%$, independente da condição metabólica, foi semelhante ao observado em estudo nacional conduzido nos estados do Nordeste e Sudeste onde cerca de $87 \%$ dos adultos relataram uma prática habitual inferior a 30 minutos semanais de atividades de lazer. ${ }^{49} \mathrm{O}$ padrão sedentário de comportamento observado entre os nipo-brasileiros pode ser um dos fatores relacionados à elevada freqüência de alterações metabólicas, fundamentado em estudos prospectivos recentes. Um estudo 
conduzido na Finlândia que acompanhou 14.290 adultos observou que a prática moderada ou intensa de atividades físicas de lazer reduziu em cerca de $40 \%$ o risco de desenvolver diabetes após 12 anos de seguimento, entretanto esta relação não foi independente do $\mathrm{IMC}^{41}$ Outro estudo prospectivo conduzido em 1.728 índios Pima observou que a prática habitual de atividades físicas de lazer promoveu uma redução do risco de desenvolver diabetes em $12 \%$ entre homens e $26 \%$ em mulheres após 3 anos de seguimento, independente da idade ou IMC. ${ }^{42}$ Embora a atividade física global, relacionada ao trabalho e outras práticas cotidianas, seja mais adequada à estimativa do gasto energético total ${ }^{46} \mathrm{e}$ implicada na gênese de GJA e diabetes entre asiáticos, ${ }^{43}$ não foi possível considerá-la no presente estudo por limitações da estrutura do questionário de atividades físicas utilizado.

Os dados antropométricos da população estudada concordam com a opinião de pesquisadores sobre o impacto da obesidade abdominal no risco de $A H G$, sugerindo ser este um dos principais fatores associados à crescente incidência mundial de diabetes observada nos últimos anos. ${ }^{23}$ Os nipo-brasileiros portadores de obesidade abdominal apresentaram incremento de $300 \%$ no risco de TGD e superior a $500 \%$ para DM (dados brutos), semelhante ao apontado em estudo prospectivo conduzido entre 128 nipo-americanos, onde o RC (IC 95\%) para cada incremento de 1 DP na área de gordura intra-abdominal foi de $3,82(1,63 ; 8,94)$ na incidência de TGD após 10 anos de seguimento. ${ }^{120}$ A obesidade abdominal entre os nipobrasileiros representou um maior impacto no risco de AHG que o observado entre 290 nipo-americanos de segunda geração com incremento de 60\% no risco de incidência de diabetes entre os portadores de obesidade abdominal após 6 anos de seguimento. ${ }^{22}$ Entre nipo-americanos residentes no Havai, não houve diferenças estatisticamente significantes para os dados de peso entre as gerações, porém observou-se uma relação inversa entre o tempo de permanência no Japão anterior ao processo migratório e o peso atual entre indivíduos de primeira geração. ${ }^{96}$ 
Quando comparada à dieta tradicional japonesa, a alta densidade energética da dieta habitual observada em nossa população de estudo vem sendo apontada como um dos fatores relacionados à elevada prevalência de obesidade abdominal e síndrome metabólica. ${ }^{104} \mathrm{O}$ padrão alimentar dos nipo-brasileiros foi semelhante ao observado entre nipo-americanas residentes no Havaí, com alto consumo de frutas, cereais refinados, carnes vermelhas e baixa ingestão de peixes, vegetais e laticínios quando comparado a uma amostra de japoneses residentes do Japão. ${ }^{121}$ Além disso, houve elevado consumo dos grupos de óleos/frituras e doces, concordando com a hipótese de que o grau de incorporação do estilo de vida local, como a adoção dos hábitos alimentares, pode constituir um dos fatores desencadeantes do acúmulo de gordura corporal e no perfil de morbidade entre populações migrantes. ${ }^{58}$

Os valores medianos de IG (86 unidades/dia) e CG (227 unidades/dia) ajustados pelas calorias totais da dieta habitual dos nipo-brasileiros foram superiores ao observado entre as mulheres do Nurses' Health Study (IG=75 e CG=166 unidades/dia), ${ }^{72}$ homens do Health Professional Study (IG=73 e $C G=160$ unidades/dia), ${ }^{90}$ mulheres do lowa Women Health Study $(I G=69$, $\mathrm{CG}=120$ unidades/dia), ${ }^{91}$ indivíduos que participaram do Framingham Offspring Cohort (IG=78 e $C G=175$ unidades/dia) ${ }^{83}$ e entre mulheres japonesas $\left(\mathrm{IG}=64\right.$ e $\mathrm{CG}=150$ unidades/dia). ${ }^{81} \mathrm{Em}$ nossa população, a porcentagem de calorias provenientes dos carboidratos totais foi adequada, mas os elevados valores de IG e CG foram observados na dieta habitual provenientes do consumo de cereais predominantemente refinados. Apesar da ausência de recomendações específicas para valores no controle e prevenção de DM, recente meta-análise com ensaios clínicos aleatorizados entre indivíduos portadores de diabetes concluiu que dietas de baixo IG (média de 65 unidades/dia) resultaram em redução 7,5\% maior em hemoglobina glicada quando comparadas a dietas com elevado IG (83 unidades/dia). ${ }^{85}$ Além disso, há evidências de que uma redução de IG da dieta habitual de 70 para 60 unidades/dia promoveria uma sensível melhora 
da sensibilidade periférica à insulina em curto período de tempo, reduzindose os riscos de DCV. ${ }^{79}$

No presente estudo, as principais fontes de IG da dieta habitual foram os grupos dos doces e de cereais, composto essencialmente pelo consumo de arroz polido e pão branco. Em relação à CG da dieta habitual, as principais fontes foram os grupos de frutas/sucos e cereais (arroz polido e pães brancos essencialmente). Em estudo em mulheres japonesas, as mesmas fontes foram observadas: $76 \%$ de cereais (arroz polido e quantias moderadas de pão branco, massas e cereais integrais), 14\% de doces (açúcar e sobremesas) e $4 \%$ de frutas. ${ }^{81}$ Por outro lado, as fontes de IG da dieta habitual relatadas em estudos conduzidos em diferentes localizações geográficas são diversificadas. Em um estudo conduzido na Europa as principais fontes de IG e CG foram batata e pão branco com consumo de cereais integrais inversamente relacionado ao IG da dieta. ${ }^{122}$ No Canadá, observou-se relação inversa entre IG com o consumo de doces. ${ }^{123} \mathrm{Na}$ Alemanha, um estudo conduzido em idosos, encontrou relação inversa entre o IG da dieta e o consumo de frutas e leite e relação positiva entre o IG da dieta e consumo de cereais integrais, açúcares e doces. ${ }^{124}$ Entre as mulheres americanas do Nurses' Health Study, uma relação positiva entre a CG da dieta e o consumo de carboidratos totais, fibra total da dieta e vitamina $E$, além de relação inversa com o consumo de gorduras e proteínas foram observados, ${ }^{72}$ sugerindo a influência cultural na escolha das fontes de carboidratos consumidos e que os valores de IG da dieta não refletem a qualidade da alimentação como um todo.

A associação de risco do IG da dieta para diabetes observada em dois estudos prospectivos americanos (Nurses' Health Study I e Health Professional Study) tornou-se estatisticamente significante somente após o ajuste pelos cereais integrais, uma das principais fontes de magnésio da dieta habitual cujo consumo foi inversamente relacionado ao risco de diabetes nestes estudos. ${ }^{72,90}$ Os resultados do estudo da coorte de lowa 
sugerem ausência de associação entre o IG da dieta com incidência do diabetes após ajuste por magnésio e fibra de cereais. ${ }^{91}$ Da mesma forma, nas mulheres de lowa observou-se efeito protetor para cereais integrais e magnésio com DM. Os resultados destes estudos sugerem a hipótese que o efeito de risco do elevado consumo de IG da dieta para diabetes pode ser atribuído a um padrão alimentar pobre em magnésio usualmente observado nestas dietas. Por outro lado, na análise do Nurses' Health Study II, cuja amostra foi composta por mulheres mais jovens, a relação positiva entre IG e incidência de diabetes foi observada em modelos ajustados ou não pelo magnésio e fibra de cereais, ${ }^{89}$ enfatizando a necessidade de um maior número de estudo para a elucidação do papel do IG no risco de diabetes em diferentes faixas etárias e condição metabólica.

Nossos dados discordam com grande parte dos estudos que avaliaram a relação entre o IG e AHG. Entretanto, uma provável explicação para a redução em $40 \%$ na chance de GJA e diabetes no tercil intermediário do consumo de doces (mediana de $100 \mathrm{~g} / \mathrm{dia}$ ) quando comparado ao tercil inferior de consumo (38 g/dia), seria o viés de causalidade reversa decorrente de sub-relato do consumo de doces pelos indivíduos portadores de AHG. Na cultura popular, a redução do consumo de açúcares e sua substituição por adoçantes dietéticos são consideradas medidas eficazes tanto na prevenção como no controle do excesso de peso e diabetes. ${ }^{125}$ Embora controversa, a ausência da relação entre o consumo de açúcar com a incidência de diabetes foi reportada em estudo prospectivo prévio ${ }^{126}$ e uma redução de $30 \%$ na incidência do diabetes foi observada entre 37.000 adultos no quartil superior de consumo de açúcares (sacarose, alimentos com adição de sacarose e frutose) quando comparado com o menor aporte (mediana da população de $100 \mathrm{~g} / \mathrm{dia}$ ) após 4 anos de seguimento. ${ }^{127}$ Estes dados fundamentam a possibilidade de sub-relato ou redução do consumo de açúcar entre indivíduos portadores de fatores de risco para o diabetes. 
No presente estudo, em relação ao consumo de fibra total da dieta, observou-se que os valores medianos foram inferiores ao recomendado pelo Ministério da Saúde para a população japonesa (17-20g/dia). ${ }^{128}$ Segundo a OMS, não há uma recomendação precisa da quantidade de fibra eficaz na prevenção do DM. Entretanto, sabe-se que o consumo adequado de frutas, verduras, legumes e cereais integrais pode oferecer um aporte adequado de fibras na dieta de cerca de $20 \mathrm{~g}$ de fibras/dia. ${ }^{13,17}$ Os cereais refinados são pobres em fibras e com elevados teores de IG, possivelmente associados à hiperglicemia pós-prandial imediata, sendo desta forma desestimulados. ${ }^{17}$ Por outro lado, os benefícios de uma dieta rica em frutas e vegetais têm sido bem documentados, com recomendações internacionais para consumo diário de 400g/dia para prevenção de DCNT. ${ }^{17,129}$ Entretanto, entre os nipobrasileiros de Bauru a mediana de consumo de frutas e sucos no tercil superior de fibras foi de $500 \mathrm{~g} / \mathrm{dia}$, atingindo consumo máximo diário de 1400g/dia: 3 vezes superior ao recomendado (150 g/dia) para japoneses. ${ }^{128}$ Além disso, os valores medianos observados (320g/dia) foram 2,5 vezes maiores do que o referido por japonesas residentes no Japão e $20 \%$ superiores ao relatado em nipo-americanas residentes no Havaí, ${ }^{121}$ observando-se padrão semelhante em nipo-brasileiros residentes de São Paulo com consumo mediano de $170 \mathrm{~g} / \mathrm{dia}^{130}$ No Brasil, a maior disponibilidade e baixo custo de frutas em relação ao Japão pode ser uma explicação para o maior consumo destes alimentos. Entretanto, o consumo de verduras relatado representou cerca de $50 \%$ da quantidade diária recomendada (300g/dia) para japoneses, ${ }^{128}$ sendo 2,5 vezes inferior ao observado entre japonesas residentes no Japão (440 g/dia) e 50\% menor que a mediana consumida entre nipo-americanas residentes no Hawaii (280 g/dia). ${ }^{121}$

Em nosso estudo, a resposta metabólica promovida pelo elevado consumo de frutas/sucos divergiu segundo sexo. Em homens, associações positivas entre o consumo de frutas/sucos e insulina de jejum e HOMA R foram observadas, assim como uma associação positiva entre fibras de 
frutas/vegetais e insulinemia de jejum. Por outro lado, nas mulheres uma relação inversa entre o consumo de frutas cítricas e insulina de jejum foi verificada. Apesar da literatura sugerir que a substituição da sacarose por frutose (carboidrato naturalmente encontrado em frutas e vegetais ou artificialmente adicionado em bebidas e alimentos) possa promover menor resposta glicêmica e insulinêmica pós-prandial em indivíduos normais e portadores de diabetes com bom controle metabólico, ${ }^{131}$ um estudo de revisão concluiu que o emprego da frutose não é recomendado para indivíduos portadores de diabetes com controle metabólico precário, contribuindo para hiperglicemia. ${ }^{132}$ Desta forma, uma possível explicação para as diferentes respostas metabólicas ao consumo elevados de frutas/sucos no presente estudo pode ser relacionada à diferença de perfil metabólico entre os sexos, uma vez que os homens apresentaram maior freqüência de sobrepeso, dislipidemia, AHG e maiores médias de HOMA R e triglicérides em relação às mulheres.

A frutose também vem sendo relacionada a hipertrigliceridemia e glicosilação de proteínas. Entretanto, como este carboidrato é rapidamente convertido em glicose no fígado, este efeito seria apenas observado na condição de um consumo elevado de frutose, ${ }^{132}$ característico do padrão alimentar da população do presente estudo. Um ensaio clínico cruzado conduzido em 12 mulheres demonstrou que uma dieta isocalórica com elevados teores de frutose (30\% dos carboidratos adicionados em bebidas) resultou em uma redução significativa na glicemia, insulinemia e leptina associado ao aumento na concentração sérica de triglicérides quando comparada a uma dieta com teor elevado de glicose $(30 \%$ dos carboidratos adicionado em bebidas). Os autores sugerem o consumo de frutose como um fator de risco potencial para o ganho de peso corporal, devido ao papel atribuído à insulina e leptina no balanço energético controlado pelo sistema nervoso central. $^{133}$ 
Uma análise transversal dos dados do Nurses' Health Study demonstrou uma relação positiva entre o consumo de frutose com a concentração de peptídeo $\mathrm{C}$ plasmático, importante marcador da síntese da insulina, resistência periférica e ao risco de diabetes. ${ }^{134}$ As principais fontes de frutose da dieta foram: suco de laranja e outras frutas, maçã, bebidas com cafeína e uva-passa. Houve uma relação positiva entre o consumo de sucos de frutas e a concentração de peptídeo $C$ plasmático após ajuste por valor calórico total da dieta, consumo habitual de álcool, idade, tabagismo, IMC, prática de atividades físicas, HA e condição de menopausa, sugerindo efeitos adversos do consumo excessivo de sucos de frutas em relação ao risco de diabetes entre as mulheres. Os autores observaram que o consumo de frutose foi associado à idade e a um padrão de estilo de vida mais saudável (menor freqüência de tabagismo, consumo de álcool e prática de atividades físicas com maior freqüência), o que foi também observado em estudos prévios. ${ }^{135,136,137,138} \mathrm{Em}$ nosso estudo, é provável que o efeito do consumo de frutas também esteja relacionado ao alto teor de açúcar habitualmente adicionado pelos brasileiros nos sucos. Uma análise prospectiva das mulheres do Nurses' Health Study II em 8 anos de seguimento observou que o maior consumo de bebidas adocicadas, como sucos e refrigerantes, representou um risco para diabetes duas vezes superior [RC 2,00 (IC 95\% 1,33; 3,01)] do que o observado entre as consumidoras de 1 porção de suco/dia em relação ao consumo de 1 porção mensal. ${ }^{89} \mathrm{O}$ consumo de frutas e vegetais é apontado como um importante fator protetor no risco de DCNT e a recomendação atual da OMS é de no mínimo 5 porções diárias. Entretanto, um estudo prospectivo sobre dieta e risco de infarto demonstrou que o efeito protetor da ingestão destes alimentos é observado até o patamar de consumo de 5 porções diárias, não havendo benefícios extras em aportes superiores na ocorrência do infarto. ${ }^{136}$ Em nossa população, a freqüência diária mediana de consumo de frutas e vegetais foi de 5,5 porções, variando entre 0,7 a 16 porções/dia. $O$ consumo excessivo de frutas aliado ao elevado aporte de cereais refinados, principais fontes de fibra observadas, resultou em risco para AHG em nipo-brasileiros. 
Em outro estudo prospectivo, o consumo de frutas e vegetais entre 195.000 mulheres do Women's Health Study reduziu em $30 \%$ o risco de DCV após 5 anos de seguimento, independente da idade. Entretanto, após ajuste por fatores de risco potenciais (tabagismo, IMC, consumo de álcool, atividade física, suplementos vitamínicos e presença de HA, diabetes e dislipidemia) esta associação não se manteve significante, sugerindo que o efeito observado pode ser atribuído a um padrão mais saudável de estilo de vida entre as consumidoras de frutas e vegetais. ${ }^{138} \mathrm{~A}$ avaliação dos efeitos isolados do consumo de frutas ou de vegetais neste estudo também não foi independente dos outros fatores de risco. Resultados semelhantes foram observados em relação à incidência de diabetes entre as mulheres do Women's Health Study após 9 anos de seguimento. ${ }^{135}$ Após ajuste múltiplo por idade, VCT e tabagismo, o maior consumo dos grupos de frutas e vegetais, frutas totais, frutas cítricas, vegetais verde escuros, vegetais amarelos e grupo de leguminosas foram protetores de diabetes em relação ao consumo inferior. Entretanto, após a inclusão nos modelos de outros fatores de risco potenciais (IMC, prática de atividades físicas, consumo de álcool, HA, dislipidemia e HF de DM) estas relações não se mantiveram estatisticamente significantes, sugerindo a influência de fatores externos, como o estilo de vida, nos resultados de estudos de consumo de frutas e DCNT. Em análises estratificadas por IMC, o consumo de vegetais verdeescuros (mediana de 0,6 porções/dia), assim como os vegetais amarelos (mediana de 0,3 porções/dia), reduziram em 10 e 20\%, respectivamente, o risco de incidência de diabetes independente de outros fatores de risco entre as mulheres com IMC $\geq 25 \mathrm{~kg} / \mathrm{m}^{2}$. Resultados semelhantes sobre efeito protetor do consumo de vegetais foram observados nas coortes da Finlândia e Alemanha do Seven Countries Study, em que um incremento de 150 g/dia para $200 \mathrm{~g} / \mathrm{dia}$ no consumo de vegetais ao longo de 20 anos reduziu em cerca de $5 \%$ os valores médios de glicemia 2 horas após sobrecarga de glicose independente da idade, variação de peso e VCT da dieta, ${ }^{56}$ concordando com dados de nosso estudo com uma redução de $40 \%$ no risco de TGD entre os indivíduos com consumo intermediário (mediana de 
$180 \mathrm{~g} /$ dia) do grupo de vegetais em relação ao tercil inferior de consumo (mediana de $115 \mathrm{~g} / \mathrm{dia})$.

Estudos prospectivos internacionais que analisaram o consumo de diferentes fontes de fibra da dieta não encontraram associação entre o consumo de fibras provenientes de frutas e vegetais e incidência de DM. Nesses estudos, a principal fonte de fibra alimentar relacionada ao efeito protetor para diabetes é a fibra de cereais. ${ }^{72,90,91,92,93} \mathrm{Em}$ uma avaliação do Nurses' Health Study o consumo de fibra de cereais (mediana de 3,9 g/dia) foi protetor para DCV, mas nenhuma associação com fibras provenientes de frutas e vegetais foi detectada. ${ }^{137}$ Entre as enfermeiras participantes deste estudo os valores medianos do consumo de frutas e vegetais foram de 3,3 e $6,0 \mathrm{~g} / \mathrm{dia}$, respectivamente. Em nosso estudo, o consumo mediano total de frutas e verduras (cerca de 7,5 g/dia) foi semelhante ao observado entre as enfermeiras. Entretanto, a contribuição dos vegetais foi de apenas $30 \%$ do valor total consumido. O consumo de cereais integrais não foi habitualmente praticado em nossa população de estudo. Conforme discutido previamente, o consumo excessivo de frutas entre indivíduos com distúrbios da homeostase glicêmica pode estar associado a maior ocorrência de hiperinsulinemia e resistência à insulina, ${ }^{132}$ concordando com nossos resultados que apontaram uma relação positiva entre o consumo de fibras de frutas e vegetais e insulinemia de jejum em homens.

O efeito protetor para diabetes do consumo de fibras provenientes de cereais não foi ainda totalmente esclarecido. Sabe-se que os cereais integrais são fontes importantes de magnésio da dieta, mineral associado à proteção e controle metabólico do diabetes. ${ }^{71}$ A ausência de relação entre o consumo de fibras de cereais e ocorrência de diabetes após o ajuste por este mineral em alguns estudos ${ }^{70,72,73}$ sugere a hipótese do efeito protetor ser atribuído ao magnésio contido nestes alimentos. No entanto, exceção a este resultado foi observada em mulheres jovens do Nurses Health Study $1{ }^{89}$ e em homens do Health Professional Follow-up Study ${ }^{90}$ nos quais a relação 
protetora do consumo de cereais integrais na incidência de diabetes foi independente do magnésio da dieta habitual. Entre as mulheres da coorte de lowa nenhuma relação entre o consumo de cereais integrais e diabetes foi encontrada após o ajuste pelo magnésio da dieta. Em nossa população de estudo, o consumo de cereais integrais foi infreqüente e os dados de magnésio da dieta não foram avaliados.

No presente estudo, o consumo de cereais refinados representou uma importante fonte de fibra total da dieta. A mediana de consumo do grupo de cereais relatada (470 $\mathrm{g} / \mathrm{dia})$ foi $40 \%$ superior ao observado entre uma amostra de japonesas residentes no Japão e semelhante aos valores consumidos por nipo-americanas residentes no Havaí (440 g/dia), ${ }^{121}$ sendo também $20 \%$ superior ao limite máximo recomendado para o consumo deste grupo de alimentos para a população japonesa. ${ }^{128}$

Entre os nipo-brasileiros estudados um consumo de fibra total da dieta acima de $15 \mathrm{~g} / \mathrm{dia}$ foi associado a um incremento de cerca de 70\% na chance de ocorrência de GJA quando comparado ao consumo mediano de $12 \mathrm{~g} / \mathrm{dia}$. As principais fontes de fibra da dieta foram os grupos de cereais e frutas/sucos, cujo consumo foi superior ao recomendado para população japonesa e ao observado entre japoneses residentes no Japão. O consumo de cereais refinados, compostos por carboidratos de rápida absorção, associado ao consumo excessivo de frutose entre indivíduos com distúrbios do metabolismo da glicose justificaria um incremento no risco da ocorrência de GJA. As relações entre o consumo de cereais refinados e risco de AHG foram também observadas entre os homens do Health Professional Study e entre as mulheres do Nurses' Health Study em que o maior consumo de pão branco, arroz polido, batata frita e cozida representou um incremento no risco de diabetes. ${ }^{72,90}$ Nestes estudos, o consumo de cereais foi predominantemente proveniente de produtos ricos em fibras insolúveis e magnésio, consumidos habitualmente no desjejum da dieta americana (cereais matinais) e as principais fontes de fibra da dieta foram os cereais 
integrais e vegetais, com uma menor contribuição de frutas. Estas diferenças sugerem a relevância de se considerar os alimentos e padrões alimentares como um todo em investigações sobre fatores associados a doenças crônicas.

Um estudo prospectivo conduzido com cerca de 37.000 adultos durante 4 anos de seguimento, Melbourne Collaborative Cohort Study, observou um risco $40 \%$ maior de incidência de diabetes no quartil superior de consumo de pão branco quando comparado ao quartil inferior independente de outros fatores de risco potenciais. Apesar da ausência de informação sobre as medianas de consumo, o grupo de cereais refinados foi positivamente associado ao IG e inversamente relacionado à prática de atividades físicas, consumo de álcool, de frutas e vegetais. ${ }^{127}$

Uma análise recente dos dados do Health Professionals Follow-up Study analisou o papel dos componentes dos grãos integrais (casca, endosperma e germe) no risco de DCV após 14 anos de seguimento. Os autores sugerem que o efeito protetor do consumo de cereais integrais para DCV seja proveniente da casca dos grãos (rica em fibras, antioxidantes, micronutrientes como o magnésio e fitoquímicos), cuja redução de cerca de $28 \%$ do risco manteve-se estatisticamente significante mesmo após o ajuste pelas fibras totais, sugerindo que o efeito observado não pode ser atribuído às fibras dos cereais. Não houve relação entre o consumo de endosperma (principal componente dos cereais refinados) e o risco de DCV. Entretanto, os autores observaram que o maior consumo de cereais integrais foi relacionado a um estilo de vida mais saudável, caracterizado por menor peso corporal, prática freqüente de atividades físicas, menor proporção de fumantes e portadores de HA, dieta habitual com maiores teores de CG, frutas, verduras, peixes e menor consumo de gorduras e doces quando comparados aos indivíduos do quintil inferior de cereais integrais. ${ }^{139}$ 
Considerando o efeito do padrão alimentar dos nipo-brasileiros em relação as principais fontes de fibra da dieta, observamos um incremento de $100 \%$ no risco de GJA e de $250 \%$ para TGD no tercil superior de consumo conjunto de cereais e frutas (dados não demonstrados). O tercil superior de consumo conjunto de cereais, leguminosas e frutas representou um aumento de $82 \%$ no risco de GJA (dados não demonstrados). Estas análises elucidam a relação da qualidade e quantidade de carboidratos consumidos na gênese de AHG, sugerindo que o consumo excessivo de arroz polido, feijão e frutas entre indivíduos portadores de fatores de risco para AHG poderia favorecer o desenvolvimento dos distúrbios do metabolismo da glicose.

As evidências da relação entre o consumo de arroz e feijão provenientes de estudos epidemiológicos conduzidos no Brasil são controversas. Estudos sobre padrões alimentares definidos através da análise de componentes principais observaram um papel protetor para a obesidade do consumo da dieta "tradicional", composta por arroz polido, feijão, farinha e açúcar, com o IMC. ${ }^{140,141}$ Entretanto, este padrão predominante de consumo foi inversamente relacionado à renda $e$ escolaridade, sugerindo que o efeito protetor para o excesso de peso pode ser atribuído ao menor acesso à variedade de opções alimentares. Embora os autores discutam os benefícios do consumo de leguminosas atribuídos aos altos teores de fibras solúveis e baixo IG, os valores de IG foram estimados segundo tabelas internacionais, ${ }^{65}$ cuja forma predominantemente consumida são feijões secos com tempo reduzido de cocção. No Brasil, o preparo do feijão é realizado sob pressão com tempo de cozimento prolongado ocasionando ruptura da estrutura da casca e elevação da resposta glicêmica pós-prandial. ${ }^{74}$

Possíveis efeitos adversos do consumo de leguminosas foram apontados por um estudo transversal conduzido entre 1.045 adultos residentes em área urbana do estado de São Paulo em que o consumo de 
feijão foi inversamente relacionado ao HDL-c sérico independente da idade, sexo, IMC, obesidade abdominal, renda, escolaridade, atividade física, tabagismo, consumo de álcool e outras variáveis dietéticas. ${ }^{142}$ Embora ainda pouco compreendida, a relação entre o consumo de feijão e risco de doenças crônicas foi observado em estudos epidemiológicos prévios. Em análise prospectiva dos dados provenientes do Women's Health Study, o consumo do tercil intermediário de leguminosas (mediana de 0,3 porções/dia) foi relacionado a um incremento de $20 \%$ no risco de incidência de diabetes após 9 anos de seguimento independente da idade, tabagismo, IMC, atividade física, HF de DM, HA, dislipidemia, consumo de álcool e VCT da dieta. ${ }^{135}$ Entretanto, não houve associação em diferentes estratos de consumo. Da mesma forma, o consumo do quarto quintil de consumo de leguminosas (mediana de 0,16 porções diárias) foi relacionado a um incremento de $40 \%$ no risco de infarto agudo do miocárdio independente de outros fatores de risco potenciais em mulheres do Nurses' Health Study após 14 anos de seguimento, sem associação entre os outros estratos de consumo. $^{136} \mathrm{Em}$ outro estudo, não houve relação entre o consumo de leguminosas (mediana de 0,3 porções diárias) e incidência de diabetes entre as mulheres do lowa Women's Health Study. ${ }^{91}$ Segundo Venn \& Mann, ${ }^{71}$ estudos que avaliem o efeito do consumo de leguminosas e estrutura dos grãos no risco de diabetes são escassos e a carência de associação apontada pelos poucos estudos que investigaram seu papel pode ser atribuído ao baixo consumo deste alimento entre os americanos. ${ }^{91}$ Embora um menor consumo de leguminosas tenha sido observado entre os nipobrasileiros de nosso estudo (mediana de 0,10 porções diárias), a associação com alteração metabólica foi mais expressiva, sugerindo que a forma de preparo do feijão no Brasil possa contribuir na gênese de doenças crônicas quando consumido com grandes quantidades de arroz polido por indivíduos com perfil de risco.

Quanto ao consumo habitual de gorduras, observamos uma dieta hiperlipídica (valores medianos de $33 \%$ do VCT), com valores percentuais 
superiores ao observado por japonesas residentes no Japão (26\%) e nipoamericanas residentes no Havaí $(29,7 \%) .{ }^{121} \mathrm{O}$ teor de colesterol $(170$ $\mathrm{mg} / \mathrm{dia}$ ) foi inferior ao relatado por japonesas residentes no Japão (335 $\mathrm{mg} / \mathrm{dia}$ ) e semelhante ao observado entre nipo-americanas no Havaí (190 $\mathrm{mg} / \mathrm{dia}){ }^{121}$ Entretanto, a proporção de ácidos graxos trans observada na população do presente estudo é alarmante (> $5 \%$ do VCT) sendo 5 vezes superior ao limite máximo recomendado pela OMS ( $<1 \%$ do VCT) para a prevenção de doenças crônicas. ${ }^{17} \mathrm{Em}$ relação ao aporte de produtos cárneos na população estudada, observamos que o consumo mediano de carnes (63 g/dia) foi predominante em relação ao hábito de consumo de peixes (13 g/dia), padrão semelhante ao observado por migrantes japoneses residentes em São Paulo (68 g de carnes/dia e $22 \mathrm{~g}$ de peixes/dia) ${ }^{130}$ e entre nipo-americanas residentes no Havaí que relataram um consumo mediano de peixes de $22 \mathrm{~g} /$ dia e de carnes vermelhas de $120 \mathrm{~g} / \mathrm{dia}$ - diferença marcante dos hábitos relatados por japonesas residentes no Japão que apresentaram um consumo de pescados predominante (90 g/dia) em relação ao consumo de carnes ( $80 \mathrm{~g} / \mathrm{dia}$ ), apesar dos valores elevados de consumo deste último grupo. ${ }^{121} \mathrm{Em}$ relação aos laticínios integrais e desnatados, observamos um consumo mediano (66 g/dia) 3 vezes inferior ao recomendado para japoneses ${ }^{128}$ e cerca de 4 vezes inferior ao observado entre japonesas no Japão (210 g/dia) ou residentes no Havaí (260 g/dia): os nipo-brasileiros relataram consumo predominante de produtos lácteos integrais em detrimento dos produtos pobres em gordura. A mediana de consumo de óleos e alimentos fritos ( $25 \mathrm{~g} / \mathrm{dia})$ estava no limite máximo recomendado (10-25 g/dia) e do grupo de doces em geral (100 g/dia) foi quase duas vezes maior do que o limite máximo recomendado para população japonesa $(<60 \mathrm{~g} / \mathrm{dia}) .{ }^{128}$

No presente estudo, uma relação positiva entre o colesterol dietético e glicemia de jejum entre as mulheres foi observada. A cada acréscimo de 1 $\mathrm{mg} / \mathrm{dia}$ de colesterol dietético resultou em um aumento de $1 \mathrm{mg} / \mathrm{dl}$ na glicemia de jejum (0,0001845 log de mg/dl de glicemia). Ou seja, cada 
porção pequena extra de carne vermelha consumida $(100 \mathrm{~g} / \mathrm{dia})$ que contém em média $30 \mathrm{mg}$ de colesterol repercutiria em um incremento de cerca de 30 $\mathrm{mg} / \mathrm{dl}$ na glicemia de jejum. Por sua vez, com base em estudo anterior, o aumento de $30 \mathrm{mg} / \mathrm{dl}$ na glicemia de jejum pode representar um aumento de $58 \%$ no risco de mortalidade por todas as causas ou DCV entre os nipobrasileiros com idade inferior a 60 anos, independente do sexo, geração, escolaridade, tabagismo, IMC, circunferência de cintura, triglicérides e níveis pressóricos. ${ }^{143}$

Por outro lado, uma relação inversa entre o consumo de laticínios integrais com a glicemia de jejum foi observada na população total e em homens. A cada incremento de $100 \mathrm{~g}$ ao dia do grupo de leite e derivados (meio copo de leite ou 3 fatias médias de queijo) houve uma redução de 100 $\mathrm{mg} / \mathrm{dl}$ na glicemia de jejum. Um efeito protetor para maior consumo de leite com obesidade foi observado em estudo conduzido entre 462 adultos iranianos, sendo que o quartil superior de consumo de leite ( $>3$ porções/dia) representou uma chance $80 \%$ menor no risco de excesso de peso - IMC $\geq$ $25 \mathrm{~kg} / \mathrm{m}^{2}$ - [RC 0,78 $\left.(0,43 ; 0,92)\right]$ e obesidade - IMC $\geq 30 \mathrm{~kg} / \mathrm{m}^{2}$ - [RC 0,73 $(0,40 ; 0,83)]$ em relação ao quartil inferior de consumo $(<1,5$ porções/dia), independente da idade, atividade física, valor calórico total, carboidratos, fibras e proteínas da dieta habitual. ${ }^{144} \mathrm{Em}$ outro estudo prospectivo conduzido com 3.000 adultos observou um efeito protetor pelo maior consumo de laticínios com a incidência de síndrome metabólica entre adultos com sobrepeso após 10 anos de seguimento, sendo que a cada porção de leite consumida ao dia representou uma redução de $21 \%$ no risco da síndrome $[\operatorname{RC} 0,79(0,70 ; 0,88)]$ independente da idade, sexo, raça, tabagismo, consumo de álcool, atividade física, escolaridade, consumo calórico total, fibras e proteínas da dieta habitual. ${ }^{145}$ Além disso, entre as mulheres do Nurses' Health Study e homens do Health Professional Study foi também observado relações de proteção entre o consumo de iogurte com a incidência de diabetes. ${ }^{72,90}$ Uma das hipóteses poderia ser o elevado teor de magnésio contido nestes alimentos, mineral considerado um possível 
fator protetor para o desenvolvimento de diabetes e DCV. ${ }^{17}$ Além disso, uma maior síntese de insulina foi observado em animais após consumo de leite, sugerindo uma ação direta dos aminoácidos encontrados nos laticínios nas células $ß$ do pâncreas. ${ }^{67}$ Este efeito pode ser explicado pela relação positiva entre o consumo de laticínios e insulinemia de jejum observada em homens no presente estudo. Em relação a $A H G$, a proteção de maior ingestão de gordura saturada para diabetes não foi independente do consumo de laticínios, que constitui a principal fonte de gorduras saturadas nesta população, sugerindo o efeito protetor possa ser atribuído ao papel do consumo de leite integral que apresentou efeito de dose-resposta com DM.

Estes efeitos reforçam a importância do estudo de alimentos e do padrão alimentar como um todo em detrimento de análises de nutrientes isolados na ocorrência de AHG. A inexistência de relação entre o consumo de laticínios desnatados com os desfechos de interesse pode ser atribuída ao baixo consumo habitual entre os participantes. 


\section{CONCLUSÃO}

A dieta habitual exerce um importante papel na gênese de AHG em nipo-brasileiros independente de outros fatores de risco potenciais. Nossos dados demonstram que o consumo excessivo de colesterol da dieta pode favorecer a hiperglicemia, assim como um aporte adequado de laticínios poderia contribuir no melhor controle glicêmico nos indivíduos estudados. Observamos que o consumo adequado de vegetais pode reduzir o risco de TGD. Por outro lado, o aporte de fibras provenientes de um consumo excessivo de arroz polido/pão branco e frutas/sucos de frutas por indivíduos com alterações metabólicas pode estar relacionado ao maior risco para AHG. Nossos resultados permitem concluir que o consumo predominante de alimentos característicos da dieta tipicamente brasileira, como arroz polido, feijão e grandes quantidades do grupo de frutas e sucos adocicados, pode representar risco para o desencadeamento de distúrbios do metabolismo da glicose, destacando-se o efeito protetor do maior consumo de vegetais para TGD na comunidade nipo-brasileira. 


\section{REFERÊNCIAS BIBLIOGRÁFICAS}

1. King H, Aubert RE, Herman WH. Global Burden of Diabetes, 1995 2025. Diabetes Care 1998; 21:1414-1431.

2. Malerbi DA, Franco LJ. Multicenter study of the prevalence of diabetes mellitus and impaired glucose tolerance in the urban Brazilian population aged 30-69 yr. Diabetes Care 1992; 15:1509-1516.

3. Franco LJ, Mameri C, Pagliaro H, lochida LC, Goldenberg P. Diabetes como causa básica e associada de morte no estado de São Paulo, Brasil, 1992. Rev Saúde Pública 1998; 32:237-245.

4. Coeli CM, Ferreira LGFD, Durbal MM, Veras RP, Camargo Jr KR, Cascão AM. Mortalidade em idosos por diabetes mellitus como causa básica e associada. Rev Saúde Pública 2002; 36:135-140.

5. Salles GF, Bloch KV, Cardoso CRL. Mortality and predictors of mortality in a cohort of Brazilian type 2 diabetic patients. Diabetes Care 2004; 27:1299-1305.

6. Dickinson S, Colagiuri S, Faramus E, Petocz P, Brand-Miller JC. Postprandial hyperglycemia and insulin sensitivity differ among lean young adults of different ethnicities. J Nutr 2002; 132:2574-2579.

7. Grupo de Estudos do Diabetes na Comunidade Nipo-Brasileira (JBDSG). Diabetes mellitus e doenças associadas em nipo-brasileiros. São Paulo: Green Forest do Brasil Editora; 2004. 
8. Gimeno SGA, Ferreira SRG, Franco LJ, Hirai A.T, Matsumura L, Moisés RS, et al. Prevalence and 7-year incidence of type 2 diabetes mellitus in a Japanese-Brazilian population: an alarming public health problem. Diabetologia 2003; 45:1635-1638.

9. Gross JL, Ferreira SRG, Franco LJ, Schimidt MI, Motta DG, Quintão E, et al. Diagnóstico e classificação do diabetes melito e tratamento do diabetes melito tipo 2. Recomendações da Sociedade Brasileira de Diabetes. Arq Bras Endocrinol Metab 2000; 44 Suppl 1:8-27.

10. Haffner SM, Stern MP, Hazuda HP, Mitchel BD, Patterson JK. Cardiovascular Risk Factors in Confirmed Prediabetic Individuals Does The Clock for Coronary Heart Disease Start Ticking Before the Onset of Clinical Diabetes? JAMA 1990; 263:2893-2898.

11. Celentano A, Vaccaro O, Tammaro P, Galderisi M, Crivaro M, Oliveiro $M$ et al. Early Abnormalities of Cardiac Function in Non-InsulinDependent Diabetes Mellitus and Impaired Glucose Tolerance. Am J Cardiol 1995; 76:1173-1176.

12. Haffner SM, Miettinen $H$. Insulin resistance Implications of Type 2 Diabetes mellitus and Coronary Heart Disease. Am J Med 1997; 103:152-161.

13. Steyn NP, Mann J, Bennett PH, Temple N, Zimmet P, Tuomilehto J, et al. Diet, nutrition and the prevention of type 2 diabetes. Public Health Nutr 2004; 7:147-165.

14. Ludwig DS, Ebbeling CB, Pereira MA, Pawlak DB. A physiological basis for disparities in diabetes and heart disease risk among racial and ethnic groups. J Nutr 2002; 132:2492-2493. 
15. Fujimoto WY, Bergstrom RW, Boyko EJ, Kinyoun JL, Leonetti DL, Newell-Morris LL, et al. Diabetes and diabetes risk factors in second and third-generation Japanese-Americans in Seattle, Washington. Diab Res Clin Prac 1994; 24 Suppl:43-52.

16. Fujimoto WY, Bergstrom RW, Boyko EJ, Chen KW, Kahn SE, Leonetti $\mathrm{DL}$, et al. Type 2 diabetes and the metabolic syndrome in Japanese Americans. Diab Res Clin Pract 2000; 50 Suppl 2:73-76.

17. World Health Organization. Food and Agriculture Organization. Joint WHO/FAO expert consultation. Diet, nutrition and the prevention of chronic diseases. Geneva: WHO/FAO; 2003.

18. Willett WC, Dietz WH, Colditz GA. Guidelines for health weight. N Engl J Med 1999; 341:427-434.

19. Everson AS, Goldberg DE, Helmrich SP, Lakka TA, Lynch JW, Kaplan GA et al. Weight gain and the risk of developing insulin resistance syndrome. Diabetes Care 1998; 21:1637-1643.

20. Gimeno SGA, Ferreira SRG, Cardoso MA, Franco LJ, lunes M for the Japanese-Brazilian Diabetes Study Group. Weight gain in adulthood and risk of developing glucose tolerance disturbance: a study of Japanese-Brazilian population. J Epidemiol 2000; 10:103-110.

21. Lerário DDG, Gimeno SG, Franco LJ, lunes M, Ferreira SRG para o Grupo de Estudo de Diabetes na comunidade Nipo-Brasileira de Bauru. Excesso de peso e gordura abdominal para a síndrome metabólica em nipo-brasileiros. Rev Saúde Pública 2002; 36: 4-11. 
22. Boyko EJ, Fujimoto WY, Leonetti DL, Newell-Morris L. Visceral adiposity and risk of type 2 diabetes: a prospective study among Japanese Americans. Diabetes Care 2000; 23:465-470.

23. Samaras K, Campbell LV. Increasing incidence of type 2 diabetes in the third millennium. Diabetes Care 2000; 23:441-442.

24. Block KV. Fatores de risco cardiovasculares e para o diabetes mellitus. In: Lessa I, organizador. $O$ adulto brasileiro $e$ as doenças da modernidade: epidemiologia das doenças crônicas não-transmissíveis. São Paulo; Rio de Janeiro: Editora Hucitec Abrasco; 1998. p. 43-72.

25. Després JP. Health consequences of visceral obesity. Ann Med 2001; 33:534-541.

26. Lessa I. Obesidade. In: Lessa I, organizador. O Adulto brasileiro e as doenças da modernidade: epidemiologia das doenças crônicas nãotransmissíveis. São Paulo, Rio de Janeiro: Editora Hucitec Abrasco; 1998. p. $139-154$.

27. Coutinho W, Federação Latino-Americana de Sociedades de Obesidade. Consenso Latino-Americano de Obesidade. Arq Bras Endocrinol Metab 1999; 43:21-67.

28. Monteiro CA, Mondini L, Souza AL, Popkin BM. The nutrition transition in Brazil. Eur J Clin Nutr 1995; 49:105-113.

29. Monteiro CA, Conde WL, Lu B, Popkin BM. Obesity and inequities in health in the developing world. Int J Obes Relat Metab Disord 2004; 28:1181-1186. 
30. Carneiro G, Faria AN, Filho FFR, Guimarães A, Lerário D, Ferreira SR et al. Influência da distribuição da gordura corporal sobre a prevalência de hipertensão arterial e outros fatores de risco cardiovascular em indivíduos obesos. Rev Assoc Med Bras 2003; 49:306-311.

31. Cruz IBM, Almeida MSC, Schwanke CHA, Moriguchi EH. Prevalência de obesidade em idosos longevos e sua associação com fatores de risco e morbidades cardiovasculares. Rev Assoc Med Bras 2004; 50:172-177.

32. Matos MFD, Silva NAS, Pimenta AJM, Cunha AJLA. Prevalence of risk factors for cardiovascular disease in employees of the Research Center at Petrobras. Arq Bras Cardiol 2004; 82:5-8.

33. Barreto SM, Passos VMA, Cardoso ARA, Lima-Costa MF. Quantifying the risk of coronary artery disease in a Community. The Bambuí Project. Arq Bras Cardiol 2003; 81: 556-561.

34. Cervato AM, Mazzilli RN, Martins IS, Marucci MFN. Dieta habitual e fatores de risco para doenças cardiovasculares. Rev Saúde Pública $1997 ; 31: 227-235$.

35. Pretence AM, Jebb AS. Obesity in Britain: gluttony or sloth? BMJ 1995; 311:437-439.

36. Manson JE, Rimm EB, Stampfer MJ, Colditz GA, Willett WC, Krolewski AS, et al. Physical activity and incidence of non-insulin-dependent diabetes mellitus in women. Lancet 1991; 338:774-778.

37. Helmirich SP, Ragland DR, Leung RW, Paffenbarger RS. Physical activity and reduced occurrence of non-insulin-dependent diabetes mellitus. N Engl J Med 1991; 325:147-152. 
38. Zimmet PZ, Mccarty DJ, Courten MP. The global epidemiology of noninsulin-dependent diabetes mellitus and the metabolic syndrome. J Diabetes Complications 1997; 11:60-68.

39. Bourn DM, Mann JI, McSkimming BJ, Waldron M, Wishart JD. Impaired glucose tolerance and NIDDM: does a lifestyle intervention program have an effect? Diabetes Care 1994; 17:1311-1319.

40. Pan XR, Li GW, Hu YH, Wang JX, Yang WY, An ZX, et al. Effect of diet and exercise in preventing NIDDM in people with impaired glucose tolerance. Diabetes Care 1997; 20:537-544.

41. Hu G, Qiao Q, Silventoimen K, Eriksson JG, Jousilahti P, Lindström J, et al. Occupational, commuting, and leisure-time physical activity in relation to risk for type 2 diabetes in middle-aged Finnish men and women. Diabetologia 2003; 46:322-329.

42. Kriska AM, Saremi A, Hanson RL, Bennett PH, Kobes S, Williams DE, et al. Physival activity, obesity, and the incidence of type 2 diabetes in a high-risk population. Am J Epidemiol 2003; 158:669-675.

43. Nakanishi N, Takatorige $T$, Suzuki K. Daily life activity and risk of developing impaired fasting glucose or type 2 diabetes in middle-aged Japanese men. Diabetologia 2004; 47:1768-1775.

44. Oshida Y, Yamanouchi K, Hayamizu S, Sato Y. Long-term mild jogging increases insulin action despite no influence on body mass or $\mathrm{VO}_{2}$ max. J Appl Physiol 1989; 66:2206-2210. 
45. Stefanick ML, Mackey S, Sheehan M, Ellsworth N, Haskell WL, Wood PD. Effects of diet and exercise in men and postmenopausal women with low levels of HDL cholesterol and high levels of LDL cholesterol. $\mathrm{N}$ Engl J Med 1998; 339:12-20.

46. Wareham NJ, Rennie KL. The assessment of physical activity in individuals and populations: why try to be more precise about how physical activity is assessed? Int J Obes Relat Metab Disord 1998; 22 Suppl 2:30-38.

47. Lakka TA, Venalainen JM, Rauramaa R, Salonen R, Tuomilehto J, Salonen J. Relation of leisure-time physical activity and cardiorespiratory fitness to the risk of acute myocardial infarction in men. N Engl J Med 1994; 330:1549-1554.

48. Young JC. Exercise prescription for individuals with metabolic disorders - Practical considerations. Sports Med 1995; 19 Suppl.1:43-54.

49. Monteiro CA, Conde WL, Matsudo VR, Bonsenor IM, Lotufo PA. A descriptive epidemiology of leisure-time physical activity in Brazil, 19961997. Rev Panam Salud Publica 2003; 14:246-254.

50. Instituto de Alimentação e Nutrição. Condições nutricionais da população brasileira: adultos e idosos. In: Ministério da Saúde, organizador. Pesquisa Nacional sobre Saúde e Nutrição. Brasília: INAN/MS; 1991.

51. Fonseca VM, Sichieri R, Veiga GV. Fatores associados à obesidade em adolescentes. Rev Saúde Pública 1998; 32:541-549. 
52. Gomes VB, Siqueira KS, Sichieri R. Atividade física em uma amostra probabilística da população do município do Rio de Janeiro. Cad Saúde Pública 2001; 17:969-976.

53. Hu FB, Manson JE, Stampfer MJ, Colditz G, Liu S, Solomon CG, et al. Diet, lifestyle, and the risk of type 2 diabetes mellitus in women. $\mathrm{N}$ Engl J Med 2001; 345:790-797.

54. Maron DJ, Fair JM, Haskel WL. Saturated fat intake and insulin resistance in men with coronary artery disease. Circulation 1991; 84:2020-2027.

55. Feskens EJM, Kromhout D. Habitual dietary intake and glucose tolerance in euglycaemic men: The Zutphen Study. Int J Epidemiol 1990; 19:953-959.

56. Feskens EJM, Virtanen SM, Rosanen L., Tuomilehto J, Stengard J, Pekkanen J, et al. Dietary factors determining diabetes and impaired glucose tolerance. Diabetes Care 1995; 18:1104-1112.

57. Parker DR, Weiss ST, Troisi R, Cassano PA, Vokonas PS, Landsberg L. Relationship of dietary saturated fatty acids and body habitus to serum insulin concentration; the Normative Aging Study. Am J Clin Nutr 1993; 58:129-136.

58. Tsunehara $\mathrm{CH}$, Leonetti DL, Fujimoto WY. Animal fat and cholesterol intake is high in men with IGT progressing to NIDDM. Diabetes 1991; 40: 427.

59. Feskens EJM, Bowles $\mathrm{CH}$, Kromhout D. Inverse association between fish intake and risk of glucose intolerance in normoglycemic elderly men and women. Diabetes Care 1991; 14:935-941. 
60. Colditz AC, Manson J, Stampfer MJ, Rosner B, Willett WC, Speizer FE. Diet and risk of clinical diabetes in women. Am J Clin Nutr 1992; 55:1018-1023.

61. Liu S, Manson JE, Stampfer MJ, Hu F, Giovannucci E, Colditz GA, et al. A prospective study of whole-grain intake and risk of diabetes mellitus in US women. Am J Public Health 2000; 90:1409-1415.

62. Williams DEM, Prevost AT, Whichelow MJ, Cox BD, Day NE, Wareham NJ. A cross-sectional study of dietary patterns with glucose intolerance and other features of metabolic syndrome. Br J Nutr 2000; 83:257-266.

63. Jenkins DJ, Wolever TM, Taylor RH, Barker HM, Fielden H, Baldwin JM, et al. Glycaemic index of foods: a physiological basis for carbohydrate exchange. Am J Clin Nutr 1981; 34:362-366.

64. Jenkins DJA, Kendall CWC, Augustin LSA, Franceschi S, Hamidi M, Marchie A, et al. Glycemic index: overview of implications in health and disease. Am J Clin Nutr 2002; 76:266-273.

65. Foster-Powell K, Holt SHA, Brand-Miller JC. International table of glycemic index and glycemic load values: 2002. Am J Clin Nutr 2002, 76:55-56.

66. Collier G, O'Dea K. The effect of co-ingestion of fat on the glucose, insulin and gastric inhibitory polypeptide responses to carbohydrate and protein. Am J Clin Nutr 1983; 37:941-944.

67. Wolever TMS, Jenkins DJA, Jenkins AL, Jesse RG. The glycemic index: methodology and clinical implications. Am J Clin Nutr 1991; 54:846-854. 
68. Würsch P, PI-Sunyer EX. The role of viscous soluble fiber in the metabolic control of diabetes. Diabetes Care 1997; 20:1774-1789.

69. Willett WC, Manson J, Liu S. Glycemic index, glycemic load, and risk of type 2 diabetes. Am J Clin Nutr 2002; 76:274-280.

70. Mckeown NM, Meigs JB, Liu S, Wilson PWF, Jacques PF. Whole-grain intake is favorably associated with metabolic risk factors for type 2 diabetes and cardiovascular disease in the Framingham Offspring Study. Am J Clin Nutr 2002; 76:390-398.

71. Venn BJ, Mann Jl. Cereal grains, legumes and diabetes. Eur J Clin Nutr 2004; 58:1443-1461.

72. Salmeron J, Manson JE, Stampfer MJ, Colditz GA, Wing AL, Willett WC. Dietary fiber, glycemic load, and risk of non-insulin-dependent diabetes mellitus in women. JAMA 1997; 277:472-477.

73. Fung TT, Hu FB, Pereira MA, Liu S, Stampfer MJ, Colditz GA, et al. Whole-grain intake and the risk of type-2 diabetes: a prospective study in men. Am J Clin Nutr 2002; 76:535-540.

74. Menezes EW, Lajolo FM. Utilização do amido de leguminosas. Arch Latinoam Nutr 1995; 45 Suppl 1:270-272.

75. Storlien LH, Kraegen EW, Jenkins AB, Chisholm DJ. Effect of sucrose vs satarch diets on in vivo insulin action, thermogenesis and obesity in rats. Am J Clin Nutr 1988; 47:420-427. 
76. Liu S, Willett WC, Stampfer MJ, Hu FB, Franz M, Sampson L, et al. A prospective study of dietary glycemic load, carbohydrate intake, and risk of coronary heart disease in US women. Am J Clin Nutr 2000; 71:1455-1461.

77. Ludwig DS. Dietary Glycemic index and obesity. J Nutr 2000; 130 Suppl 2:280-283.

78. Brand-Miller JC, Holt SHA, Pawlak DB, McMillan J. Glycemic index and obesity. Am J Clin Nutr 2002; 76 Suppl 1:281-285.

79. Leeds AR. Glycemic index and heart disease. Am J Clin Nutr 2002; 76 Suppl 1:286-289.

80. Liu S, Manson JE, Stamfer MJ, Holmes MD, Hu FB, Hankinson SE, et al. Dietary glycemic load assessed by food-frequency questionnaire in relation to plasma high-density-lipoprotein cholesterol and fasting plasma triacylglycerol in postmenopausal women. Am J Clin Nutr 2001; 73:560-566.

81. Amano Y, Kawakubo K, Lee JS, Tang AC Sugiyama M, Mori K. Correlation between dietary glycemic index and cardiovascular disease risk factors among Japanese women. Eur J Clin Nutr 2004; 58: 14721478.

82. Liu S, Manson JE, Buring JE, Stampfer MJ, Willett WC, Ridker PM. Relation between a diet with a high glycemic load and plasma concentrations of high-sensitivity C-reactive protein in middle-aged women. Am J Clin Nutr 2002; 75:492-498. 
83. McKeown NM, Meigs JB, Liu S, Saltzman E, Wilson PWF, Jacques PF. Carbohydrate nutrition, insulin resistance, and the Prevalence of the Metabolic Syndrome in the Framingham Offspring Cohort. Diabetes Care $2004 ; 27: 538-546$.

84. Parks EJ, Hellerstein MK. Carbohydrate-induced hypertriacylglycerolemia: historical perspective and review of biological mechanisms. Am J Clin Nutr 2000; 71: 412-433.

85. Brand-Miller JC, Hayne S, Petocz P, Colagiuri S. Low-glycemic index diets in the management of diabetes. Diabetes Care 2003; 26:22612267.

86. Sheard NF, Clark NG, Brand-Miller JC, Franz MJ, Pi-Sunyer FX, MayerDavis E, et al. Dietary carbohydrate (amount and type) in the prevention and management of diabetes: A statement by the American Diabetes Association. Diabetes Care 2004; 27:2266-2271.

87. Wolever TMS, Mehling C. Long-term effect of varying the source or amount of dietary carbohydrate on postprandial plasma glucose, insulin, triacylglycerol, and free fatty acid concentrations in subjects with impaired glucose tolerance. Am J Clin Nutr 2003; 77:612-621.

88. Jenkins DJ, Wolever TM, Ocana AM, Vuksan V, Cunnane SC, Jenkins $M$, et al. Metabolic effects of reducing rate of glucose ingestion by single bolus versus continuous sipping. Diabetes 1990; 39:775-781.

89. Schulze MB, Manson JE, Ludwig DS, Colditz GA, Stampfer MJ, Willett WC, et al. Sugar-sweetened beverages, weight gain, and incidence of type 2 diabetes in young and middle-aged women. JAMA 2004; 292:927-934. 
90. Salmeron J, Aschero A, Rimm EB, Colditz GA, Spiegelman D, Jenkins DJ, et al. Dietary fiber, glycemic load, and risk of NIDDM in men. Diabetes Care 1997; 20:545-550.

91. Meyer KA, Kushi LH, Jacobs DR, Slavin J, Sellers TA, Folsom AR. Carbohydrates, dietary fiber, and incident type 2 diabetes in older women. Am J Clin Nutr 2000; 71:921-930.

92. Stevens J, Ahn K, Juhaeri, Houston D, Steffan L, Couper D. Dietary fiber intake and glycemic index and incidence of diabetes in AfricanAmerican and white adults. Diabetes Care 2002; 25:1715-1721.

93. Montonen J, Knekt P, Järvinen R, Aromaa A, Reunanen A. Whole-grain and fiber intake and the incidence of type 2 diabetes. Am $\mathrm{J}$ Clin Nutr 2003; 77:622-629.

94. Liese AD, Roach AK, Sparks KC, Marquart L, D’Agostino RB, MayerDavis EJ. Whole-grain intake and insulin sensitivity: the Insulin resistance Atherosclerosis Study. Am J Clin Nutr 2003; 78:965-971.

95. Kagan A, Harris BR, Winkelstein W Jr, Johnson KG, Kato H, Syme SL, et al. Epidemiologic studies of coronary heart disease and stroke in Japanese men living in Japan, Hawaii and California: demographic, physical, dietary and biochemical characteristics. J Chronic Dis 1974; 27:345- 364.

96. Huang B, Rodriguez BL, Burchfiel CM, Chyou PH, Curb D, Yano K. Acculturation and prevalence of diabetes among Japanese-American men in Hawaii. Am J Epidemiol 1996; 144:674-681. 
97. Fujimoto WY, Bergstrom RW, Boyko EJ, Chen KW, Kahn SE, Leonetti DL, et al. Preventing diabetes - applying pathophysiological and epidemiological evidence. Brit J Nutr 2000; 84 Suppl 2:173-176.

98. Center for Japan-Brazil Studies. The result of survey for Japanese population in Brazil. São Paulo: Center for Japan-Brazil Studies; 1988.

99. Souza RKT, Gotlieb SLD. Mortalidade em migrantes japoneses residentes no Paraná, Brasil. Rev Saúde Pública 1999; 33:262-272.

100. Gotlieb SL. Mortalidade em migrantes japoneses residentes no município de São Paulo, Brasil, 1990. Rev Saúde Pública 1990; 24:453-467.

101. Tsugane S, Gotlieb SLD, Laurenti R, Souza JMP, Watanabe S. Mortality and cause of death among first-generation Japanese in São Paulo, Brazil. Int J Epidemiol 1989; 18:647-651.

102. lunes M, Franco LJ, Wakisaka K, lochida LC, Osiro K, Hirai A, et al. Self-reported prevalence of non-insulin-dependent diabetes mellitus in the $1^{\text {st }}$ (Issei) and $2^{\text {nd }}$ (Nisei) generation of Japanese-Brazilians over 40 years of age. Diabetes Res Clin Pract 1994; Suppl24:53-57.

103. Ioshida LC. Estudo da tolerância à glicose na população nipo-brasileira de Bauru, SP. São Paulo; 1995. [Tese de Doutorado -Universidade Federal de São Paulo]

104. Freire RD, Cardoso MA, Shinzato AR, Ferreira SRG and The Japanese-Brazilian Diabetes Study Group. Nutritional status of Japanese-Brazilians: comparison across gender and generation. $\mathrm{Br} \mathrm{J}$ Nutr 2003; 89:705-712. 
105. Castro TG. Alterações do consumo alimentar e perfil de lipídeos séricos de nipo-brasileiros de Bauru. São Paulo; 2004. [Dissertação de Mestrado - Universidade de São Paulo]. <http:// www.teses.usp.br>.

106. Cardoso MA, Stocco PR. Desenvolvimento de um questionário quantitativo de freqüência alimentar em imigrantes japoneses e seus dês residentes em São Paulo, Brasil. Cad Saúde Pública 2000; 16:107114.

107. Cardoso MA, Kida AA, Tomita LY, Stocco PR. Reproducibility and validity of a food frequency questionnaire among women of Japanese ancestry living in Brazil. Nutr Res 2001; 21:725-733.

108. Chiara VL, Sichieri R, Carvalho TSF. Teores de ácidos graxos trans de alguns alimentos consumidos no Rio de Janeiro. Rev Nutr 2003; 16:227-233.

109. Enig MG, Pallansch LA, Sampugna J, Keeney M. Fatty acid composition of the fat in selected food items with emphasis on trans components. J Am Oil Chem Soc 1938; 60:1788-1794.

110. World Health Organization. Hypertension Control. 862. Geneva: WHO; 1996.

111. World Health Organization. Stering Committee of the Western Pacific Region of the WHO, the International Association for the Study of Obesity, and the International Obesity Task Force. The Asia-Pacific perspective: redefining obesity and its treatment. Geneva: WHO; 2000. <http://www.diabetes.com.au/research/report_obesity.htm> 
112. World Health Organization. Diabetes and Noncommunicable Disease Risk Factor Surveys. Geneva: WHO; 2000.

113. The Expert Committee on the Diagnosis and Classification of Diabetes Mellitus. Follow-up report on the diagnosis of diabetes mellitus. Diabetes Care 2003; 26:3160-3166.

114. Alberti KGMM, Zimmet $\mathrm{PZ}$ for the WHO Consultation. Definition, Diagnosis and Classification of Diabetes Mellitus and its Complications. Part 1: Diagnosis and Classification of Diabetes Mellitus. Provisional Report of a WHO Consulation. Diabet Med 1998; 15:539-553.

115. Vieira JGH, Nishida SK, Lombardi N. Development of a monoclonal antiboby-based immunofluorimetric assay for serum insulin and its comparison to a classical raioimmunassay: Implications of different specificities in the interpretation of clinical data. Braz $\mathrm{J}$ Med Biol Res 1995; 28:537-543.

116. Executive summary of the third report of the National Cholesterol Education Program (NCEP). Expert Panel on detection, evaluation and treatment of high blood cholesterol in adults (adults treatment panel 3). JAMA 2001; 285:1486-1497.

117. Matthews DR, Hosker JP, Rudenski AS, Naylor BA, Treacher DF, Turner RC. Homeostasis model assessment: insulin resistance and beta-cell function from fasting plasma glucose and insulin concentration in man. Diabetologia 1985; 28:412-419.

118. Willett WC, Stampfer MJ. Total energy intake: implications for epidemiologic analyses. Am J Epidemiol 1996; 124:17-27. 
119. Willett WC, organizer. Nutritional Epidemiology. New York: Oxford University Press, Inc; 1990.

120. Hayashi T, Boyko EJ, Leonetti DL, McNeely MJ, Newell-Morris L, Kahn $\mathrm{SE}$, et al. Visceral adiposity and the risk of impaired glucose tolerance: a prospective study among Japanese Americans. Diabetes Care 2003; 26:650-655.

121. Takata Y, Maskatinec G, Franke A, Nagata C, Shimizu H. A comparison of dietary habits among women in Japan and Hawaii. Public Health Nutr 2003; 7:319-326.

122. Buyken AE, Toeller M, Heitkamp G, Karamanos B, Rottiers R, Muggeo $\mathrm{M}$ et al. Glycemic index in the diet of European outpatiens with type 1 diabetes: relations to glycated hemoglobin and serum lipids. Am J Clin Nutr 2001; 73:574-581.

123. Wolever TMS, Nguyen PM, Chiasson JL, Hunt JA, Josse RG, Palmason C, et al. Determinants of diet glycaemic index calculated retrospectively from diet records of 342 individuals with non-insulindependent diabetes mellitus. Am J Clin Nutr 1994; 59:1265-1269.

124. Van Dam RM, Vischer AW, Feskens EJ, Verhoef $P$, Krumhout D. Dietary glycaemic index in relation to metabolic risk factors and incidence of coronary heart disease: the Zutphen Elderly Study. Eur J Clin Nutr 2000; 54:726-731.

125. Castro AGP; Franco JL. Caracterização do consumo de adoçantes alternativos e produtos dietéticos por indivíduos diabéticos. Arq Bras Endocrinol Metab 2002; 46:280-287. 
126. Janket SJ, Manson JE, Sesso H, Buring JE, Liu S. A prospective study of sugar intake and risk of type 2 diabetes in women. Diabetes Care 2003; 26:1008-1015.

127. Hodge AM, English DR, O'Dea K, Giles GG. Glycemic index and dietary fiber and the risk of type 2 diabetes. Diabetes Care 2004; 27:27012706.

128. Ministry of Health and Welfare. Recommended dietary allowances for the Japaneses. Tokyo, Japan: Dai-ichi Shuppan; 1994.

129. World Cancer Research Fund / American Institute for Cancer Research. Food, Nutrition and the Prevention of Cancer: a Global Perspective. Washington: WCRF / AIRC; 1997.

130. Cardoso MA, Hamada GS, Souza JMP, Tsugane S, Tokudome S. Dietary patterns in Japanese migrants to Southeastern Brazil and their descendants. J Epidemiol 1997; 7:198-204.

131. Heacock PM, Hertzler SR, Wolf BW. Fructose prefeeding reduces the glycemic responses to a high-glycemic index, starchy food in humans. J Nutr 2002; 132:2601-2604.

132. Uusitupa MIJ. Fructose in the diabetic diet. Am J Clin Nutr 1994; 59 Suppl 3:753-757.

133. Teff KL, Elliott SS, Tschöp M, Kieffer TJ, Rader D, Heiman M, et al. Dietary fructose reduces circulating insulin and leptin, attenuates postprandial suppression of ghrelin, and increases trglycerides in women. J Clin Endocrinol Metab 2004; 89:2963-2972. 
134. Wu T, Giovannucci E, Pischom T, Hankinson SE, Ma J, Rifai N, et al. Fructose, glycemic load, and quantity and quality of carbohydrate in relation to plasma C-peptide concentrations in US women. Am J Clin Nutr 2004; 80:1043-1049.

135. Liu S, Serdula M, Janket SJ, Cook NR, Sesso HD, Willett WC, et al. A prospective study of fruits and vegetable intake and the risk of type 2 diabetes in women. Diabetes Care 2004; 27:2993-2996.

136. Joshipura KJ, Ascherio A, Manson JE, Stampfer MJ, Rimm EB, Speizer $\mathrm{FE}$, et al. Fruit and vegetable intake in relation to risk of ischemic stroke. JAMA 1999; 282:1233-1239.

137. Wolk A, Manson JE, Stampfer MJ, Colditz GA, Hu FB, Speizer FE, et al. Long-term intake of dietary fiber and decreased risk of coronary heart disease among women. JAMA 1999; 281:1998-2004.

138. Liu S, Manson J, Lee IM, Cole SR, Hennekens CH, Willett WC, et al. Fruit and vegetable intake and risk of cardiovascular disease: the Women's Health Study. Am J Clin Nutr 2000; 72:922-928.

139. Jensen MK, Banerjee PK, Hu FB, Franz M, Sampson L, Gronbek M, et al. Intakes of hole grains, bran, and germ and the risk of coronary heart disease in men. Am J Clin Nutr 2004; 80:1492-1499.

140. Sichieri R. Dietary Patterns and their associations with obesity in the Brazilian city of Rio de Janeiro. Int J Obes Relat Metab Disord 2002; 10:42-48.

141. Sichieri R, Castro JFG, Moura AS. Fatores associados ao padrão de consumo alimentar da população brasileira urbana. Cad Saúde Pública 2003; 19 Suppl 1:47-53. 
142. Fornés NS, Martins IS, Hernan M, Velásquez-Meléndez G, Ascherio A. Food frequency consumption and lipoproteins serum levels in the population of an urban area, Brazil. Rev Saúde Pública 2000; 34:380387.

143. Gimeno SGA, Osiro K, Matsumura L, Massimino FC, Ferreira SRG. Glucose intolerance and all-cause mortality in Japanese migrants. Diabetes Res Clin Pract 2005; prelo.

144. Mirmiran P, Esmaillzadeh A, Azizi F. Dairy consumption and body mass index: an inverse relationship. Int J Obes Relat Metab Disord 2005; 29:115-121.

145. Pereira MA, Jacobs DR, Horn LV, Slattery ML, Kartashov AI, Ludwig DS. Dairy consumption, obesity, and the insulin resistance syndrome in young adults: The CARDIA Study. JAMA 2002; 287:2081-2089. 


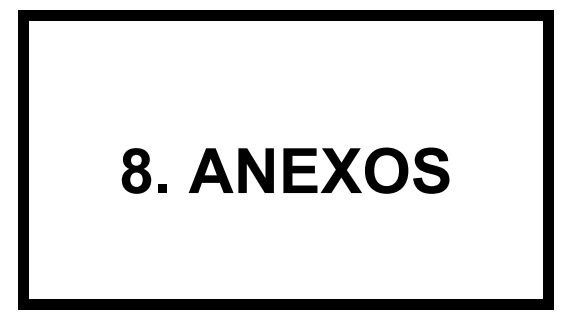




\section{ANEXO 1}

Aprovação do Comitê de Ética em Pesquisa da Escola Paulista de Medicina da Universidade Federal de São Paulo (UNIFESP) + Carta de Informação + Termo de Consentimento 


\section{ANEXO 2}

Questionário estruturado utilizado em entrevista domiciliar 


\section{ANEXO 3}

Questionário quantitativo de freqüência alimentar (QQFA) desenvolvido e validado para a população Nipo-Brasileira 


\section{ANEXO 4}

Valores de carboidratos (CH), índice glicêmico (IG) e carga glicêmica (CG) atribuídos aos alimentos do Questionário Quantitativo de freqüência alimentar (QQFA) 
